ROMANIAN ACADEMY

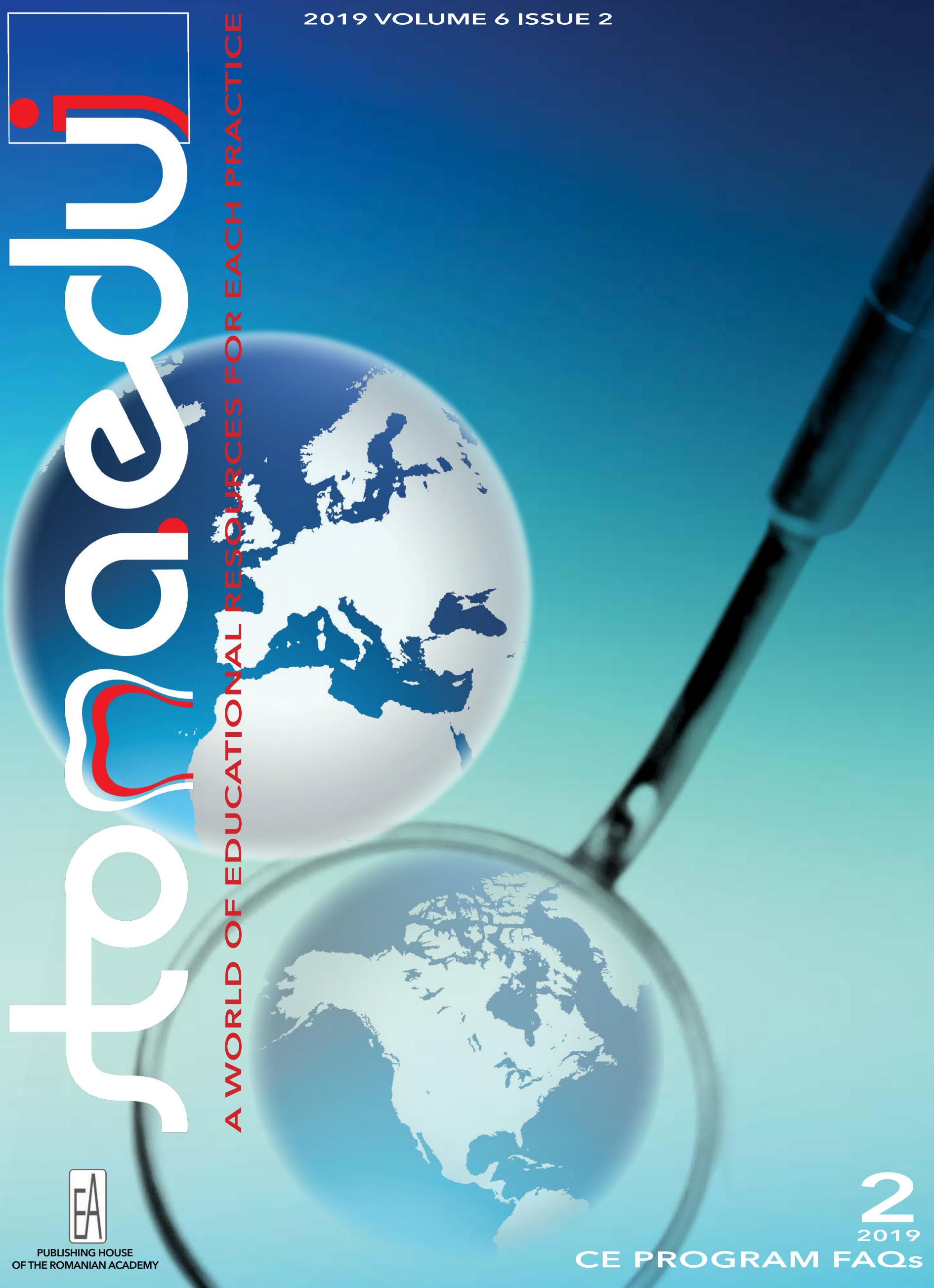




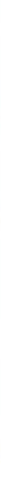

\section{Hofident $Q_{10}$}

Product presentation: Solution for oral hygiene.

Composition (INCI): aqua/water, alcohol, Capsella Bursa Pastoris extract, Plantago Lanceolata extract, Chamomilla Recutita extract, Achillea Millefolium extract, Aesculus Hippocastanum extract, Mentha Piperita extract, Ubiquinone.

Action: The product has antiseptic, healing, hemostatic, anti-inflammatory aєtion, it acts as a antioxidant, detoxifier, deodorant. It is strongly recommended in gingivitis, stomatitis, thrush, compression pain causedby dental prostheses, after tooth extraction, in case of nipple lesion, bleeding gums, mouth and gum ulcers.

Recommendations: It delays dental plaque formation, it prevents bad odour and provides daily mouth hygiene.

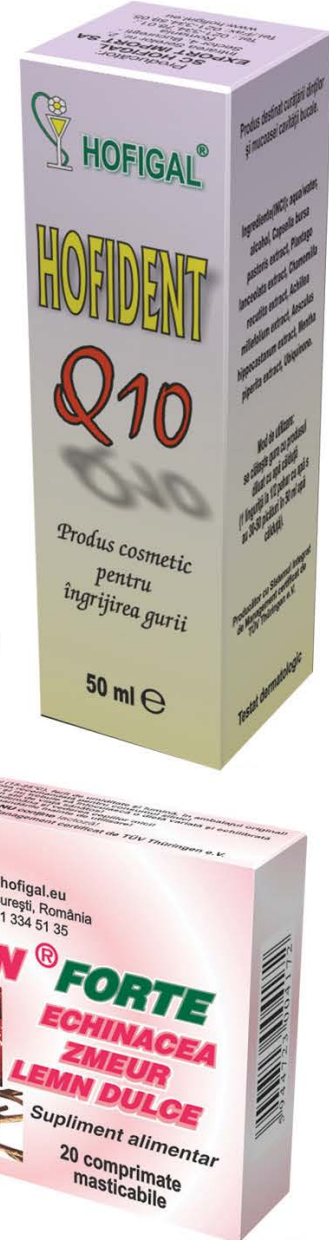

\section{Hoflmun ${ }^{\oplus}$ FORTE}

Product presentation:

Chewable tablets to stimulate the immune system

Composition: Each chewable tablet contains raspberry fruit extract (Rubii idaei fructus), Echinacea extract (Echinacea purpurea), concentrated extract of licorice root (Glycyrrhiza radix), magnesium ascorbate and excipients.

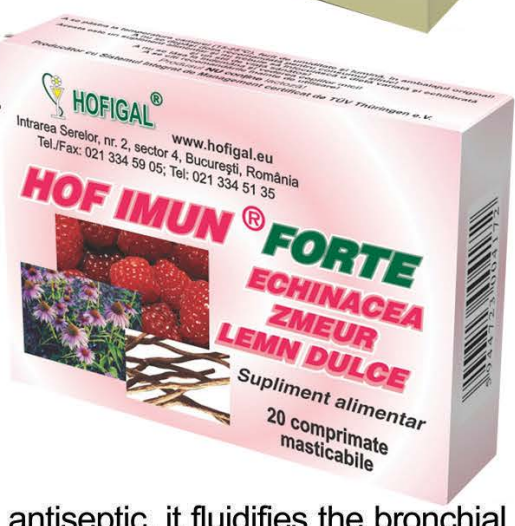

Action:It stimulates the immune system, it is antiinflammatory, antiviral, antiseptic, it fluidifies the bronchial and pharyngeal secretions, antioxidant, cardioprotective, vasoprotective, it has antineoplastic antileukimic action, (due to the ellagic acid), it contributes to wound healing, fortifies and remineralizes (it regulates the potassium balance), it has antiulcer effects and is an overall body tonic.

Recommendations: to supplement the diet with nutrients and bioactive substances in: acute and chronic infections of the upper airways (angina, pharyngitis, laryngitis, bronchitis), prophylactic during periods with increased risk of infection with influenza viruses, it has sweating effects in fever, in recurrent herpes episodes of mucocutaneous rash, frequent urinary tract infections, inflammatory urogenital processes; immunodepression after radiotherapy or chemotherapy, bacterial skin infections, psoriasis, neurodermitis, chronic cardiovascular diseases associated with hypercholesterolemia, adjuvant in the diet indicated in the treatment of gastroduodenal ulcers, tonic during periods of physical and mental strain, exhaustion.

\section{Bucoprotect gel}

Product presentation: Gel for oral hygiene.

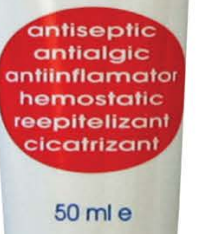

Composition (INCI): aqua, capsella bursa pastoris, calendula officinalis, achillea milefolium, hippophae rhamnoides, olea europea, hypericum perforatum, carbomer triethanolamine, collagen, foeniculum vulgare, mentha piperita, citrus amara.

Action: Antiseptic, anti-inflammatory, healing, stimulates the inside lining of the mouth and gums trophicity, reduces pain caused by specific oral diseases (gingivitis, stomatitis, lesions of the prosthesis, thrush, periodontitis). Recommendations: Fights against bad breath (halitositive nets). 


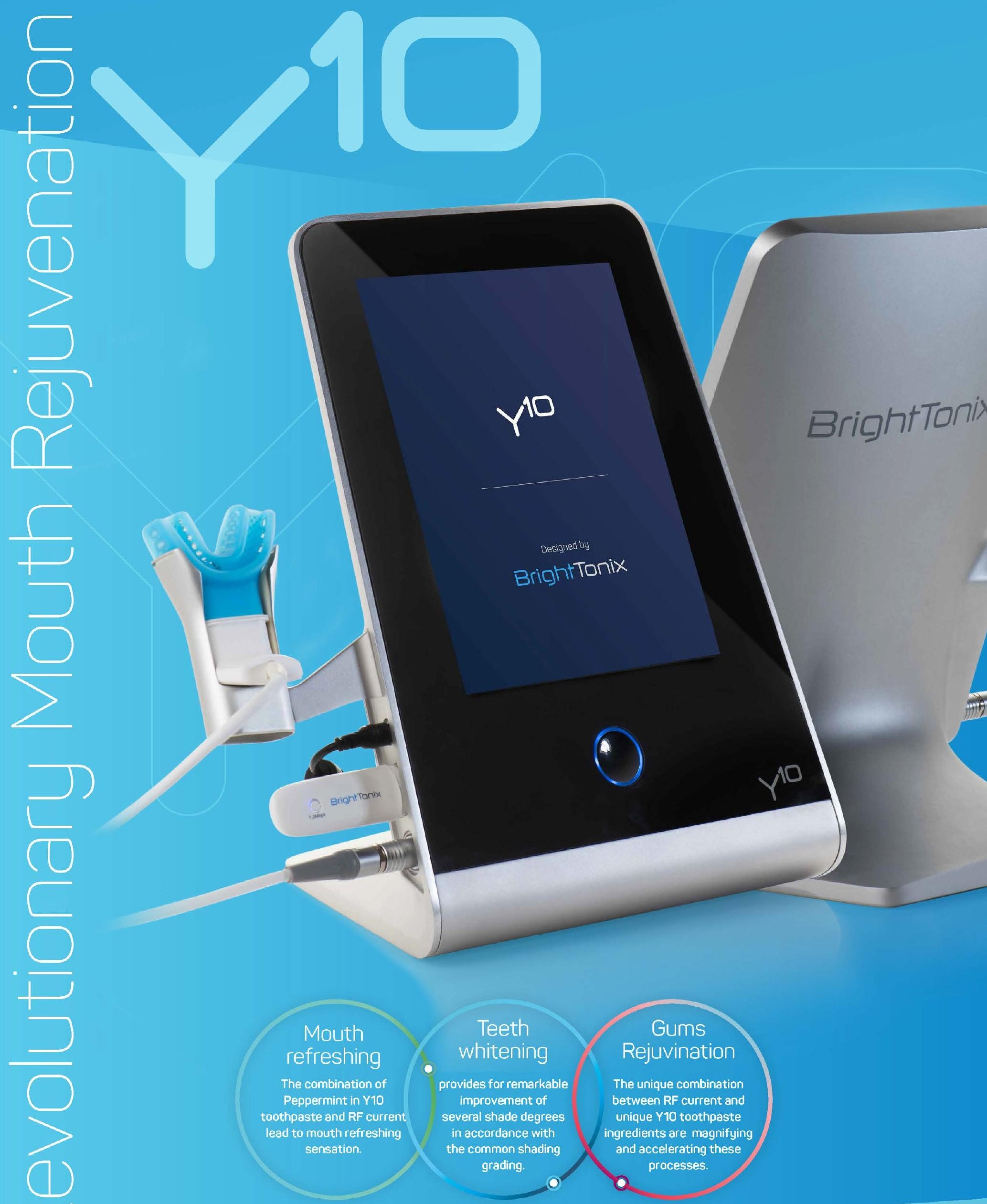




\section{Contents}

\section{stona.edij}

2019 Volume 6 Issue 2

ISSN (print) 2360-2406; ISSN (on-line) 2502-0285;

Pages 81-150

ISSN-L 2360-2406

\section{EDITORIAL}

81 Think globally - act locally

83 Why l love Orthodontics

Fabio Savastano

85 Our uninterrupted joint effort on the path of certification

85 Marian-Vladimir Constantinescu

\section{LETTERS} 87 Laudatio to the „Iron Lady of Orthodontics" Professor Birthe Melsen
Irina Nicoleta Zetu

\section{CONTINUING EDUCATION ONLINE}

89 JADA CE Online

\section{ORIGINAL ARTICLES}

Q1 DENTAL MATERIALS: In vitro wear of ten universal composites

Jean-François-Roulet, Hind Hussein, Nader Abdulhameed, Chiayi Shen

DENTAL MATERIALS: Susceptibility of RBC to various clinical relevant curing

100 conditions: Effect of filler amount and chemical composition of the organic matrix Nicoleta Ilie, Eva-Maria Plenk

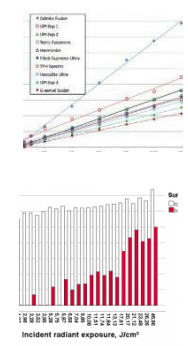

111

DENTAL MATERIALS: Effects of etching mode on bond strength of universal adhesives

Andre Figueiredo Reis, Paula Maria Mendes Alves, Rose Yakushijin Kumagai

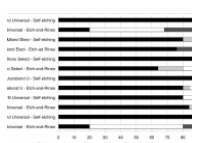

MAXILLOFACIAL SURGERY: Effect of platelet-rich plasma on chronic odontogenic maxillary sinusitis: a pilot study

118

Daniela Miricescu, Alexandra Totan, loana Ruxandra Rusu, Vitali Movradin,

Mihaela Moisescu, Constatin Ștefani, Iulia-loana Stănescu, Radu Rădulescu, Cosmin Totan, George Costin Rusu, Maria Greabu

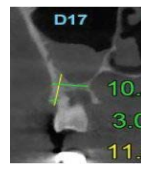




\section{CASE REPORTS}

125 ORAL SURGERY: Root tip migration into the infundibulum of the maxillary sinus after

125 complicated first molar extraction

Isabel Miclotte, Laurence Verstraete, Constantinus Politis

MAXILLOFACIAL SURGERY: Large odontogenic keratocyst of the mandible: A

129 combined intra/extra oral approach followed by enucleation

Maximilien Vercruysse, Patricia D'Haeseleire, Sidney Kunz, Bart Lutin,

Constantinus Politis

\section{DENTISTRY CONFERENCES}

138 Dentistry Conferences

\section{PRODUCT NEWS}

13 Improving the realization of individualized prostheses by optical measurement of

139 mandibular kinematics

Florin - Eugen Constantinescu
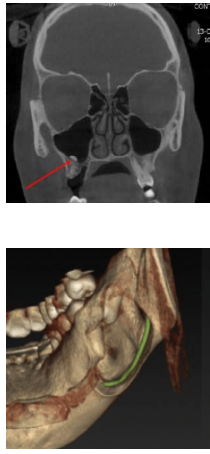

\section{BOOK REVIEWS}

141

The Complete Dentist Manual

Peter E. Dawson / John C. Cranham

142

Implant Dentistry at a Glance. Second Edition

Jacques Malet / Francis Mora / Philippe Bouchard

14 Oral Cancer Detection. Novel Strategies and Clinical Impact

Prashanth Panta

143 Journal of Prosthodontics on Complete and Removable Dentures Jonathan P. Wiens / Jennifer Wiens Priebe / Donald A. Curtis

154 Contemporary Management of Temporomandibular Disorders. Surgical Treatment S. Thaddeus Connelly / Gianluca Martino Tartaglia / Rebeka G. Silva

155 The ADA Practical Guide to Soft Tissue / Oral Disease Michael A. Kahn / J. Michael Hal

156 Bone Management in Dental Implantology Andi Setiawan Budihardja / Thomas Mücke

\section{INSTRUCTIONS FOR AUTHORS}

148 instructions for authors 
Editors-in-Chief

Jean-François Roulet

DDS, Habil, Prof hc, Dr hc, Professor

University of Florida, Gainesville, FL, USA

MD, DMD, PhD Professor and Chairman em.

Medical University of Vienna, Vienna, Austria

\section{Marian-Vladimir Constantinescu}

DDS, MSC, PhD, Professor

7. "Carol Davila" University of Medicine and Pharmacy, Bucharest, Romania Co-Editors-in-Chief (Americas)

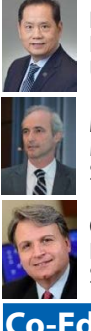

m-Lay Wang

DDS MSD PhD Professor

University of Michigan, Ann Arbor, MI, USA

\section{Mauro Marincola}

MD, DDS, Clinical Professor

State University of Cartagena, Cartagena, Colombia

\section{George E. Romanos}

DDS, PhD, DMD, Professor

Stony Brook University, Stony Brook, NY, USA

\section{Co-Editors-in-Chief (Asia-Pacific)}

\section{Lakshman Perera Samaranayake}

Hon DSC, FDSRCS (Edin), FDS RCPS (Glas), FRACDS, FRCPath (UK), BDS, DDS (Glas),

FHKCPath FCDSHK FHKAM (Pathology), FHKAM (Dental Surgery), Professor

University of Sharjah, Sharjah, United Arab Emirates

\section{Hiroshi 0gawa}

DDS, MDSC PhD Associate Professor

Niigata University, Niigata, Japan

Mahesh Verma

BDS, MDS, MBA, FAMS, FDSRCS (England), FDSRCPSG (Glasgow), FDSRCS (Edinburgh), $\mathrm{PhD}(\mathrm{HC})$, Professor

Maulana Azad Institute of Dental Sciences, New Delhi, India Emeritus Editors-in-Chief

Peter E. Dawson

DDS, Founder Emeritus of The Dawson Academy

Saint Petersburg, FL, USA

\section{Birte Melsen}

DDS, Dr Odont, Professo

Aarhus University, Aarhus, Denmark

\section{Alexandre Merse}

DDS, PhD, Professor, Director of Studies

Geneva Institute of Medical Dentistry (GIMD), Versoix, Switzerland

Associate Editors-in-Chief

Vasile lulian Antoniac, Eng, PhD, Professor, Habil Vice Dean, University “Politehnica” of Bucharest, Bucharest Romania

Noemí Bordoni, DDS, PhD, Director

Public Health Research Institute, University of Buenos Aires Buenos Aires, Argentina

Radu Septimiu Câmpian, DMD, MD, Professor Dean, "Iuliu Hațieganu" University of Medicine and Pharmacy

Cluj-Napoca, Cluj-Napoca, Romania

Sergiu Ciobanu, DDS, PhD, Professor, Dean

"Nicolae Testemițanu" State Medical and Pharmaceutical

University Chişinău, Chişinău, Moldova

Francois Duret, DDS, DSO, PhD, MS, MD, PhD, Professor

Acad (ANCD) University of Montpellier, Montpellier, France

Michael Frank, DDS, PhD

ERO President Elect, President Dental Chamber Hesse

Frankfurt am Main, Germany

Luigi M Gallo, PhD, Dr Eng, MEng

Professor and Chairman, University of Zürich, Zürich, Switzerland

Klaus Gotfredsen, DDS, PhD, Dr Odont

University of Copenhagen, Copenhagen, Denmark
Maria Greabu, MD, PhD

"Carol Davila" University of Medicine and Pharmacy Bucharest Bucharest Romania

Peter Hermann, DMD, MSc, PhD, Professor and Head Vice-Rector, Semmelweis University Budapest, Hungary Ecaterina lonescu, DDS, PhD, Professor, Vice-Rector "Carol Davila"University of Medicine and Pharmacy Bucharest Bucharest, Romania

Amid I Ismail, BDS, MPH, MBA, Dr Ph, Dean

Temple University, Philadelphia, PA, USA

Vjekoslav Jerolimov, DDS, PhD, Acad (CASA)

University of Zagreb, Zagreb, Croatia

Veronica Mercuț, DMD, PhD, Professor, Dean

University of Medicine and Pharmacy Craiova, Dolj, Romania Georg B. Meyer, DMD, PhD, Dr hc, Professor and Chairman Ernst-Moritz-Arndt University, Greifswald, Germany Takahiro Ono, DDS, PhD, Chief Professor

Niigata University, Niigata, Japan

Poul Erik Petersen, DDS, Dr Odont, BA, MSC, Professor

WHO Senior Consultant, University of Copenhagen Copenhagen,Denmark
Deputy Editors-in-Chief

Adrian Bejan

Eng, PhD, J.A. Jones Distinguished Professor, Acad (AR)

Duke University, Durham, NC, USA

Constantin lonescu-Târgoviste

MD, PhD, Professor, Acad (AR)

"Carol Davila" University of Medicine and Pharmacy, Bucharest, Romania

Gabriel Octavian Lază

CPhys, PhD, Professor

"Vasile Alecsandri" University of Bacău, Bacău, România

Nicoleta llie

Dipl-Eng, PhD, Professo

Ludwig-Maximilians-Universität München, München, Germany

Hande Şar Sancak

DDS, PhD, Associate Professo

FDI Regional CE Director Europe, Geneva-Cointrin, Switzerland

Constantinus Politis

MD, DDS, MM, MHA, PhD, Professor and Chairperson University of Leuven, Leuven, Belgium

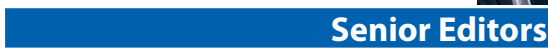

Senior Editors

Bruce Robert Donof

DMD, MD, Professor, Dean Medicine Harvard University, Boston, MA, USA

Adrian Podoleanu

Eng, PhD, Professor FInstP, FOSA FSPIE, Professor University of Kent, Canterbury, Kent, UK

Kasturi Warnakulasuriya FOP(RCPA), FICD FILT, FMedSci, Professor King's College London, London, UK

\section{Emeritus Editors-in-Chief}

Prathip Phantumvanit

DDS, MS, FRCDT, Professo Thammasat University, Bangkok, Thailand

Rudolf Slavice MD, DMD, Professo Medical University of Vienna, Vienna, Austria

David Wray David Wray
MD (Honours), BDS, MB ChB, FDS, RCPS (Glasgow), FDS RCS (Edinburgh) F Med Sci
Professor Emeritus, Professor Professor Emeritus, Professor
eersity of Glasgow, Glasgow, UK

\section{University of Glasgow, Glasgow, UK}

Mariano Alonso Sanz, DDS, MSD, PhD, Professor Complutense University of Madrid, Madrid, Spain Gottfried Schmalz, DDS, PhD, Drhc, Professor Acad (Leopoldina), University of Regensburg Regensburg, Germany

Anton Sculean, DMD, Dr hc, MS, Professor University of Bern, Bern, Switzerland

Igor Alexandrovici Shugailov, MD, PhD, Professor Vice-Rector, "A.I. Evdokimov" Moscow State University of Medicine and Stomatology, Moscow, Russia Adam Stabholz, DDS, PhD, Professor, Head Adam Stabholz, DDS, PhD, Professor, Head
The Hebrew University-Hadassah, Jerusalem, Israel Zrinka Tarle, DMD, PhD, Professor, Dean University of Zagreb, Zagreb, Croati Douglas A. Terry, DDS, PhD, Clinical Assistant Professo University of Texas, Houston, TX, USA Jacques Vanobbergen, MDS, PhD, Professor Em. Professor and Chairman

Gent University, Gent, Belgium

Yongsheng Zhou, DDS, PhD, Chair and Professor Associate Dean, Peking University, Beijing, China
The Stomatology Edu Journal (Stoma Edu J), ISSN (printed) 23602406, ISSN (on-line) 2502-0285, ISSN-L 2360-2406, is a scientific magazine of the Romanian Association of Oral Rehabilitatio and Posturotherapy - ROPOSTURO, a partner of the FDI regular member, the Romanian Society of Stomatology - RSS (founded in 1923) under the aegis of The Romanian Academy.

\section{Editor Office}

Stomatology Edu Journal, 102-104 Mihai Eminescu st., $2^{\text {nd }}$ District, R0-020082 Bucharest, ROMANIA, Tel/Fax: +40314327930, e-mail: stomatology.edu@gmail.com, www.stomaeduj.com

Editors

Jean-François Roulet, Rolf Ewers, Marian-Vladimir Constantinescu

Managing Editor

Florin-Eugen Constantinescu

\section{ROPOSTURO}

Romanian Association of Oral Rehabilitation and Posturotherap 10, Ionel Perlea St., 1st District, R0-010209 Bucharest, Romania Tel: +4021314 1062, Fax: +4021312 1357

e-mail: roposturo@gmail.com, www.roposturo.stomaeduj.com

\section{Technical Editor}

Gabriel Octavian Lazar, Valentin Miroiu, Edgar Moraru

\section{Project Editor}

Irina-Adriana Beuran

Design Editor

Dragoș Georgian Guțoi

Cover by

Arch. Florin Adamescu

\section{Publisher Office}

Romanian Academy Publishing House, 13, Calea 13 Septembrie, 5th District, R0-050711 Bucharest, Romania, Tel: +40213188146, 40213188106, Fax: +40213182444

e-mail: edacad@ear.ro,www.ear.ro

Technical Editor

Doina Argeșanu

Editorial Assistant

Monica Stanciu

Computer Editing

Iolanda Povară

All the original content published is the sole responsibility of the authors. All the interviewed persons are responsible for their declaration and the advertisers are responsible for the information included in their commercials. 


\section{Associate Editors}

Rafael Benoliel, DDS, PhD, BDS, Professor, Associate Dean The State University of New Jersey Newark, NJ, USA Dana Cristina Bodnar, DDS, PhD, Professor

"Carol Davila" University of Medicine and Pharmacy Bucharest, Bucharest, Romania

Romeo Călărasu, MD, PhD, Professor, Acad (ASM) "Carol Davila" University of Medicine and Pharmacy Bucharest, Bucharest, Romania

Asja Čelebić, DDS, MSc, PhD, Professor

University of Zagreb, Zagreb, Croatia

Lola Giusti, DDS, CERT, Associate Professor

University of the Pacific, San Francisco, CA, USA

Galip Gürel, DDS, MSC

Dentis Dental Clinic, Istanbul, Turkiye

Fawad Javed, BDS, PhD

University of Rochester, NY, USA

Joannis Katsoulis, DMD, PhD, MAS, Professor

University of Bern, Bern, Switzerland

Anastassia E Kossioni, DDS, PhD, Associate Professor

University of Athens, Athens, Greece

Luca Levrini, DDS, PhD, Professor

University of Insubria, Varese, Italy

Giorgio Lombardo, MD, DDS, Professo

University of Verona, Verona, Italy

Armelle Maniere-Ezvan, DDS, PhD, Professor, Dean

Nice Sophia-Antipolis University, Nice, France

Domenico Massironi, DDS, PhD

MSC Massironi Study Club, Melegnano (MI), Italy

Noshir R. Mehta, DMD, MDS, MS, Professor, Assoc. Dean

Tufts University, Boston, MA, USA

Marian Neguț, MD, PhD, Professor, Acad (ASM)

"Carol Davila" University of Medicine and Pharmacy

Bucharest, Bucharest, Romania

Jean-Daniel Orthlieb, DDS, PhD, Professor, Vice-Dean

Aix Marseille University, Marseille, France

Letizia Perillo, MD, MS, PhD, Professor, Head, Dean

University of Campania Luigi Vanvitelli, Naples, Italy

Paula Perlea, DDS, PhD, Professor, Dean

"Carol Davila" University of Medicine and Pharmacy

Bucharest, Bucharest, Romania

Chiarella Sforza, MD, PhD, Professor

University of Milan, Milan, Italy

Roman Šmucler, MD, PhD, Professor

Charles University Prague, Praque, Czech Republic

Roberto Carlo Spreafico, DM, DMD

Busto-Arsizio (MI), Italy

Jon B Suzuki, DDS, PhD, MBA, Professor, Associate Dean

Temple University, Philadelphia, PA, USA

\section{Editors}

Sorin Andrian, DDS, PhD, Professor and Chairman

"Gr. T. Popa" University of Medicine and Pharmacy lassi

lasi, Romania

Vasile Astărăstoae, MD, PhD, Professor

"Gr. T. Popa" University of Medicine and Pharmacy lași

\section{lasi, Romania}

Gabriela Băncescu, MD, PhD, Professo

"Carol Davila"University of Medicine and Pharmacy Bucharest Bucharest, Romania

Alexandru Dumitru Brezoescu, DDS, Chairma

Dentists'College, Bucharest, Bucharest, Romania

Octavian Buda, MD, PhD, Professor

"Carol Davila" University of Medicine and Pharmacy Bucharest Bucharest, Romania

Arnaldo Castellucci, DDS, PhD

Florence, Italy

Ingrida Čêma, DDS, PhD, Professor

Riga Stradins University, Riga, Latvia

Gabi Chaushu, DMD, MD Professor

Gabi Chaushu, DMD, MD, Professor

Rayleigh Ping-Ying Chiang, MD, MMS

Rayleigh Ping-Ying Chiang, MD, MMS

Taipei Veterans General Hospital, Taipe
Ioan Dănilă, DDS, PhD, Professor

"Gr. T. Popa" University of Medicine and Pharmacy lași
"Lan Danila, DDS, PhD, Professor

"Gr. T. Popa" Unive

lassi, Romania
Yuri Dekhtyar, Eng, Dr phys, Professor

Riga Technical University, Riga, Latvia

Valeriu Fala, DDS, PhD, MSc, Associate Professor

"Nicolae Testemițanu" State University of Medicine and Pharma

"Chişinău, Chişinău, Republic of Moldova

Daniela Aparecida Godoi Gonçalves, DDS, PhD, Professor

UNESP - Univ Est Paulista, Araraquara, Brazil

Martin D Gross, BDS, LDS, MSC, Associate Clinical Professor

Tel Aviv University, Tel Aviv, Israel

Emilian Hutu, DDS, PhD, Professor

"Carol Davila" University of Medicine and Pharmacy Bucharest

Bucharest, Romania

Andrei Cristian lonescu, DDS, PhD

University of Milan, Milan, Italy

Abdolreza Jamilian, DDS, PhD, Professor

Islamic Azad University, Tehran, Iran

Joanna Kempler, DDS, PhD, Associate Professor

University of Maryland, Baltimore, MD, USA

Amar Hassan Khamis, PhD, DEA, MSC, BSc, Professor

Mohammed Bin Rashid University of Medicine and Health

Sciences (MBRU), Dubai, UAE

Henriette Lerner, DDS, PhD

Baden-Baden, Germany

Paulo Ribeiro de Melo, DDS, PhD, Professor

University of Porto, Porto, Portugal
Annalisa Monaco, DDS, MSc, Associate Professor

University of L'Aquila, L'Aquila, Italy

Nina Mussurlieva, DDS, PhD, Professor

Medical University of Plovdiv, Plovdiv, Bulgaria

Radmila R. Obradović, DDS, PhD, Associate Professor

University of Nišs, Niš, Serbia

Sever Toma Popa, DDS, PhD, Professor

"Iuliu Hațtieganu" University of Medicine and Pharmacy Cluj-Napoca Cluj-Napoca, Romania

Mihaela Răescu, DDS, PhD, Professor

"Titu Maiorescu" University, Bucharest, Romani

lulia Romanova, DMS, PhD, Professor

Odessa National Medical University "ONMedU", Odessa, Ukrain

Mare Saag, DDS, PhD, Professor

University of Tartu, Tartu, Estonia

Fabio Savastano, MD, MOrth, Professor

University Jaume I Castellon, Castellon, Spain

Luc De Visschere, DDS, PhD, Professor

Gent University, Gent, Belgium

Constantin Marian Vârlan, DDS, PhD, Professor

"Carol Davila" University of Medicine and Pharmacy Bucharest

Bucharest, Romania

Irina Nicoleta Zetu, DDS, PhD, Professor

"Gr. T. Popa" University of Medicine and Pharmacy lași, lași, Romania Editorial Advisory Board

Marcus Oliver Ahlers, DDS, PD

Department of Operative Dentistry and Preventive Dentistry Center for Oral and Maxillofacial Surgery, University Medical Center

Hamburg-Eppendorf, Hamburg University Eppendorf

Hamburg, Germany

Cristina Maria Borțun, DDS, PhD, Professor and Head

Prosthetic Dentistry Technology Department

Faculty of Dental Medicine, "Victor Babeș" University of Medicine

and Pharmacy Timisoara, Timișoara, Romania

Bogdan Calenic, DDS, PhD, Associate Professor

Biochemistry Department, Faculty of Dental Medicine

"Carol Davila" University of Medicine and Pharmacy Bucharest Bucharest, Romania

Nardi Casap-Caspi, DDMD, MD, Professor and Head

Oral and Maxillofacial Surgery Department

Hadassah School of Dental Medicine

Hebrew University Hadassah Jerusalem, Jerusalem, Israel

Paulo G. Coelho, DDS, PhD, Professor

Hansjorg Wyss Department of Plastic Surger

NYU Langone Health, NYU School of Medicine, New York University New York NY, USA

Daniel Edelhoff, CDT, DMD, PhD, Professor and Head

Department of Prosthodontics, Faculty of Medicine

Ludwig-Maximilians - München University, München, Germany

Claudia Maria de Felicio, MD, PhD, Professor

Orofacial Motricity Unit, Department of Ophthalmology and Otolaryngology, School of Medicine, Universidade de São Paulo (USP) Ribeirão Preto, Brazil

Dorjan Hysi, DMD, MsC, PhD, Associate Professor, Chair Conservative Dental Department, Faculty of Dental Medicine Tirana

University of Medicine Tirana, Tirana, Albania

Heinz Kniha DDS, MD, PhD, Associate Professor

Oral and Maxillofacial Surgery Department, Faculty of Medicine

Ludwig-Maximilians-München University, München, Germany

Rodica Luca, DDS, PhD, Professor

Pedodontics Department, Faculty of Dental Medicine

"Carol Davila" University of Medicine and Pharmacy Bucharest Bucharest, Romania

Mariam Margvelashvili-Malament, DDS, MSc, PhD, Professor Department of Prosthodontics and Operative Dentistry, School of Dental Medicine, Tufts University, Boston, MA, USA

Domenico Massironi, DDS

MEG - Master Educational Group, Melegnano (MI), Italy

Rodolfo Isaac Miralles Lozano, MD, PhD, Professor

Physiology and Biophysics Department, Institute of Biomedical

Sciences, Faculty of Medicine, University of Chile, Santiago, Chile

Mutlu Özcan, DDS, PhD, Professor, Head

Dental Biomaterials Unit, Clinic of Fixed and Removable

Prosthodontics and Dental Material Science, Center of Dental

Medicine (ZZM), University of Zürich, Zürich, Switzerland

Mariana Păcurar, DDS, PhD, Professor and Head,

Orthodontics and DentoFacial Orthopedics Department, Faculty of

Dental Medicine, University of Medicine and Pharmacy Târgu Mureș Târgu Mureș, Romania

Alexandru Eugen Petre, DDS, PhD, Professor

Department of Fixed Prosthodontics and Occlusology

"Carol Davila" University of Medicine and Pharmacy Bucharest Bucharest, Romanis

Sanda Mihaela Popescu, DDS, PhD, Professor and Head

Dental Rehabilitation and Medical Surgery Emergencies

Department, Faculty of Dental Medicine, University of Medicine and

Pharmacy of Craiova, Dolj, Romania

Elena Preoteasa, DDS, PhD, Professor and Head

Complete Denture Department, Faculty of Dental Medicine

"Carol Davila" University of Medicine and Pharmacy Bucharest

Bucharest, Romania

Alina Pürienè, BS, PhD, Dr habil, Professor

Periodontics Department, Institute of Odontology

Faculty of Medicine, Vilnius University, Vilnius, Lithuani

Lucien Reclaru, Eng, PhD, Biomaterials Consultant, University of

Geneva Geneva, Switzerland

Stephen F. Rosenstiel, BDS, MSD, Professor and Chair

Restorative and Prosthetic Dentistry, College of Dentistry

The Ohio State University Columbus, Columbus, OH, USA
Martina Schmid-Schwap, DDS, PhD, Professor

Department of Prosthodontics, Bernhard Gottlieb

University of Dentistry, Medical University of Vienna, Vienna, Austria

Gregor Slavicek, DDS, PhD, Professor,

Steinbeis Transfer Institute of Biotechnology in Interdisciplinary

Dentistry, Steinbeis University Berlin, Berlin, Germany

Marius Steigmann, DDS, PhD, Professor

Steigmann Implant Institute, Neckargemund, Germany

Gianluca Martino Tartaglia, DDS, PhD, Associate Professor

Functional Anatomy Research Center Laboratory of Functional

Anatomy of the Stomatognathic Apparatus, Department of

Biomedical Sciences for Health, Faculty of Medicine

University of Milan, Milan, Italy

Bernard Touati, DDS, PhD, Assistant Professor

Prosthodontics Department, Faculty of Odontology, Paris V University, Paris, France

Tamara Tserakhava, DDS, PhD, Professor and Chair

Department of Pediatric Dentistry, Dental Faculty, Belarusian State Medical University Minsk, Belarus

Sorin Uram-Țuculescu, DDS, PhD, Assistant Professo

Prosthodontics Department, School of Dentistry

Virginia Commonwealth University Richmond, Richmond, VA, USA

\section{Reviewers-in-Chief}

Stephen F. Rosenstiel, BDS, MSD, Professor Emeritus

The Ohio State University Columbus, Columbus, OH, USA

Mihaela Rodica Păuna, DDS, PhD, Professor

"Carol Davila" University of Medicine and Pharmacy Bucharest

Bucharest, Romania

Nissan Joseph, DMD, Associate Professor

Tel Aviv University, Tel Aviv, Israel

Reviewers

Petr Bartak, Prague, Czech Republic

Cristian Niky Cumpătă, Bucharest, Roman

Andrezza Lauria de Moura, São Paulo, Brazi

Nikolay Ishkitiev, Sofia, Bulgaria

Barbara Janssens, Gent, Belgium

John Kois, Seattle, WA, USA

Cinel Malița, Bucharest, Romania

Enrico Manca, Cagliari, Italy

Vlademir Margvelashvili, Tbilisi, Georgia

Costin Marinescu, München, Germany

Marina Melescanu-Imre, Bucharest, Romania

Joel Motta Junior Manas, AM Brazil

Paz, AM, Brazil

Hazem Mourad, Qassim, Saudi Arabia

Paula Perlea, Bucharest, Roman

Crich

Comania

Robert Sabiniu Şerban, Bucharest, Romani

Elina Teodorescu, Bucharest, Romani

Mei-Qing Wang, Xi'an, China

English Language Editor-in-Chief

Roxana-Cristina Petcu, Phil, PhD, Professor

Faculty of Foreign Languages, University of Bucharest

Bucharest, Romania

English Language Editors

Valeria Clucerescu, Biol.

Honorary Statistical Advisers

Radu Burlacu, PhD, Bucharest, Romania

loan Opriș, PhD, Associate Scientist, Miami, USA

Book Reviewers

lulia Ciolachi, DMD, Bucharest, Romania

Florin-Eugen Constantinescu, DMD, PhD Student Bucharest, Romania

\section{Project Editor}

Irina-Adriana Beuran, $\mathrm{DMD}, \mathrm{PhD}$

Faculty of Dental Medicine "Carol Davila" University of Medicine and

Pharmacy Bucharest, Bucharest, Romania

Indexing Databases

indexing Databases

\section{Crossref}

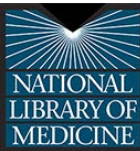

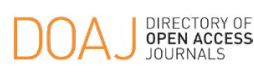

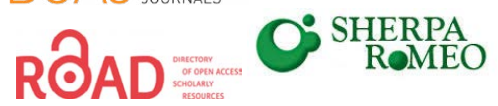

INFOBASE INDEX

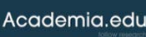

Google

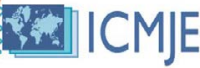

NTERNATIONAL COMMITTEE of
MEDICAL JOURNAL EDITORS 


\section{Dentsply Sirona}

\section{Meet}<smiles>CC1CCCC2CCCCC12</smiles><smiles>[SiH2]C1[CH][CH]1</smiles>

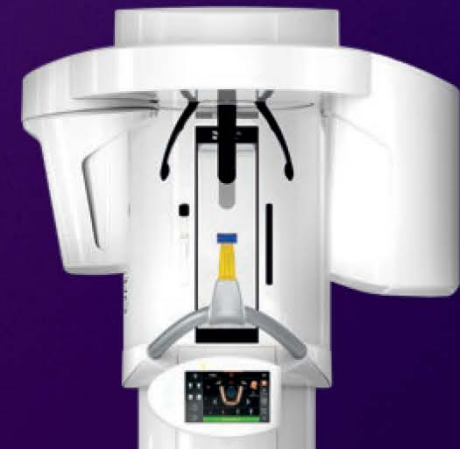

As part of the New Orthophos Society, he's the only choice

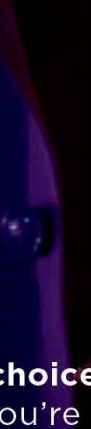
for superior image quality. When you choose Sir SL, you're
choosing the Orthophos SL in 2D or 3D. Stick to your standards and join the NOS.

dentsplysirona.com/NOS

\section{NOS}




\section{Think globally - act locally}

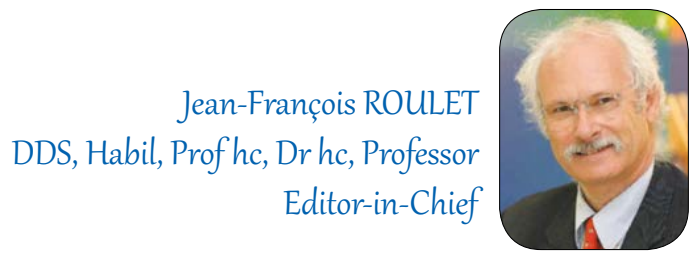

Dear Readers,

A very positive effect of the globalized information streams is that everybody willing to know what is going on can be very well informed. If you stick to facts rather than believe opinions, an analytic mind can infer from the information available that local actions usually have global effects. The global distribution of pollutants is quite easy to understand, since the weather is quite a global system. I remember two clear examples.

When 1 was a student, 1 think it was in 1969, I saw a huge tube leaning on the side of the Institute of Physics at the University of Bern. Curious 1 went to the people working on it and asked them what it was for. They explained to me that the tube was supposed to melt through the ice of Antarctica and that they would take water samples at different depths.

Due to the radiocarbon method, they were able to date the samples. Later 1 learned that with that device they could find soot that was correlated to the first industrial revolution in Europe in the late 180o's. Another example is the worldwide distribution of nuclear isotopes.

1 remember that in the 1950's, when the US was exploding Hydrogen bombs on atolls in the Pacific, it was not allowed to collect rain water for drinking purposes in Switzerland, due to nuclear pollution. The same happened after the 1986 nuclear accident in Chernobyl. $40 \%$ of the surface of Europe were contaminated with more than $4 \mathrm{kBq} / \mathrm{m}^{2}$. Radionuclides traceable to the reactor of Chernobyl were found in all countries of the northern hemisphere.

Another good example is business. Since today's business is interlinked worldwide, every national decision (e.g. tariffs, import/export restrictions etc.) will globally affect the people of other nations.

1 claim that dentistry is not different and further more 1 even claim that this is what makes dentistry that interesting. We dentists are dealing with more than teeth. My teacher and mentor Prof. André Schroeder used to say: "To every tooth there is attached a human being!" Isn't this a wonderful way to say that the teeth we are concerned with are part of the very complex machinery of the human body?

This is especially true with the ageing population we are faced with today, in combination with successful prevention. This means that the mainstream work of dentists moves from repairing single teeth to treating oral diseases or doing complex reconstructions. Whatever we do, we must consider the individual as a whole that has carried his/her teeth to our office. To understand what has lead to the situation the patients present, we need to know all the general health problems that are associated with the patient, the patient's habits and wishes, we need to understand the individual oral functions the patient has or has gotten adapted to. Remember that a faulty occlusion may lead to severe muscle pain in the neck and back, which may get chronical, with severe consequences for the patient. 
Medication-releated xerostomia will severely increase the caries risk of a patient; an allergic reaction after a local anesthesia can end up with a life-threatening situation and finally we all know that there are strong correlations between periodontal disease and general health.

Furthermore, we need to understand the materials and techniques we use and so on.

No wonder, as 1 learned from Prof. Marcello Kalabata, that 90\% of the errors that compromise a final treatment result are committed in the treatment planning phase.

This is what makes dentistry so thrilling. Despite the fact that Dentistry has evolved into a cluster of specialization, when we act locally in our specialty, we need to think globally like the "oumo universale", the ideal of Renaissance!

Sincerely yours,

J-F Roulet ${ }^{(\mathbb{D}}$

Editor-in-Chief

\section{References}

1. Sources and effects of ionizing radiation. United Nations Scientific Committee on the Effects of the Atomic Radiation. Volume II. New York, NY: United Nations Publication; 2011. [updated 2019 May 10; cited 2019 June 06].

Available from: http://www.unscear.org/docs/reports/2008/11-80076_Report_2008_Annex_D.pdf 


\section{Why l love Orthodontics}

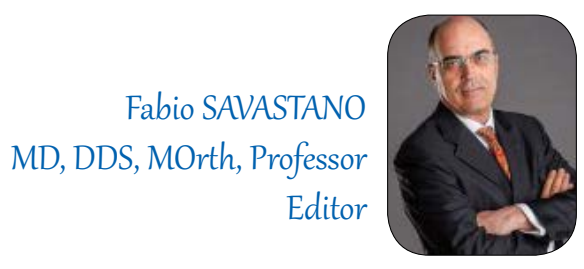

Dear Readers,

Many of my friends who are dentists believe that Orthodontics is boring and repetitive. 1 have thought a lot about this general idea that dentists have towards my specialty, and 1 cannot totally blame them. Generally speaking, 1 have to admit that, if 1 had to perform orthodontics "by the book," my specialty would probably be more than boring to me. Taking impressions, categorizing the occlusion and growth pattern and applying a fixed appliance involves waiting months to see results and then worrying for relapse and retention compliance. In addition, you have to cope with every single mother and father requesting endless explanations and selfish kids that do not bother with oral hygiene. An Inferno.

On the other hand, dentists are living a very interesting and passionate part of their profession: implants and advancements in surgical techniques, CAD-CAM and 3 D, just to name a few. Not that this progress in techniques and biomaterials is not important, but is it not the same dentistry we've done for years?

In a society where you feel the pressure of delivering fast results, you often become a victim of this absurd system and forget the unicity of your profession to become just an executer of teeth alignment. Your main goal is a distorted idea of success: aligning teeth fast, making the patient's parents happy and making money. 1 cannot say that these should not be some of the objectives in our line of practice, but 1 think there is more than this to any profession. If you take a closer look at what type of orthodontic courses sell the most, you will see that these courses advocate the use of new appliances, invented to deliver faster results with less patient compliance. No matter how deep your search is, you will always see fewer courses based on orthodontic diagnosis. So, what should be defined as success in Orthodontic Treatment?

1 think success in orthodontic treatment is not what you deliver at the end of treatment, but what can be delivered for the upcoming years: the stability and conservation of TM] function. This is a common point that both dentists and orthodontists have; we should practice delivering a functional occlusion as our main objective. Gnathology has benefitted from several advancements in technology, and this has opened a door previously closed to many dentists that can now objectively diagnose occlusion with ease. It has never been a better year to start a gnathology class: courses around the globe are increasing because there is more awareness among dentists about occlusion, TM] problems, and sleep disorders. Think about CBCT which is now present in many dental offices. What about electromyography and occlusion analyzers that were very seldom seen until just ten years or so ago. These are just a few examples that have and are changing the dental profession.

For many, occlusion remains a myth. The general opinion about occlusion is that it is related to TM] function. Despite this, the literature is full of publications that state that occlusal rehabilitation and orthodontic treatment does not cause any problems to the TM]. The literature lacks publications that link the treatment of the occlusion with TM] disease. While this is great news for us, it is quite sad for our patients. It is sad for an important reason: in a way it justifies the conscious ignorance of some dentists in not worrying about the TMJ, on the other hand it enforces the right to practice any doubtful dental or orthodontic procedure because it will not cause TMD. So, you could be closing your eyes when finishing an occlusion but be willing to apply a "bite" for TM] related problems. On the one hand, you hope to treat the TM] by applying a bite, trying to unlink the patient's occlusion, on the other hand, you are not willing to determine a correct functional occlusion that could avoid occlusal problems after treatment. This is a contradiction. 
l've been practicing orthodontics for over 30 years, 29 of which involved applying the neuromuscular principals taught by Bernard Jankelson [1-7] to orthodontic diagnosis. Mandibular Tracking, electromyography, and TENS have all been in my office ever since. This has been a great opportunity for me; I have been able to see and measure the physiology of my patients. 1 am one of the lucky ones that did less investing in cosmetic appliances and more investing in knowledge. That myth about occlusion has been translated to a paradigm with continuous discoveries and its application in treatment protocols. 1 have been able to reduce relapse (every orthodontist has relapse cases, just in case you smiled) and find new therapeutic strategies [8-10]. 1 have had a chance to work with doctors around the world that are part of a growing neuromuscular community, who have stimulated me and with whom 1 share and confront my opinions and results. 1 have had a chance to really focus on my final occlusion. It has been a long journey and 1 do not regret one single moment.

1 love orthodontics for many reasons. 1 think it will be the most important dental specialty in the future. Orthodontics is the specialty of specialties, meaning that orthodontists can help in periodontal patients, prosthetic, and surgical cases. The orthodontist probably remains the best candidate to treat occlusal problems and related TM] symptoms. Orthodontists are patient and are happy to wait for results, and unless they become victim of the system, they will achieve an optimal occlusion for the patient. 1 love orthodontics because it has given me a chance to express my artistic side. Ars Medica: it is the creativity you put into crafting a balanced functional occlusion that is exciting and stimulating. Every case is a unique challenge and is different from the previous.

The neuromuscular approach gives the dental community the opportunity to free itself from old misconceptions that are deeply rooted in our profession. We need a wider perspective on occlusion and most of all we need to stop shouting out opinions while we have instruments we could measure them with. Weneed to try Neuromuscular Dentistry because we know deep inside that muscles are the engine that drives the stomatognathic system. Muscles, nerves, and fascia are all taken into consideration during neuromuscular dental diagnosis. We need to stop this purely technical and mechanistic approach to dentistry and leave more space for physiology, function, and occlusion.

Fabio Savastano ${ }^{(D)}$, MD, DDS, M.Orth

Adjunct Professor, Masters in Neuromuscular Orthodontics,

University Jaume 1, Castellon, Spain

Editor

\section{References}

1. Jankelson RR. Neuromuscular dental diagnosis and treatment. St. Louis: Ishiyaku EuroAmerica; 1990 in Am J Orthod Dentofacial Orthop (AJO-DO). 1991;99(3):283-284.

2. Jankelson B. Neuromuscular aspects of occlusion. Effects of occlusal position on the physiology and dysfunction of the mandibular musculature. Dent Clin North Am. 1979;23(2):157-168.

3. Jankelson B. Physiology of human dental occlusion. J Am Dent Assoc. 1955;50(6):664-680.

4. Jankelson B, Hoffman GM, Hendron JA Jr. The physiology of the stomatognathic system.J Am Dent Assoc. 1952;46(4):375-386.

5. Constantinescu MV, Traistaru T. [The concept of neuromuscular occlusion. II. The apparatus and its function]. [Article in Romanian] Rev Chir Oncol Radiol O R L Oftalmol Stomatol Ser Stomatol. 1984;31(3):193-198.

6. Ene L, Constantinescu MV, Traistaru T. [The neuromuscular occlusion concept. III. Myofunctional impressions in completely edentulous denture arches]. [Article in Romanian] Rev Chir Oncol Radiol O R L Oftalmol Stomatol Ser Stomatol. 1985;32(1):35-48.

7. Monaco A, Cattaneo R, Ortu E, Constantinescu MV, Pietropaoli D. Sensory trigeminal ULF-TENS stimulation reduces HRV response to experimentally induced arithmetic stress: A randomized clinical trial. Physiol Behav. 2017;173:209-215. 8. Savastano F. Correction of a Class II Occlusion in an Adult. J Dent Oral Disord Ther. 2014;4:1-10.

9. Savastano F. Applying neuromuscular techniques in the orthodontic setting. South Eur J Orthod Dentfac Res. 2017;4:20-31. 10. Savastano F. Contemporary Dental Occlusion in Orthodontics. BAOJ Dentistry. 2015;1(1):1-4. 


\title{
Our uninterrupted joint effort on the path of certification
}

\author{
Marian-Vladimir CONSTANTINESCU
DDS, MSc, PhD, Professor
Editor-in-Chief
}

Dear Readers,

1 would like to believe that you have already started enjoying your summer vacation. Given the fact that you are now trying to feel comfortable, to find as much time as possible to relax, I want to briefly share with you the current situation of the Stomatology Edu Journal (Stoma Edu J), the journal you have shown your interest for since 2014.

The Stomatology Edu Journal (Stoma Edu J), an international peer-reviewed Open Access journal, has been published continuously since 2014, initially bi-annually, and as of 2016, quarterly. So far, it has managed to have over 240,00o readers. This performance is indeed an achievement of the Operative Editorial Team, but also of the very numerous Editorial Board, who very kindly agreed to contribute to the consolidation of a new journal in Central and Eastern Europe, addressing mainly the dental practitioners in Romania and the Republic of Moldova.

From the very beginning the Stomatology Edu Journal (Stoma EduJ), via its tireless Operative Editorial Team, adopted the quality recommendations imposed by the International Committee of Medical Journal Editors (ICMJE), with which it also registered.

Prof.] Jean-François Roulet's exceptional editorial expertise and his permanent struggle to raise the quality standard of each published article have led to the publication of over 120 articles, individualized through DOI by Crossref. Out of them all, a total of 61 articles were credited by the Directory of Open Access Journals (DOAJ).

The authors, regardless of their nationality, be they native Romanians or Moldovans or foreigners (originating in one of the over 40 countries where the editors come from), do appreciate the progress achieved by the Stomatology Edu Journal (Stoma Edu J), but have constantly raised the issue of its certification.

The Stomatology Edu Journal (Stoma Edu J) has been under evaluation by Clarivate Analytics for over a year, and we will receive an answer only after the publication of this year's second issue.

The Stomatology Edu Journal (Stoma Edu J) is also being evaluated by PubMed / PMC / MEDLINE. 
Dear Readers,

When we know the result of the evaluation of the Stomatology Edu Journal (Stoma EduJ) we will immediately communicate it to you. Both our Authors and Editors hope that their tireless work to provide you with quality articles will be rewarded with our certification as soon as possible.

May God help us all!

Marian-Vladimir Constantinescu

Editor-in-Chief

\section{References}

1. Bona AD, Bello YD, Sartoretto SC. Use of standards in papers published in dental journals. Braz Dent J. 2012;23(5):471-476.

[Full text links] [CrossRef] [PubMed] Google Scholar Scopus

2. Jayaratne YS, Zwahlen RA. The evolution of dental journals from 2003 to 2012: a bibliometric analysis. PLoS One. 2015;10(3):e0119503.

[Full text links] [Free PMC Article] [CrossRef] [PubMed] Google Scholar Scopus

DOI: https://doi.org/10.25241/stomaeduj.2019.6(2).edit.3 


\section{Laudatio to the ,Iron Lady of Orthodontics" Professor Birthe Melsen}

Birthe Melsen, one of the most recognized and respected Orthodontists, was born in Aabenraa, Denmark in 1939. She received her Dental Degree in 1964 from Aarhus University in Aarhus, Denmark. Melsen began her ascending road with obtaining the orthodontics specialty in the year of 1971 and received her orthodontic certificate in 1974 from Royal Dental College.

Her complex academic activity was accomplished with abnegation and dedication, over the course of decades dedicated to study and scientific creation. She has been a full professor since 1975, and between 1975 and 2012 she was Head of Department of Orthodontics at the School of Dentistry, Aarhus University, Denmark. Since 1986, she has been working part-time in a private practice in Lübeck, Germany

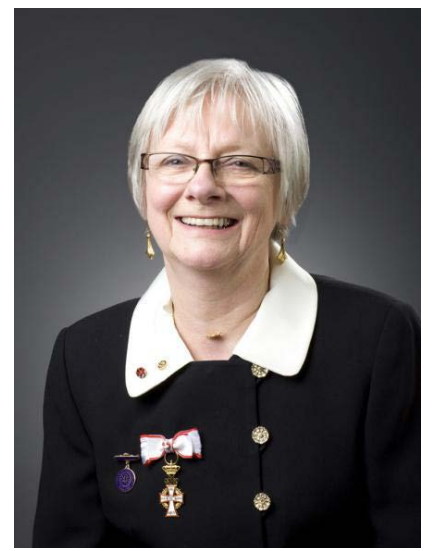
(Adult Orthodontics only).

The intense research activity, her passion and organizational capabilities, have brought her many leadership positions over the years, in different scientific societies.

Writing about professor Melsen is a more difficult task than it seems, One can say a lot about her impressive and complex activity and also about the multiple sides of her defining personality, but we must summarize the vast information that we possess.

A remarcable university specialist and reputed scientist, professor Birthe Melsen is also actively involved in philanthropic causes, since 1989 fundraising for third world children, especially in South America, where she lectures to generate money for the unprivileged children, and also regularly donating for several Children Organisations.

\section{The leadership positions}

1976 - President, Scandinavian Orthodontic Society; 1984 - President, Nordic Orthodontic Society; 1988 - President, Danish Orthodontic Society; 1989 - President, Third International Symposium on Dentofacial Development, Aarhus, Denmark; 1990 Vice-president, European Orthodontic Society Congress, Copenhagen, Denmark; 1993-96 Vice-president of International Symposium on Comprehensive Management of Craniofacial Anomalies; 1994-97 President of the Danish Orthodontic Society; 1994- Associate Editor of Orthodontics and Craniofacial Research; In 2000 she received the "Knighthood of Dannebrog 1st degree", the highest possible award for University affiliated researchers. In 2004 he was elected President of the European Orthodontic Society.

She has supervised 18 Phd theses and advised for research projects in Australia, Brazil, Italy and Thailand. She has, since 1975, been a regular lecturer at a large number of the postgraduate programs in the US and South America and during the last decenium also in Australia and various Asian countries. She is a regular member of The Angle Society and an international member of the American Association of Orthodontics and the World Society of Orthodontics. 


\section{The scientist}

Professor Melsen has made significant contributions in the field of orthodontics with her research. She has authored more than 380 publications in the fields of growth and development based on research on human autopsy material, bone biology and clinical implant studies.

Her entire activity was oriented in three major directions all with profound practical implications: Skeletal Anchorage- Mini-Implants: Where Are We? In 2005 Birthe Melsen said "In my opinion, skeletal anchorage is clearly not a replacement for other proven anchorage systems. Skeletal anchorage should serve merely to expand the orthodontic services we can offer our patients" An innovation that professor Birthe Melsen introduced and developed was the Aarhus System. These miniscrews yield a perfect balance of sizing, strength and working diameter for maximum clinical application. The system has an excellent one-dimensional control through button head screws, ideal for elastic chains and NiTi spring applications, and two-dimensional control accepting wires, hooks, lever arms and other auxiliaries.

\section{Virtual Imaging}

Professor Melsen's "3-D occlusogram" software, as suggested by Fiorelli and Melsen, was determined to develop a user-friendly software which in addition to the advantages mentioned by Marcotte can also provide the bases for the computerized appliance design.

\section{Adult Orthodontic Treatment}

She has published a textbook called Adult Orthodontics in 2012 and has made significant contributions in the field of orthodontics with her research, publishing many papers in different scientific journals. This is a major new work dedicated to the increasingly prominent area of adult orthodontics. The opening chapters provide the context for adult orthodontics, including patient demographics and a etiology, and the book goes on to detail treatment planning considerations, including patient case profiles, suggesting initial outcomes and longer term expectations.

After having lectured for so many years about biomechanics, and after working together for more than 20 years on the "Biomechanics in Orthodontics" software, professor Melsen and dr. Fiorelli have decided to undertake a new challenge of teaching the "real" biomechanics in five weeks of hard work. In 2013, professor Melsen started alongside dr. Giorgio Fiorelli, The Orthodontic Biomechanics Summer School, with the 1st edition in Arezzo, and then went on yearly in Viareggio and Lido di Camaiore.

From 2006 she is Associate Editor of the Journal of Clinical Orthodontics.

Over the last few years I have had the chance and the joy of getting to know her more closely, discussing at different international congresses either in France, at the FFO Congress where we discussed about the next two meetings scheduled in Romania for AREO members, or in America during the meeting of the AAO ambassadors, where we had the pleasure to work together, along with other big names from the orthodontic world, at the working meeting of the WIOA advisors for the preparation of the WIOC 2019 congress, which will be held in Bucharest from October 23-26, the second time after many years in Europe again.

As of 9 June 2019, Birthe Melsen is 80 years old. Happy birthday dear lady Birthe Melsen!

Irina Nicoleta Zetu, DDS, PhD, Dr.-Habil. Professor and Chair Division of Orthodontics "Grigore T. Popa" University of Medicine and Pharmacy lași, lași, Romania Editor of Stomatology Edu Journal 


\section{stomaedij}

From The Journal of the American Dental Association

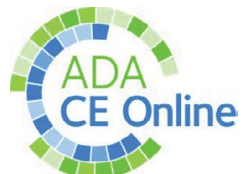

\section{JADA ONHWE CE EXAMS}

http://jada.ada.org/ce/home

http://jada.ada.org/ceworksheets

July 2019

Meloto CB, Slade GD, Lichtenwalter RN, Bair E, Rathnayaka N, Diatchenko L, Greenspan JD, Maixner W, Fillingim RB, Ohrbach R.

CLINICAL PREDICTORS OF PERSISTENT TEMPOROMANDIBULAR DISORDER IN PEOPLE WITH FIRST-ONSET TEMPOROMANDIBULAR DISORDER: A PROSPECTIVE CASE-CONTROL STUDY.

J Am Dent Assoc. 2019 Jul;150(7):572-581.e10. doi: 10.1016/j.adaj.2019.03.023.

This article has an accompanying online continuing education activity available at: http://jada.ada.org/ce/home. 


\title{
IN VITRO WEAR OF TEN UNIVERSAL COMPOSITES
}

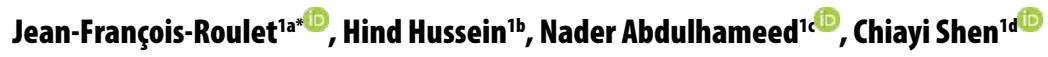 \\ 'Department of Restorative Dental Science, Center of Dental Biomaterials College of Dentistry \\ University of Florida, Gainesville, FL32610, USA \\ ${ }^{a}$ Dr. med.dent, Dr. hc, Professor \\ ${ }^{\mathrm{b} D D S}$ \\ DDS \\ ${ }^{\mathrm{D} D M D}, \mathrm{PhD}$
}

DOI: https://doi.org/10.25241/stomaeduj.2019.6(2).art.1

\begin{tabular}{|c|c|}
\hline 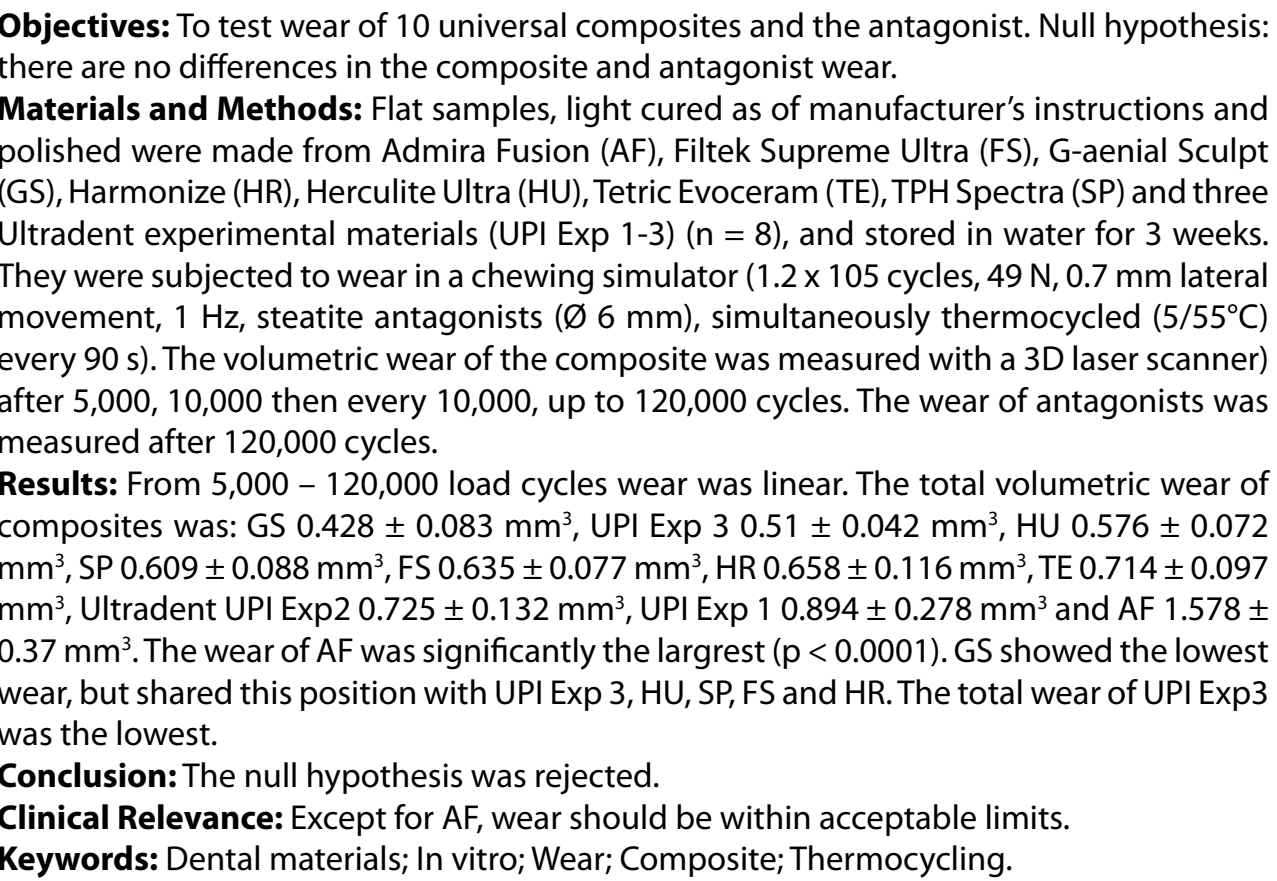 & 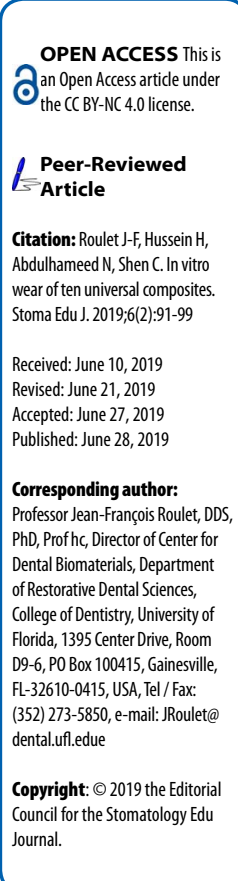 \\
\hline
\end{tabular}

\section{Introduction}

Since their invention in the 1950s [1-3], composites have been continuously improved, however without abandoning their basic concepts. Over the years it became very obvious that the fillers used had the greatest influence on their physical and mechanical properties [4]. The fillers determine the mechanical properties, they reduce the polymerization shrinkage, the filler selection may optimize wear behavior, they influence the optical properties (translucency) and may enhance the radiopacity. Furthermore, the surface characteristics and thus the polishability depend on the fillers, with consequences for the handling properties and finally the aesthetic appearance of a composite restoration [5]. Historically quartz was first replaced by a variety of different glasses, followed by socalled microfillers (Aerosil, fumed silica), which were first introduced into a resin matrix, which was polymerized and ground into powder. This filler was also referred to as prepolymerized particles [68] which were incorporated into a matrix filled with fumed silica. Optimal X-ray contrast was achieved by ytterbium trifluoride filler [9]. In parallel with the improvement in glass milling technology, it was also recognized that optimal "intelligent" filler particle size distribution reduced the resin content, which had a positive effect on polymerization shrinkage [8]. Using flame spray pyrolysis [10] silica based nanoparticles over a wide range of size could be produced. Furthermore, it was possible to create spherical mixed oxide (ytterbium oxide and silica) nanoparticles that matched the refractive index of the resin mix (1.53) resulting in radiopaque composites with high translucency [11]. Finally, composites based solely on nanoparticle technology were introduced. However, the true single particle nanofillers are dispersed in a matrix, which is filled with so-called nanoclusters, with dimensions far away from the nano range [12]. Being aggregated nanoparticles, the clusters lost many advantages of the nanotechnology. The changes outlined above are reflected in a multitude of composite classifications based on their fillers $[4,6,7,13-17]$.

Clinical Studies of early composites placed in posterior teeth have revealed substantial wear [18]. With the improvement of the filler technology as described above, the longevity of posterior composite restorations can be excellent. The survival behavior of restorations is shown best with Kaplan- 
ITable 1.Materials used incl. filler composition.

\begin{tabular}{|c|c|c|c|c|c|}
\hline Name & Color & Type & Filler & Manufacturer & Batch \# \\
\hline $\begin{array}{l}\text { Admira Fusion } \\
\text { (AF) }\end{array}$ & $\mathrm{A} 2$ & $\begin{array}{l}\text { Universal } \\
\text { Nanohybrid- } \\
\text { Ormocer }\end{array}$ & $\begin{array}{l}84 \% \mathrm{w} / \mathrm{w} \text { inorganic fillers: } \mathrm{SiO}_{2} \text { glass and } \\
\text { nanoparticles }\end{array}$ & $\begin{array}{l}\text { Voco GmbH, } \\
\text { Cuxhaven, Germany }\end{array}$ & 1638273 \\
\hline $\begin{array}{l}\text { Filtek Supreme } \\
\text { Ultra (FS) }\end{array}$ & $\begin{array}{l}\text { A2 } \\
\text { Enamel }\end{array}$ & Ultra Universal & $\begin{array}{l}\text { Agglomerated zirconia/silica cluster, } \\
\text { average cluster size } 0.6-20 \mu \mathrm{m} \text {. Non } \\
\text { agglomerated/non aggregated silica } \\
\text { filler } 20 \mathrm{~nm} \text {, and zirconia filler } 4-11 \mathrm{~nm} \text {. } \\
\text { Total filler } 72.5 \% \mathrm{w} / \mathrm{w}\end{array}$ & $\begin{array}{l}\text { 3M Espe St. Paul, MN, } \\
\text { USA }\end{array}$ & N808359 \\
\hline $\begin{array}{l}\text { G-aenial } \\
\text { Sculpt (GS) }\end{array}$ & $\begin{array}{l}\text { Adult } \\
\text { Enamel }\end{array}$ & $\begin{array}{l}\text { Universal } \\
\text { Nanohybrid } \\
\text { Compactable }\end{array}$ & $\begin{array}{l}\text { Uniform nano-filler dispersion } \\
\text { technology Barium glass } 300 \mathrm{~nm}\end{array}$ & $\begin{array}{l}\text { GC Corp, Tokyo, } \\
\text { Japan }\end{array}$ & 1506111 \\
\hline $\begin{array}{l}\text { Harmonize } \\
\text { (HR) }\end{array}$ & $\begin{array}{l}\mathrm{A} 2 \mathrm{E} \\
\text { Enamel }\end{array}$ & $\begin{array}{l}\text { Nanohybrid } \\
\text { Universal }\end{array}$ & $\begin{array}{l}\text { Barium glass } 400 \mathrm{~nm} \text {, Silica and zirconia } \\
\text { nanoparticles }>5 \mathrm{~nm} \text {. Average particle } \\
\text { size } 50 \mathrm{~nm} \text { Total filler } 81 \% \mathrm{w} / \mathrm{w}\end{array}$ & $\begin{array}{l}\text { Kerr Co., Orange, CA, } \\
\text { USA }\end{array}$ & 6173894 \\
\hline $\begin{array}{l}\text { Herculite Ultra } \\
\text { (HU) }\end{array}$ & $\begin{array}{l}\text { A2 } \\
\text { Enamel }\end{array}$ & Nanohybrid & $\begin{array}{l}\text { Ba-glass filler } 0.4 \mu \mathrm{m} \text {, Prepolymerized } \\
\text { Filler, Silica nanofiller, } 20-50 \mathrm{~nm} \text { Total } \\
\text { filler } 78 \% \mathrm{w} / \mathrm{w}\end{array}$ & Kerr Co., Orange, CA & 6037221 \\
\hline $\begin{array}{l}\text { Tetric } \\
\text { EvoCeram (TE) }\end{array}$ & $\begin{array}{l}\text { A2 } \\
\text { Enamel }\end{array}$ & $\begin{array}{l}\text { Universal } \\
\text { Composite }\end{array}$ & $\begin{array}{l}\text { Ba-Al-Silicate glass } 0.4 \text { and } 0.7 \mu \mathrm{m}, \\
\text { Yterbuimfluoride, Mixed Oxyde } 160 \mathrm{~nm} \text {, } \\
\text { Isofiller (Prepolymerized Filler), } \mathrm{SiO}_{2} 40 \\
\mathrm{~nm}\end{array}$ & $\begin{array}{l}\text { Ivoclar Vivadent, } \\
\text { Schaan Liechtenstein }\end{array}$ & V27337 \\
\hline $\begin{array}{l}\text { TPH Spectra } \\
\text { (SP) }\end{array}$ & $\mathrm{A} 2 \mathrm{HV}$ & $\begin{array}{l}\text { Universal } \\
\text { Composite }\end{array}$ & $\begin{array}{l}\text { Ba-Al-borosilicate glass, Ba-B-F-al- } \\
\text { silicate glass, } \mathrm{SiO}_{2} \text {. Total filler } 77.2 \% \mathrm{w} / \mathrm{w}\end{array}$ & $\begin{array}{l}\text { Dentsply Caulk, } \\
\text { Milford, DE, USA }\end{array}$ & 160401 \\
\hline $\begin{array}{l}\text { Ultradent UPI } \\
\text { Exp } 1\end{array}$ & $\begin{array}{l}\text { A2 } \\
\text { Dentin }\end{array}$ & $\begin{array}{l}\text { Universal } \\
\text { Composite }\end{array}$ & $\begin{array}{l}\text { Total filler: } 68 \% \text { v/v } \\
\text { zirconia-silica glass ceramic and } 20 \\
\text { nanometer silica }\end{array}$ & $\begin{array}{l}\text { Ultradent Products } \\
\text { Inc., South Jordan, } \\
\text { UT, USA }\end{array}$ & RTO0E00A \\
\hline $\begin{array}{l}\text { Ultradent UPI } \\
\text { Exp } 2\end{array}$ & Enamel & $\begin{array}{l}\text { Universal } \\
\text { Composite }\end{array}$ & $\begin{array}{l}\text { Total filler: } 56 \% \text { v/v } \\
\text { zirconia-silica glass ceramic and } 20 \\
\text { nanometer silica }\end{array}$ & $\begin{array}{l}\text { Ultradent Products } \\
\text { Inc., South Jordan, } \\
\text { UT, USA }\end{array}$ & SW20E15B \\
\hline $\begin{array}{l}\text { Ultradent UPI } \\
\text { Exp } 3\end{array}$ & Enamel & $\begin{array}{l}\text { Nano-hybrid } \\
\text { Composite }\end{array}$ & $\begin{array}{l}\text { Total filler: } 80.9 \% \mathrm{w} / \mathrm{w} \\
\text { barium borosilicate glass filler. Average } \\
\text { particle size is } 0.89 \text { micrometers }\end{array}$ & $\begin{array}{l}\text { Ultradent Products } \\
\text { Inc., South Jordan, } \\
\text { UT, USA }\end{array}$ & 20E15B \\
\hline
\end{tabular}

Meier survival statistics. However, with those the comparison of different studies is difficult. Therefore, most authors report the \% survival of restorations after a given time (e.g. 5 or 10 years). For direct comparisons these can be converted into \%-annual failure rates (AFR). On the one side, clinical long-term studies show annual failure rates (AFR) between $0.1 \%$ and $0.67 \%$ after 10 years [19], $1.1 \%$ after 30 years [20], and $1.5 / 2.2 \%$ after 22 years [21]. On the other hand, higher AFRs have been reported. In a systematic review Opdam et al [22] reported AFRs of $1.8 \%$ (5 years) and $2.4 \%$ (10 years). However, when discriminating between high caries risk and low caries risk, the respective numbers were $3.2 \%$ and $4.6 \%$ for high caries risk and $1.2 \%$ and $1.6 \%$ for low caries risk respectively. A significant material effect could be found as well. In another review article, Demarco et al [23] reported AFRs between $0 \%$ and $8.6 \%$, which may allow the question that the dentist may be a significant cofactor. Hickel and Manhart [24] found similar results. They reported AFRs between $0 \%$ and $9 \%$. Only 3 out of 24 studies reported wear. The authors concluded that the factors influencing longevity of restorations were the patient, the dentist and the material. In an extensive review about the longevity of restorations Manhart et al [25] found that over time composites have significantly improved. For direct restorations they found in publications before 1990 an AFR of 4.2, while in papers published after 1990 the AFR was 2.0. In the past, composites were specifically developed for a specific indication (anterior or posterior restorations), based on their aesthetic or wear behavior. Contemporary composite materials that have reached a high degree of maturity, are complex constructs [26], and well accepted by the profession. They are designed as universal composites suitable for the application in the anterior and posterior segment. Furthermore, with the improved knowledge of application techniques composites are used for larger restorations as in the past, which brings back the question if composites are sufficiently wear resistant to carry occlusal load. Composite restorations should have similar wear to enamel so restorations behave similarly to teeth. This is important, especially when the indication of 
I Table 2. Light curing parameters according to manufacturers' instructions for use.

\begin{tabular}{lccc}
\hline Material & $\begin{array}{c}\text { Curing } \\
\text { time } \\
(\mathbf{s})\end{array}$ & $\begin{array}{c}\text { Exitance } \\
\text { irradiation } \\
\left(\mathbf{m W} / \mathbf{c m}^{2}\right)\end{array}$ & $\begin{array}{c}\text { Radiant } \\
\text { exposure } \\
\left(\mathbf{J} / \mathbf{c m}^{2}\right)\end{array}$ \\
\hline Admira Fusion & 20 & 1170 & 23.40 \\
$\begin{array}{l}\text { Filtek Supreme } \\
\text { Ultra }\end{array}$ & 10 & 1170 & 11.70 \\
G-aenial Sculpt & 10 & 1170 & 11.70 \\
Harmonize & 10 & 1170 & 11.70 \\
Herculite Ultra & 10 & 1170 & 11.70 \\
Tetric EvoCeram & 10 & 1170 & 11.70 \\
TPH Spectra & 10 & 1170 & 11.70 \\
UPI Exp 1 & 20 & 1170 & 23.40 \\
UPI EXP 2 & 20 & 1170 & 23.40 \\
UPI EXP 3 & 20 & 1170 & 23.40 \\
\hline
\end{tabular}

direct composite restorations includes the buildup of missing cusps. Then the occlusion cannot be supported by natural tooth structure (enamel). Therefore, the aim of this study was to test the wear characteristics of three experimental universal composites as compared to seven commercially available contemporary composites with different filler-compositions. The null hypothesis was that there are no differences in the composite wear as well as in the wear of the antagonists.

\section{Materials and Methods}

The Universal composite materials used are described in Table 1.

Eighty aluminum sample holders (inner $\varnothing 8 \mathrm{~mm}$ depth $1.5 \mathrm{~mm}$ ) were modified to have mechanical retention, then one coat of universal bond (Monobond Plus, Ivoclar Vivadent, Liechtenstein) was added and left for $60 \mathrm{~s}$, followed by air blasting to evaporate the solvent. Then one coat of adhesive (Optibond FL 2, Kerr, CA, USA) was applied and light cured according to the manufacturers' instructions using a Valo Grand (Ultradent Products, South Jordan, UT, USA) at standard mode delivering $1170 \mathrm{~mW} / \mathrm{cm}^{2}$, measured with a Bluephase Meter II (Ivoclar Vivadent, Liechtenstein). The composites were filled into the sample holders in one increment, then the top surface was flattened with a Mylar ${ }^{\otimes}$ matrix band and the composites were light cured with a Valo Grand in contact with the matrix band according to the composites manufacturers' instructions (Table 2).

The composite surfaces where finished and polished by using (Sof-Lex Disks, 3M, MN, USA), light orange disc for finishing and yellow disc for polishing for 10$15 \mathrm{~s}$, and the final gloss was obtained with Astropl silicon polishers (Ivoclar Vivadent, Liechtenstein). All samples were stored in distilled water for 3 weeks at $37^{\circ} \mathrm{C}$. Steatite balls $(\varnothing 6 \mathrm{~mm}$ ) mounted into aluminum
Table 3. Settings of Chewing Simulator.

\begin{tabular}{r|l} 
Load & $5 \mathrm{~kg}$ \\
Upstroke & $2 \mathrm{~mm}$ \\
Downstroke & $1 \mathrm{~mm}$ \\
$\begin{array}{r}\text { Horizontal } \\
\text { movement }\end{array}$ & $0.7 \mathrm{~mm}$ \\
Upward speed & $60 \mathrm{~mm} / \mathrm{s}$ \\
Downward speed & $60 \mathrm{~mm} / \mathrm{s}$ \\
Horizontal speed & $40 \mathrm{~mm} / \mathrm{s}$ \\
Frequency & $1 \mathrm{~Hz}$ \\
& $5^{\circ} \mathrm{C}-55^{\circ} \mathrm{C} 30 \mathrm{~s}$ holding time, \\
transfer time $15 \mathrm{~s}$, total cycle $90 \mathrm{~s}$ \\
Thermocycling
\end{tabular}

holders with composite were used as antagonists. One antagonist per sample $(n=64)$ was used and discarded after finishing all cycles.

The chewing simulator was run according to the parameters listed in Table 3. The specimens were simultaneously thermocycled $\left(5 / 55^{\circ} \mathrm{C}\right)$ every $90 \mathrm{~s}$. This resulted in 120,000 mechanical cycles and 1333 thermal cycles as a total. After 5,000, 10,000, 20,000, 40,000, $60,000,80,000,100,000$, and 120,000 load cycles, Polyvinylsiloxane impressions (Virtual Extra light body, Fast set Wash material, Ivoclar Vivadent, Liechtenstein) using small cylindrical PVC trays were taken from the samples. From the antagonists, impressions were taken before the experiment and after 120,000 cycles (end point of the experiment). All impressions were cast using a dental stone (Micro stone, Whip Mix Co, Louisville, KY, USA).

The stone models were then scanned with a 3D laser scanner, Laserscanner LAS-20 (SD Mechatronik GmbH, Feldkirchen-Westerham, Germany). By using geometric software Geomagic control 2014 (3D Systems, Inc, USA), the scanned data were used to measure the wear of the samples after each round. The flat surface of the sample was used as a reference plain and the wear was calculated as the volume of the wear facet relative to the reference plane. The wear of the steatite antagonists was measured as well in volume loss comparing the initial with the final model. Data were analyzed using ANOVA, linear regression and the Tukey test.

From every group selected samples were dried in ambient air, sputtered with AuPd, and SEM, MIRA3 (TESCAN, PA, USA) pictures at magnifications up to 3200 were taken from the worn surfaces (composite and antagonist) in order to see the wear patterns and possible breakdowns in the surfaces.

\section{Results}

As expected, from 10,000 - 120,000 load cycles we found a statistically significant linear correlation of wear with chewing cycle (Fig. 1) The ANOVA showed significant differences $(p<0.0001$ ). After 120,000 cycles, the total wear of composite in volume varied from $0.428 \mathrm{~mm}^{3}$ to $1.578 \mathrm{~mm}^{3}$.

The volumetric wear for every material after 120,000 
Table 4. Wear of composites in $\mathrm{mm}^{3}$ after $120 \mathrm{~K}$ cycles. Same letter = same statistical group $(p<0.05)$.

\begin{tabular}{lll}
\hline Material & Mean \pm SD & $\begin{array}{l}\text { Statistical } \\
\text { group }\end{array}$ \\
\hline Admira Fusion & $1.578 \pm 0.369 \mathrm{~mm}^{3}$ & $\mathrm{~A}$ \\
UPI Exp 1 & $0.894 \pm 0.278 \mathrm{~mm}^{3}$ & $\mathrm{~B}$ \\
UPI Exp 2 & $0.725 \pm 0.132 \mathrm{~mm}^{3}$ & $\mathrm{BC}$ \\
Tetric EvoCeram & $0.714 \pm 0.097 \mathrm{~mm}^{3}$ & $\mathrm{BC}$ \\
Harmonize & $0.658 \pm 0.116 \mathrm{~mm}^{3}$ & $\mathrm{BCD}$ \\
Filtek Supreme Ultra & $0.635 \pm 0.077 \mathrm{~mm}^{3}$ & $\mathrm{BCD}$ \\
TPH Spectra & $0.609 \pm 0.088 \mathrm{~mm}^{3}$ & $\mathrm{CD}$ \\
Herculite Ultra & $0.576 \pm 0.072 \mathrm{~mm}^{3}$ & $\mathrm{CD}$ \\
UPI Exp 3 & $0.510 \pm 0.042 \mathrm{~mm}^{3}$ & $\mathrm{CD}$ \\
G-aenial Sculpt & $0.428 \pm 0.083 \mathrm{~mm}^{3}$ & $\mathrm{D}$ \\
\hline
\end{tabular}

Table 5. Wear of antagonists in $\mathrm{mm}^{3}$ generated by the different composites tested after $120 \mathrm{~K}$ cycles. Same letter $=$ same statistical group $(p<0.05)$.

\begin{tabular}{lll}
\hline Material & mean \pm SD & $\begin{array}{l}\text { Statistical } \\
\text { group }\end{array}$ \\
\hline G-aenial Sculpt & $0.290 \pm 0.023 \mathrm{~mm}^{3}$ & $\mathrm{~A}$ \\
Herculite Ultra & $0.231 \pm 0.024 \mathrm{~mm}^{3}$ & B \\
UPI Exp 2 & $0.210 \pm 0.024 \mathrm{~mm}^{3}$ & BC \\
Harmonize & $0.206 \pm 0.025 \mathrm{~mm}^{3}$ & BC \\
TPH Spectra & $0.175 \pm 0.018 \mathrm{~mm}^{3}$ & $\mathrm{C}$ \\
UPI Exp 3 & $0.130 \pm 0.037 \mathrm{~mm}^{3}$ & D \\
Tetric EvoCeram & $0.129 \pm 0.028 \mathrm{~mm}^{3}$ & D \\
UPI Exp 1 & $0.121 \pm 0.026 \mathrm{~mm}^{3}$ & D \\
Filtek Supreme Ultra & $0.113 \pm 0.017 \mathrm{~mm}^{3}$ & D \\
Admira Fusion & $0.100 \pm 0.017 \mathrm{~mm}^{3}$ & D \\
\hline
\end{tabular}

load cycles is shown in Table 4. The different composites created significantly different wear of the steatite antagonists $(p<0.05)$ (Table 5 and Fig. 2). Note that AF had significantly more wear than all other materials tested. GS showed the least wear; however, it shared this position with UPI Exp3, HU, SP, FS and HR. Since most composites wear in a similar way, there is a lot of overlap between $0.6 \mathrm{~mm}^{3}$ and $0.9 \mathrm{~mm}^{3}$ volume loss.

In general, the antagonist wear was a fraction of the composite wear and as a trend, materials which were worn a lot, produced the least antagonist wear, as seen with AF. On the other side, the material that showed the least wear (GS), was the most aggressive against the antagonist. When looking at wear as a system, then the total wear ( $\Sigma$ composite wear + antagonist wear) is of interest Fig. 3). Here the ranking was similar to the one of composite wear. However, UPI Exp 3 due to its very low antagonist wear ended up having the least total wear.

Some selected SEMs are shown in Figs 5-11. The composites mostly revealed the filler structure at high magnification (Figs 4-9), while the antagonists were either smooth or showed various degrees of

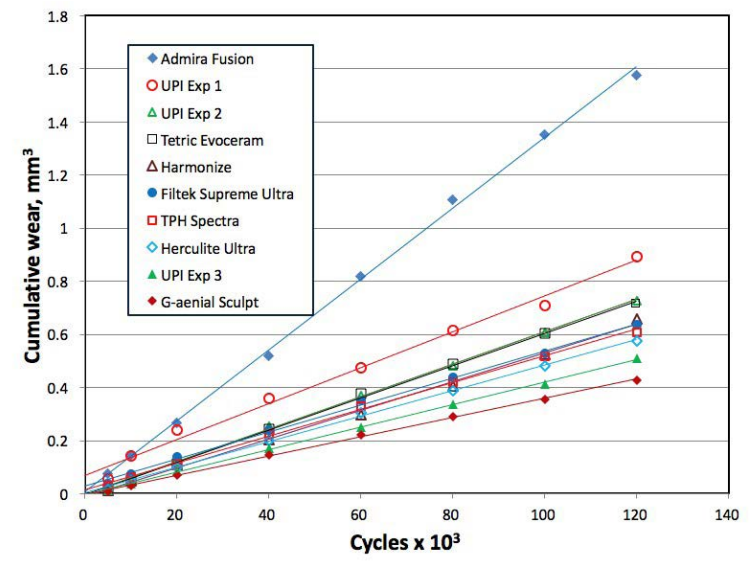

Figure 1. Cumulative wear of ten composites up to 120,000 load cycles. $(p<0.0001)$.

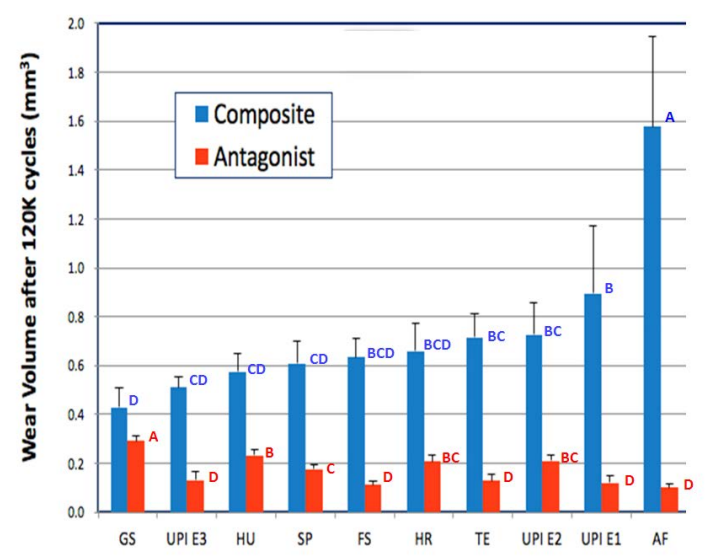

Figure 2. Wear volume of ten composites and the corresponding antagonists after 120,000 load cycles. Blue letters show same statistical group for composites, red letter for antagonists $(p<0.05)$. AF = Admira Fusion, FS $=$ Filtek Supreme, $\mathrm{GS}=\mathrm{G}$-aenial Sculpt, $\mathrm{HR}=$ Harmonize, $\mathrm{HU}=$ Herculite Ultra, TE = Tetric Evoceram, SP = TPH Spectra, UPI Exp 1-3 = Ultradent experimental composites.

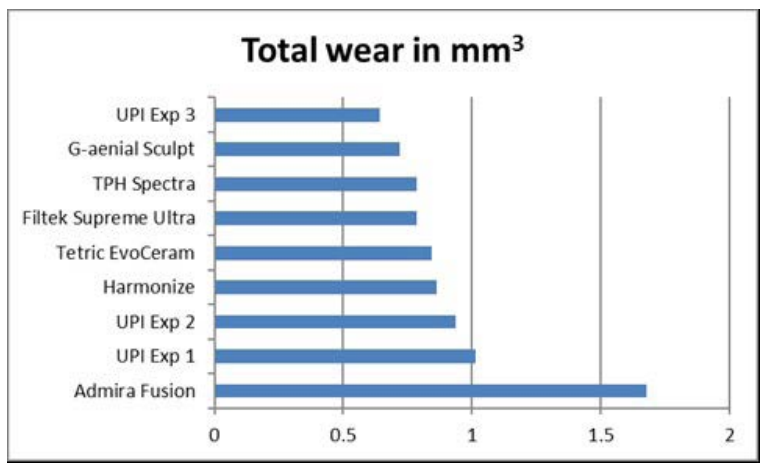

IFigure 3. Total wear ( of composite + antagonist wear) in $\mathrm{mm}^{3}$.

scratches. Furthermore, pores were visible as well (Figs. 10 and 11).

\section{Discussion}

The seven commercial universal composites represent a selection of widely used materials. The three experimental materials were formulations of composites to be placed in the same market segment. All composites were light cured according to manufacturer's recommendations which reflects the condition of their clinical use. As can be seen in Table 2 the radiant exposure was 


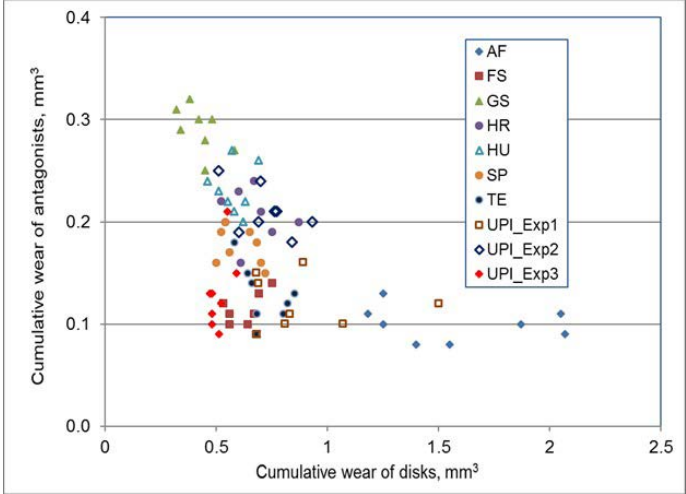

Figure 4. Cumulative wear of composites vs cumulative wear of Antagonists. AF = Admira Fusion, $\mathrm{FS}=$ Filtek Supreme, $\mathrm{GS}=\mathrm{G}$-aenial Sculpt, $\mathrm{HR}=$ Harmonize, $\mathrm{HU}=$ Herculite Ultra, $\mathrm{TE}=$ Tetric Evoceram, $\mathrm{SP}=$ TPH Spectra, UPI Exp 1-3 = Ultradent experimental composites.

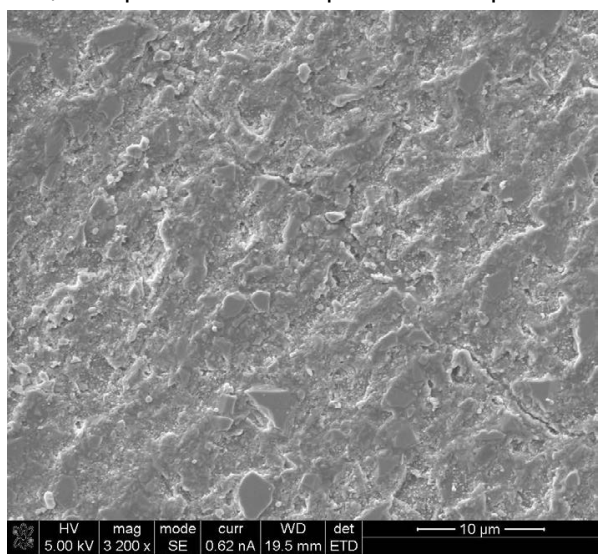

I Figure 5. Worn surface of AF. Note the sharp filler particles and the fracture line. SEM 3200 (AF1 011).

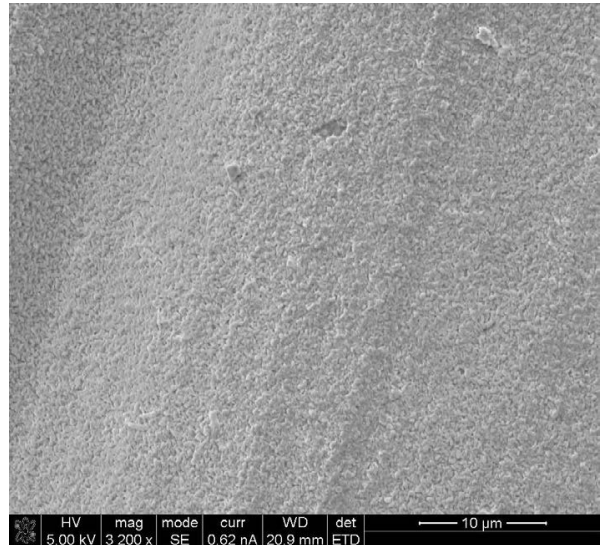

IFigure 6. Worn surface of GS. Note the fine granular surface. SEM 3200x (GS2-016).

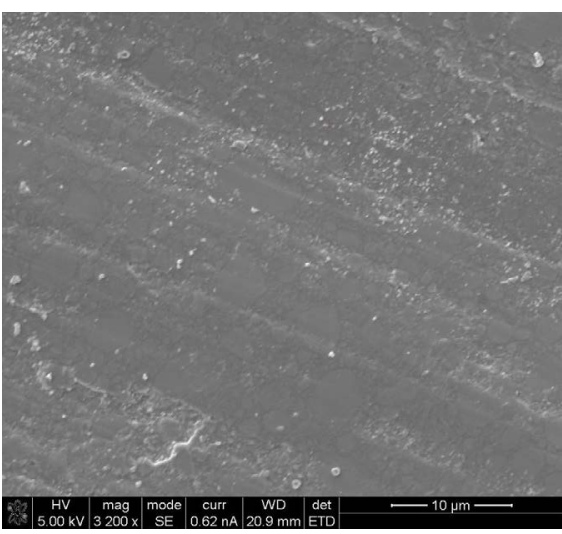

IFigure 7 Worn surface of UPI Exp 1 Note the filler particles that are well integrated SEM 3200x (MO1-014).

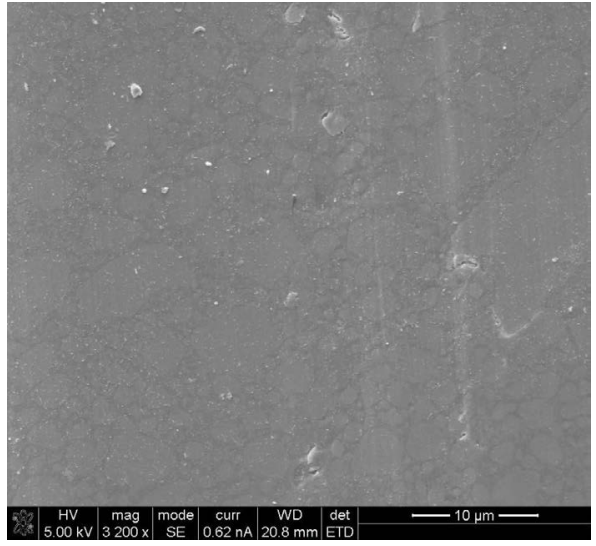

IFigure 8. Worn surface of UPI Exp2. Note the larger particles as compared to the ones in Fig 6 (M006).

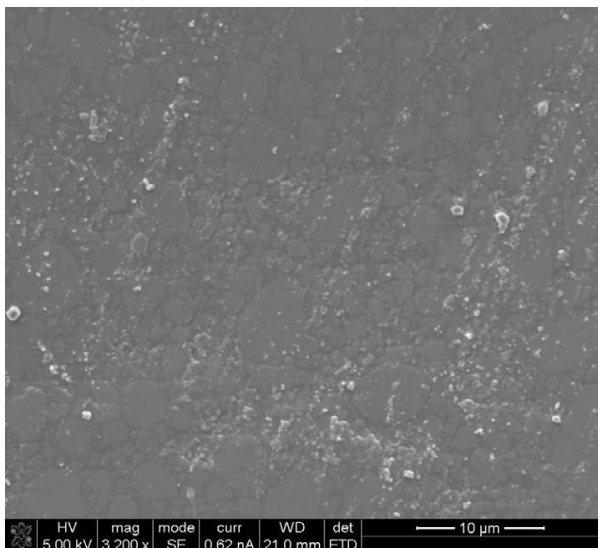

Figure 9. Worn surface of UPI Exp 3. Note the densly packed spherical particles of various sizes. (Mu2-15).

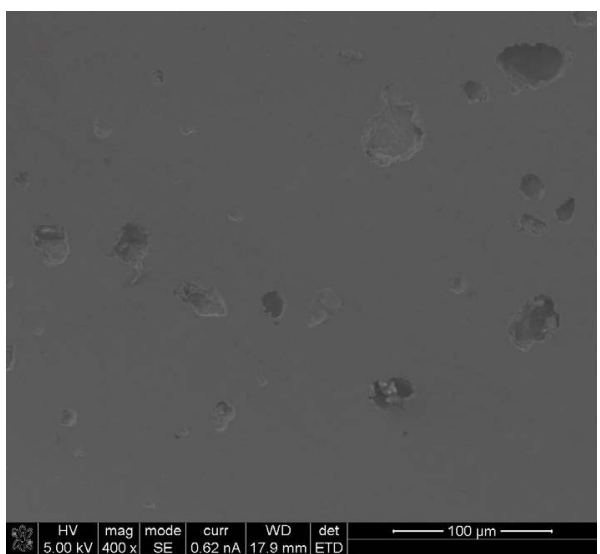

IFigure 10. Antagonist worn by AF. Note the smooth surface and the pores SEM 400x. (Af Ant 004).

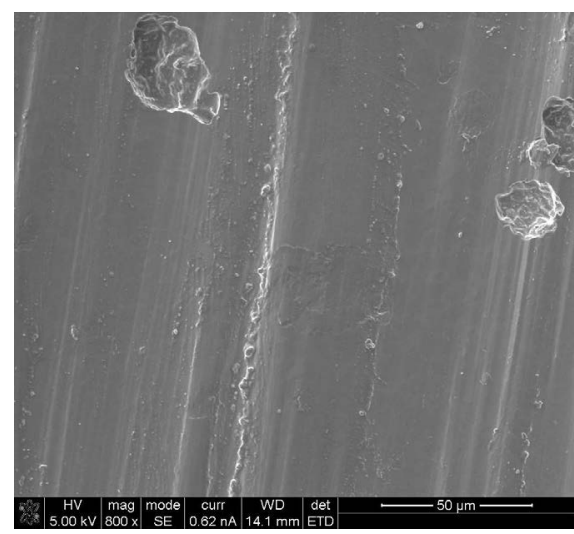

Figure 11. Antagonist surface worn by GS. Note the pores and the scratches. (GS2 Ant 004). 
between 11.7 and $23.4 \mathrm{~J} / \mathrm{cm}^{2}$, which is within the recommendations found in the literature to cure 2 $\mathrm{mm}$ depth of composite $[27,28]$.

Wear is a complex process. Therefore, there is no specific standard for testing wear of dental restorative materials. Especially in vitro, it is difficult to completely mimic the clinical situation. The various in vitro wear simulating machines use different approaches; recently, however, twobody wear machines with a sliding component and preferably computer-controlled forces and movements have been preferred [29]. Since every wear tester uses a different theoretical model [29], different antagonists are used in terms of material, shape and dimensions [30-35]. In the present work, spherical steatite antagonists ( $\varnothing 6 \mathrm{~mm}$ ) were used because of their hardness, reproducibility, the standard shape similar to a molar cusp, and the easy availability. It was deliberately decided not to use enamel as antagonists, due to variability in mechanical properties and shape. Attempts to grind natural cusp tips into a standard shape have revealed additional defects which would contribute to the variability of the expected results. In addition, most Mechatronics chewing simulator users use steatite antagonists, allowing comparisons with other studies. For the operation of the chewing simulator standard parameters as recommended by the manufacturer were used [36]. Therefore, our data are comparable to those of the Ivoclar Vivadent group in Schaan [26]. The Ivoclar protocol uses standardized Empress (leucite ceramics) antagonists that are in the shape of a molar cusp, while in the present experiment spherical steatite antagonists were used, which may explain the slightly different findings.

The wear values obtained with similar composite materials in a previous experiment [37] were approximately twice that of those in the present study using the same chewing simulator. This difference can be explained by the different chewing force [37]. In the present experiment, a load of 49 $\mathrm{N}$ was used, while in the previous experiment the load was $59 \mathrm{~N}$, which seems to be too much since fractures of the same samples had occurred. It is difficult to determine the actual chewing force in vivo under function. Literature data show a large variation $(20-120 \mathrm{~N})$. The decision to use $49 \mathrm{~N}$ was based on a publication by Gibbs et al. [38], where 49 $\mathrm{N}$ were found to be the average chewing force under normal function.

A laser scanner was used to measure wear facets. Heintze et al. [39] have shown that there is no significant difference between a mechanical or optical profilometer and a laser scanner.

For the present study, almost the same method was used as in previous studies [36,37]. The difference was that in the Matias study, the composite samples and the antagonists were directly scanned, while in the present study we chose to use hard plaster replicas. The reason for this was that when we scanned directly facets in polished, flat composite or ceramic surfaces and analyzed them with the Geomagic software, we found distortions in the flat surface at the transition to the facet [40]. In addition,
Table 6. Wear rate in $\times 10^{-6} \mathrm{~mm}^{3} /$ cycle of the tested materials. Same letter $=$ means same statistical group $(p<0.05)$.

\begin{tabular}{lll}
\hline Material & mean \pm SD & $\begin{array}{l}\text { Statistical } \\
\text { group }\end{array}$ \\
\hline Admira Fusion & $13.33 \pm 3.24$ & $\mathrm{~A}$ \\
UPI Exp 1 & $6.77 \pm 1.83$ & $\mathrm{~B}$ \\
UPI Exp 2 & $6.11 \pm 1.15$ & $\mathrm{BC}$ \\
Tetric EvoCeram & $6.09 \pm 0.95$ & $\mathrm{BC}$ \\
Harmonize & $5.40 \pm 1.00$ & $\mathrm{BCD}$ \\
Filtek Supreme Ultra & $5.1 \pm 0.72$ & $\mathrm{BCD}$ \\
TPH Spectra & $5.04 \pm 0.74$ & $\mathrm{CD}$ \\
Herculite Ultra & $5.40 \pm 0.54$ & $\mathrm{CD}$ \\
UPI Exp 3 & $4.26 \pm 0.49$ & $\mathrm{CD}$ \\
G-aenial Sculpt & $3.26 \pm 0.73$ & $\mathrm{D}$ \\
\hline
\end{tabular}

we had two evaluators who outlined the wear facets and measured the volume as an expression of wear based on the LAS 20 scans, which obtained identical data. All in all, this resulted in small standard deviations so that we could differentiate the material wear of the different materials at an early stage.

As in earlier experiments [36,37], the wear behavior was inconsistent in the first 5,000 - 10,000 cycles and had a higher variability. This is a well-known effect called "running in". Therefore, the analysis of the data began at 10,000 cycles. From this point on the wear development was linear with an excellent correlation with the number of cycles $\left(R^{2}>0.98\right.$, see Fig. 2), reflecting the results of Heintze et al. [31,39], Wang et al. [41] and Matias et al [37].

When comparing the wear volume, the tested composites had approximately the same values as Tetric N Ceram Bulkfil, as tested in an earlier study [36], where at 120,000 load cycles, Tetric Ceram Bulkfil showed $0.66 \pm 0.27 \mathrm{~mm}^{3}$ whereas in the present study Tetric Ceram had $0.714 \pm 0.097 \mathrm{~mm}^{3}$ wear. The wear data of the present study are also comparable to those presented by Lendenmann and Wanner [26] for a large group of composites. The slight differences can be explained by the fact that different antagonists were used. In the present work, steatite spheres with a diameter of $6 \mathrm{~mm}$ were used, while the Ivoclar-Vivadent method used Empress antagonists in the shape of a molar cusp [26].

The linear wear development over time confirms the results of previous studies and allows formulating a wear rate for each material (Table 6). Considering that there are 4 statistical groups for the wear and the wear rate of the composites (Table 4 and 6, Fig. 2 ) the null hypothesis is rejected. The same is true for the antagonist wear (Table 5, Fig. 2).

To better understand the wear behavior of the tested composites, a plot of wear of composite vs wear of antagonists was created (Fig. 4). Some trends became visible. On the one side there is GS which forms a quite well-defined cluster with low wear and high antagonist wear. On the other side, namely the other extreme, it seems that AF forms its own group with very low antagonist wear but high composite wear. There we notice as well that for the composite wear there is a wide spread of the data points especially towards high wear. All other 
composites, with the exception of UPI Exp1 that has two "outlieres" they all form a big cluster which explains the overlap with statistical groups. Using the SEM pictures one can speculate about different wear mechanisms. AF (Fig. 5) seems to contain sharp edged filler particles up to $3 \mu \mathrm{m}$, which seem to be dislocating from the surface. In Fig. 4 even a fracture line is visible. These may explain the high wear of the material. Furthermore, AF is the only material under test that contains an ormocere as matrix, which may as well be the reason for the higher wear. On the other side, GS showed itself a scratch pattern, but "grooves" and "mountains" showed the same very small granular structure (Fig. 6). It seems that very small and hard filler particles, which are well retained to the matrix are responsible for the high wear of the antagonists as well as for the low wear of the material itself.

The UPI Exp1 and UPI Exp2 are the "Dentin" and the "Enamel" version of the same material. Regarding wear, they are in the same statistical group, which they share with TE, HR and FS. However, their structure as seen in Figs. 7 and 8 is slightly different. Both have spheroid/spherical fillers which seem to be perfectly integrated into the matrix. However, the size seems to vary slightly. The "dentin" version (UPI Exp 1) contains particles which have sizes below $4 \mu \mathrm{m}$, while the "enamel" version has not only filler particles of about the same dimension, but there are also definitely larger particles (8-10 $\mu \mathrm{m}$ and larger).This makes sense, since the light is scattered at the resin filler interface, which means that with larger filler particle less scattering and thus more translucency may be expected. UPI EXP3 (Fig. 9) seems to be based on a different approach. Most of the particles seem to be spherical, but there is a wide range of sizes. Thus, they may have been produced with spray flame pyrolysis [10] and the manufacturer has attempted to reach a maximum filler load by using different ranges of particle distributions [8]. This may be an explanation for its good wear behavior.

The different scratch patterns seen on the antagonists should correlate to the measured wear. This was only partly conclusive. The antagonists of AF seem polished (Fig. 10) while the antagonists of UPI EXP3 seem almost untouched. On the other side severe scratches could be observed on the antagonists of GS (Fig. 11) and SP. The other materials have more or less similar scratch patterns of median expression. Basically, one could expect that fillers with lower hardness would produce less scratches.

Every known wear testing device has a different approach on how to simulate wear [31]. Therefore, direct comparisons of numeric values, e.g. volumetric or vertical wear are impossible. Thus, only studies done with Willitec/Mechatronik wear testing machines can be used to perform direct comparisons with the present study. However, this is difficult as well, since there are only a few studies available which have tested the same composite materials. Lazaridou et al [33] have tested among others G-aenial Posterior, Tetric Evo Ceram and Filtek Supreme XTE. From these 3 materials only Tetric EvoCeram is the same material as the one tested in the present study. The other two are predecessors with a less developed technology as the comparable ones in the present study. For Tetric EvoCeram they report $0.33 \pm 0.052 \mathrm{~mm}^{3}$, while in the present study the same material showed $0.714 \pm 0.097 \mathrm{~mm}^{3}$ volumetric wear. This is substantially higher. The comparison between Filtek Suprem XTE and Filtec Supreme Ultra is about the same $\left(0.374 \pm 0.05 \mathrm{~mm}^{3}\right.$ vs $0.635 \pm 0.077 \mathrm{~mm}^{3}$ ) with the incertitude about the slight material difference. The discrepancy can be explained with a slight difference in the methods. Lazaridou et al were loading the samples in water at $37^{\circ} \mathrm{C}$, while in the present study the samples were thermocycled, which represents an additional stress. On the other hand, the difference between G-aenial Posterior and GS $\left(0.342 \pm 0.07 \mathrm{~mm}^{3}\right.$ vs $0.427 \pm 0.083$ $\mathrm{mm}^{3}$ ) is only minimal, which leads to the assumption that this material has been significantly improved over the years.

In the present study the wear of TE was determined to be $0.7 \mathrm{~mm}^{3}$. Heintze et al [39] have used almost the same approach as used in this study and measured for Tetric Ceram, approx. $0.6 \mathrm{~mm}^{3}$; Tetric N Ceram's wear was determined with the same method being approximately $0.5 \mathrm{~mm}^{3}$ and the one of Tetric EvoCeram was approximately $0.4 \mathrm{~mm}^{3}$ [42]. These data compare well with the values of D'Arcangelo et al. [30] which reported mean wear values for different direct composites between $0.529 \pm 0.139$ $\mathrm{mm}^{3}$ and $1.425 \pm 0.245 \mathrm{~mm}^{3}$. This is almost the same range as was found in the present study despite the fact that they used a different antagonist $(3 \mathrm{~mm} \varnothing$ zirkonium oxide).

Early composites showed definitely more wear than enamel [18], but during the continuous improvement of composite resins, the materials characteristics, especially the physical and mechanical data got improved much [5] and the wear characteristics improved as well. With this fact, other characteristics have become more important for the clinicians in the selection process for the favorite material to use. Aesthetic considerations (shade, chameleon effect), ease of application (bulk fil, thixotropy, low stickiness) or good short-term outcome (no postoperative pain) got more into the focus in the last years. Never the less wear of the tested composites is still higher than the wear of enamel [36]. Therefore, the wear behavior should, among other parameters, still be part of the evaluation process of resin composites.

\section{Conclusions}

The majority of the tested composites showed a similar wear behavior with slight differences of the measured volumetric wear. Some materials were either positioned on the high side (AF with significantly higher wear) and GS with the lowest wear. If one considers total wear, then UPI EXP 3 showed the most favorable outcome with low wear and the lowest antagonist wear.

Since these results were produced with an in vitro wear simulation, the transposition of the outcome into the clinical situation should be done with much caution. 


\section{Authors contributions}

JFR: idea, experimental design, wrote manuscript. $\mathrm{HH}$ : performed experiment, measured wear. NA: performed experiment, measured wear. CS: did statistical analysis, contributed substantially to discussion.

\section{Conflict of Interest}

All authors declare that they have no conflict of interest.

\section{Aknowledgements}

The work was supported by Ultradent Products INC. South Jordan, UTAH, USA (AGR 3309 UF, 1/15/16) and with exception of UPI Exp 1-3 the used materials were purchased by Ultradent Products Inc as well.

\section{References}

1. Bowen RL. Use of epoxy resins in restorative materials. J Dent Res. 1956;35(3):360-369. [CrossRef] [PubMed] Google Scholar Scopus

2. Bowen RL. Synthesis of a silica-resin filling material: progress report. J Dent Res. 1958;37(1):90. [CrossRef]

3. Bowen RL.Dentalfilling material comprising vinyl silanetreated fused silica and a binder consisting of the reaction product of bisphenol and glycidyl acrylate. US Patent 3066. 1962;112. Google Scholar

4. Ferracane JL. Current trends in dental composites Crit Rev Oral Biol Med. 1995;6(4):302-318. [CrossRef] [PubMed] Google Scholar Scopus

5. Ilie N, Hickel R. Investigations on mechanical behavior of dental composites. Clin Oral Investig. 2009;13(4):427-438. [CrossRef] [PubMed] Google Scholar Scopus

6. Roulet JF. [Plastic restorations in molar region]. [Article in German] Freie Zahnarzt. 1982;26(6):79-90.

7. Lutz F, Setcos JC, Phillips RW, Roulet JF. Dental restorative resins - types and characteristics. Dent Clin North Am 1983;27(4):697-712. [PubMed] Google Scholar Scopus

8. Roulet JF. Degradation of dental polymers. Basel, Switzerland Karger; 1987.

9. Michl P, Rheinberger V, Ott G. [X-ray opaque dental material]. Pat. DE 3502594A1; 1985.

10. Mädler L, Kammler HK, Muelller R, Pratsinis SE. Controlled synthesis of nanostructured particles by flame spray pyrolysis. J Aerosol Sci. 2002;33(2):369-389. [CrossRef] Google Scholar Scopus

11. MädlerL,KrumeichF,BurtscherP,MosznerN.Visiblytransparent \& radiopaque inorganic organic composites from flamemade mixed-oxide fillers. J Nanopart Res. 2006;8(3-4):323-333. [CrossRef] Google Scholar Scopus

12. Craig BD. Fillers and composite material with zirconia and silica nanoparticles. US Pat. No 8722759; 2014. Google Scholar

13. Willems G, Lambrechts $P$, Braem $M$, et al. A classification of dental composites according to their morphological and mechanical characteristics. Dent Mater. 1992;8(5):310-319. [CrossRef] [PubMed] Google Scholar Scopus

14. Bayne SC, Heymann HO, Swift EJ Jr. Update on dental composite restorations. J Am Dent Assoc. 1994;125(6):687-701. [Full text links] [PubMed] Google Scholar

15. Hickel R, Dasch $W$, Janda $R$, et al. New direct restorative materials. FDI Commission Project. Int Dent J. 1998;48(1):3-16. [CrossRef] [PubMed] Google Scholar Scopus

16. Ferracane JL. Resin composite - State of the art. Dent Mater. 2011;27(1):29-38. [CrossRef] [PubMed] Google Scholar Scopus

17. Randolph LD, Palin WM, Leloup G, Leprince JG. Filler characteristics of modern dental resin composites and their influence on physico-mechanical properties. Dent Mater. 2016;32(12):1586-1599. [CrossRef] [PubMed] Google Scholar Scopus

18. Phillips RW, Avery DR, Mehra $\mathrm{R}$, et al. Observations on a resin or Class II restorations: three year report. J Prosthet Dent. 1973;30(6):891-897. [CrossRef] [PubMed] Google Scholar Scopus

19. Lempel $\mathrm{E}$, Tóth Á, Fábián $\mathrm{T}$, et al. Retrospective evaluation of posterior direct composite restorations: 10-year findings. Dent Mater. 2015;31(2):115-122. [CrossRef] [PubMed] Google Scholar Scopus

20. Pallesen $U$ van Dijken JW. A randomized controlled 30 years follow up of three conventional resin composites in Class II restorations. Dent Mater. 2015;31(10):1232-1244. [CrossRef] [PubMed] Google Scholar

21. Da Rosa Rodolpho PA, Donasollo TA, Cenci MS, et al. 22-year clinical evaluation of the performance of two posterior composites with different filler characteristics. Dent Mater. 2011;27(10):955-963. [CrossRef] [PubMed] Google Scholar Scopus

22. Opdam NJ, van d Sade FH, Bronkhorst E, et al. Longevity of posterior composite restorations: a systematic review and meta-analysis. J Dent Res. 2014;93(10):943-949. [Full text links] [Free PMC Article] [PubMed] Google Scholar Scopus

23. Demarco FF, Corrêa MB, Censi MS, et al. Longevity of posterior composite restorations: not only a matter of materials. Dent Mater. 2012;28(1):87-101. [CrossRef] [PubMed] Google Scholar Scopus

24. Hickel R, Manhart J. Longevity of restorations in posterio teeth and reasons for failure. J Adhes Dent. 2001;3(1):45-64. [PubMed] Google Scholar Scopus

25. Manhart J, Chen HY, Hamm G, Hickel R. Review of the clinical survival of direct and indirect restorations in posterior teeth of the permanent dentition. Oper Dent. 2004;29(5):481-508. [PubMed] Google Scholar Scopus

26. Lendenmann U, Wanner M. Tetric EvoCeram. Scientific Documentation. Schaan, Liechtenstein: Ivoclar Vivadent; 2011.

27. Calheiros FC, Kawano $Y$, Stansbury JW, Braga RR Influence of radiant exposure on contraction stress, degree of conversion and mechanical properties of resin composites. Dent Mater. 2006;22(9):799-803. [CrossRef] [PubMed] Google Scholar Scopus

28. Fan PL, Schumacher RM, Azzolin K, et al. Curing-light intensity and depth of cure of resin-based composites tested according to international standards. J $A m$ Dent Assoc. 2002;133(4):429-434; quiz 491-493. [CrossRef] [PubMed] Google Scholar Scopus

29. Ilie N, Hilton TJ, Heintze SD, et al. Academy of Denta Materials guidance - Resin composites: Part I Mechanical properties. Dent Mater. 2017;33(8):880-894. [CrossRef] [PubMed] Google Scholar Scopus

30. D'Arcangelo C, Vanini L, Rondoni GD, et al. Wear properties of a novel resin composite to human enamel and other restorative materials. Oper Dent. 2014;39(6):612-618. [CrossRef] [PubMed] Google Scholar Scopus

31. Heintze SD. How to qualify and validate wear simulation devices and methods. Dent Mater. 2006;22(8):712-734. [CrossRef] [PubMed] Google Scholar Scopus

32. Koottathape $\mathrm{N}$, Takahashi $\mathrm{H}$, Iwasaki $\mathrm{N}$, et al Quantitative wear and wear damage analysis of composite resin in vitro. J Mech Behav Biomed Mater. 2014;29:508-516. [CrossRef] [PubMed] Google Scholar Scopus

33. Lazaridou $D$, Belli $R$, Petschelt $A$, Lohbauer $U$. Are resin composites suitable replacements for amalgam? A study of two-body wear. Clin Oral Investig. 2015;19(6):1485-1492. [CrossRef] [PubMed] Google Scholar

34. Leinfelder KF, Beaudreau RW, Mazer RB. An in vitro device for predicting clinical wear. Quintessence Int. 1989;20(10):755-761. [PubMed] Google Scholar Scopus

35. Mehl C, Scheibner S, Ludwig K, Kern M. Wear of composite resin veneering materials and enamel in a chewing simulator. Dent Mater. 2007;23(11):1382-1389. [CrossRef] [PubMed] Google Scholar Scopus

36. Roulet JF, Abdulhameed N, Shen C. In vitro wear of three bulkfill composites and enamel. Stoma Edu J. 2017;4(4):248-253. [CrossRef]

37. Matias $\mathrm{P}$, Roulet JF, Abdulhameed $\mathrm{N}$, Shen $\mathrm{C}$. In vitro wear of 4 different universal composites. Stoma Edu J. 2016;3(1-2):39-46.

38. Gibbs $\mathrm{CH}$, Mahan $\mathrm{PE}$, Lundeen $\mathrm{HC}$, et al. Occlusal force during chewing and swallowing as measured by sound transmission. J Prosthet Dent. 1981;46(4):443-449. [CrossRef] [PubMed] Google Scholar Scopus

39. Heintze SD, Cavalleri A, Forjanic $M$, et al. A comparison of three different methods for the quantification of the in vitro wear of dental materials. Dent Mater. 2006;22(11):1051-1062. [CrossRef] [PubMed] Google Scholar Scopus

40. Esquivel-Upshaw J, Hsu S, Abdulhameed N, et al. Volume loss 
and depth analysis using stylos profiler and laser scanner. Abstract \# 0668. IADR/AADR/CADR; March 22-25, 2017; San Francisco, CA, USA.

41. Wang $R$, Bao $S$, Liu $F$, et al. Wear behavior of light-cured resin composites with bimodal silica nanostructures as fillers. Mater Sci Eng C Mater Biol Appl. 2013;33(8):4759-4766. [CrossRef] [PubMed] Google Scholar Scopus

42. Fischer K, Lendenmann U. Tetric N-Collection. Scientific Documentation. Schaan, Liechtenstein: Ivoclar Vivadent: 2010.

\section{Jean-François ROULET}

DDS, DMD, PhD, Dr hc, Prof hc, Professor

Department of Restorative Dental Sciences, Center for Dental Biomaterials

College of Dentistry, University of Florida

Gainesville, FL, USA

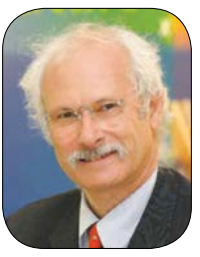

Jean-François Roulet, DDS, Dr med dent, $\mathrm{PhD}$, is the former chair and current professor of the Department of Restorative Dental Sciences at the University of Florida. Professor Roulet is author/coauthor of more than 210 papers, edited/contributed to 27 textbooks and mentored more than 150 theses. He is a renowned international lecturer with over 920 appearances to date. Dr. Roulet is a member of many professional organizations, has won numerous awards, and holds four patents. He is editor of Stomatology Edu Journal. His areas of interest include minimally invasive dentistry, dental materials (ie, composites and ceramics), adhesive dentistry, esthetic dentistry, and application concepts in preventive dentistry.

\section{An universal composite is:}

Da. A composite with a universal, standard filler;

b. A composite which allows restorations with all cavity classes;

ac. A composite for high esthetic indications;

ad. A composite with high wear resistance.

\section{The materials were stressed as follows:}

a. Mechanical stress static $100 \mathrm{~N}$ for $50 \mathrm{~h}$;

b. Thermocycling for 1333 cycles from $5^{\circ} \mathrm{C}$ to $55^{\circ} \mathrm{C}$;

ac. 120,000 mechanical cycles with $50 \mathrm{~N}$ maximum force and lateral movement under load;

$\square d$. 120,000 mechanical cycles with $50 \mathrm{~N}$ maximum force and lateral movement under load and thermocycling for 1333 cycles from $5^{\circ} \mathrm{C}$ to $55^{\circ} \mathrm{C}$.

\section{Composite wear results:}

$\square$ a. There were significant differences between the materials with G-aenial Sculpt having the least wear and UPI Exp1 and 2, Tetric EvoCeram, Filtec Supreme Ultra, and Admira Fusion being in the group with the highest wear;

ab. There were no statistical differences in the wear rate of the different composites tested;

$\square c$. The measured wear varied between $0.05 \mathrm{~mm}^{3}$ and $0.4 \mathrm{~mm}^{3}$;

$\square$ d. The standard deviation was more than $50 \%$.

\section{The antagonist wear was:}

$\square$ a. Larger than the composite wear;

b. Equal to the composite wear;

ac. Strongly correlated to the composite wear;

$\square$ d. Much smaller than the composite wear with the exception of G-aenial Sculpt. 


\title{
SUSCEPTIBILITY OF RBC TO VARIOUSCLINICAL RELEVANT CURING CONDITIONS
}

\author{
Nicoleta Ilie ${ }^{1 b^{*}}{ }^{(10)}$ Eva-Maria Plenk ${ }^{2 b}$ \\ 'Department of Operative Dentistry and Periodontology, University Hospital, Ludwig-Maximilians University Munich, Goethestr. 70, D-80336 \\ Munich, Germany \\ ${ }^{2}$ Privat clinic, Bahnhofsweg 6, D-82008 Unterhaching, Germany \\ ¿Dipl Eng' PhD' Professor \\ 'DMD' private practitioner
}

\begin{abstract}
DOI: https://doi.org/10.25241/stomaeduj.2019.6(2).art.2

Introduction: The study aims to quantify the impact of various curing conditions on the micro-mechanical properties of methacrylate and silorane resin-based composites (RBCs) in order to determine the threshold for sufficient polymerization.

Methodology: The analyzed RBCs have either a similar filler volume amount (55\%) but a different monomer matrix composition (methacrylate or silorane) or a similar monomer matrix but a different filler volume amount (63.3\% vs. 55\%). Twenty-four different curing conditions were simulated. A blue-violet LED curing unit was applied in different curing modes, exposure times and distances (0-mm and 7-mm). Measurements (Vickers hardness, $\mathrm{HV}$, and Indentation modulus, E) were performed after $24 \mathrm{~h}$ of storage in distilled water at $37^{\circ} \mathrm{C}$ at the top and bottom of $2-\mathrm{mm}$ thick specimens ( 360 specimens in total).

One and multiple-way ANOVA and Tukey HSD post hoc-test $(a=0.05)$ was used. A multivariate analysis (general linear model) assessed the effect strength of the parameters exposure time, location of measurement (top-bottom), incident irradiance, radiant exposure (ranging from 1.0 to $47.0 \mathrm{~J} / \mathrm{cm}^{2}$ ) and exposure distance on $\mathrm{HV}$ and $\mathrm{E}$.

Results: In all materials, the highest effect on $\mathrm{HV}$ and $\mathrm{E}$ was exerted by the exposure time and location of measurement. Susceptibility to various curing conditions is material dependent, while less filled methacrylate-based as well as the silorane micro-hybrid are more robust to these variations. Fast polymerization (3s) with high irradiance is not recommended.

Conclusions: The best micro-mechanical properties at the top and bottom of 2-mm thick specimens are generated with a curing time of at least 20 s at moderate irradiance.

Keywords: Resin-based composites; Hardness; Modulus of elasticity; Light curing unit; Radiant exposure.
\end{abstract}

\section{Introduction}

Incremental layering technique is accepted as a golden standard for the placement of regular resin-based composite (RBC) restorations [1]. The increments are limited to a thickness of $2 \mathrm{~mm}$ to allow for adequate polymerization in a clinically reasonable time. In spite of decades of expert knowledge in light curing, the amount of light needed to adequately cure a regular 2-mm thick RBC increment is still debatable. This is justified in the observation of a material-dependent susceptibility to variation in radiant emittance (= radiant flux emitted by a surface per unit area) under simulated clinical conditions [2,3]. In addition, calculations based on the total energy delivered to guide irradiation protocols were shown to be invalid and not to recognize product behavior [2]. Nonetheless, there is a high demand to set a general limit for adequate curing, in order to support clinicians choosing a proper curing strategy. Literature data, based on the direct evaluation of the curing quality in various modern $\mathrm{RBCs}$, indicate radiant exposure values in the range of $(21-24) \mathrm{J} / \mathrm{cm}^{2}$ $[4,5]$ as sufficient for adequate polymerization. These values are often not met in a clinical situation, due to a number of factors that are related either to the technique sensitivity of the polymerization process $[6,7]$ or to erroneously chosen curing strategies. Particularly in posterior cavities that are difficult to access, where the light curing unit (LCU) may not be placed perpendicularly to the restoration, the exposure distance may vary from an ideal position, the exposure time may be chosen too short or the LCU be contaminated with resins. The total amount of light received by the material may be further reduced by using curing strategies involving a pre-curing of the lowest increment when incrementally reconstructing a deep cavity, based on the wrong estimate [8] that the lowest increment will receive enough light when curing the upper increments or when curing through the tooth structure [9]. 
Table 1. Resin composite brand, type, chemical composition of matrix and filler as well as filler content by weight (wt.) and volume (vol.) \%.

\begin{tabular}{|c|c|c|c|c|c|c|}
\hline RBCs & RBC-Type & Batch & Shade & Resin Matrix & Filler & $\begin{array}{c}\text { Filler } \\
\text { wt\%/vol\% }\end{array}$ \\
\hline $\begin{array}{c}\text { Filtek }^{\mathrm{TM}} \text { Supremee } \\
\text { XTE }\end{array}$ & Nano & N229448 & $\begin{array}{c}\text { A3 } \\
\text { Dentin }\end{array}$ & $\begin{array}{c}\text { Bis-GMA, Bis-EMA, UDMA, TEGDMA, } \\
\text { PEGDMA }\end{array}$ & $\begin{array}{c}\mathrm{ZrO}_{2^{\prime}} \\
\mathrm{SiO}_{2^{\prime}} \\
\mathrm{ZrO}_{2} / \mathrm{SiO}_{2}\end{array}$ & $78.5 / 63.3$ \\
\hline $\begin{array}{l}\text { Filtek }^{\mathrm{TM}} \text { Supremee } \\
\text { XTE flow }\end{array}$ & $\begin{array}{l}\text { flowable } \\
\text { Nano }\end{array}$ & N236527 & A3 & $\begin{array}{c}\text { Bis-GMA, Bis-EMA, TEGDMA, } \\
\text { PEGDMA }\end{array}$ & $\begin{array}{c}\mathrm{ZrO}_{2^{\prime}} \\
\mathrm{SiO}_{2^{\prime}} \\
\mathrm{ZrO}_{2} / \mathrm{SiO}_{2}\end{array}$ & $65 / 55$ \\
\hline Filtek $^{\mathrm{TM}}$ Silorane & Microhybrid & N225426 & A3 & $\begin{array}{c}\text { 3,4-Epoxycyclo- } \\
\text { hexylethylcyclopolymethylsiloxane } \\
\text { Bis-3,4-epoxycyclo- } \\
\text { hexylethylphenyl-methylsilane }\end{array}$ & $\mathrm{SiO}_{2}, \mathrm{YF}_{3}$ & $76 / 55$ \\
\hline
\end{tabular}

Abbreviations: Bis-GMA, bisphenol-A diglycidyl ether dimethacrylate; Bis-EMA, ethoxylated Bisphenol-A-dimethacrylate; UDMA, Urethane dimethacrylate; TEGDMA, Triethyleneglycol dimethacrylate, PEGDMA, polyethylene glycol dimethacrylate. Data are provided by manufacturer $(3 \mathrm{M})$ in the instruction leaflet.

A very low transmitted irradiance was identified through 2-mm thick layers of various RBCs as well as through the tooth structure $[8,9]$. In a nano RBC (Filtek Supreme XTE), the transmitted light through 2 -mm thick increments amounted only $1.4 \%$ to $2.1 \%$ of the incident light and was merely slightly higher $(4.2 \%$ to $7.4 \%)$ in the more translucent, low viscous version of the same material (flowable nano RBC Filtek Supreme XTE flow) [8].

The same applies for RBCs with a non-methacrylate polymer matrix, such as the micro-hybrid Filtek Silorane (4.2\% to $6.5 \%$ ) [8]. Note that a variety of clinical relevant irradiances (= radiant flux or power received by a surface per unit area; $656.4 \mathrm{~mW} / \mathrm{cm}^{2}$ to $\left.3361.5 \mathrm{~mW} / \mathrm{cm}^{2}\right)$, radiant exposures (46.96 to $0.99 \mathrm{~J} /$ $\mathrm{cm}^{2}$ ) and exposure distances ( 0 to $7 \mathrm{~mm}$ ) were considered in these calculations.

The indicated \% limits for the light transmittance through the various materials are related to the irradiance while the lower the irradiance, the higher the $\%$ transmitted light in the above indicated interval [8]. Based on these calculations, it was assumed that the low light transmittance will be directly reflected in the mechanical properties of the RBCs [8].

When transferring the transmitted irradiance to the more clinically relevant term of radiant exposure, the transmitted light at the bottom of $2-\mathrm{mm}$ thick increments is quantified as to not exceed $4 \mathrm{~J} / \mathrm{cm}^{2}$ at an ideal exposure distance. This involved the application of the LCU in close contact and perpendicularly to the material. The transmitted light is lowered to $<2 \mathrm{~J} / \mathrm{cm}^{2}$ when the exposure distance is elevated at $7 \mathrm{~mm}$ [8].

The values shown above are far below the radiant exposure values indicated in the literature for adequate polymerization (21-24) $\mathrm{J} / \mathrm{cm}^{2}[4,5]$. An initially improper cured lower increment will consequently receive low light during curing the upper ones, which is insufficient to compensate the initial deficits [8]. The aim of this study was to evaluate the effect of simulating clinically relevant curing conditions on the micro-mechanical properties of RBCs with various fillers content and similar chemical composition of the organic matrix (regular vs. flowable methacrylate-based RBCs), as well as similar volume filler content but different chemical composition of the organic matrix (methacrylate vs. silorane monomers). Therefore, 24 different radiant exposures were simulated by varying the irradiance $\left(656.4 \mathrm{~mW} / \mathrm{cm}^{2}\right.$ to $\left.3361.5 \mathrm{~mW} / \mathrm{cm}^{2}\right)$, the radiant exposure $(0.99$ and $47.0 \mathrm{~J} / \mathrm{cm}^{2}$ ) and the exposure distance (0 to $7 \mathrm{~mm}$ ) [8]. Moreover, the study aims to determine the bandwidth for adequate curing in response to the application of light.

The tested null hypothesis were: i) the impact of the curing conditions would be similar in all materials; ii) there would be no difference within one material among the assessed curing conditions; iii) there would be no difference in the mechanical properties among the analysed materials.

\section{Material and Methods}

The micro-mechanical properties of three regular RBCs (Table 1) were analyzed under different curing conditions at a specimen thickness of $2 \mathrm{~mm}$. The violet-blue LED LCU VALO (Ultradent, South Jordan, USA, serial number VO 7710) was used in three different exposure modes (Standard, High Power and Plasma Emulation), at various exposure times $(5 s, 10 s, 15 s, 20 s$ and $40 s$ ( $=2 \times 20 s$ with no delay in between exposures) the Standard mode; $1 \mathrm{~s}, 2 \mathrm{~s}, 3 \mathrm{~s}, 4 \mathrm{~s}$ and $12 \mathrm{~s}$ ( $=3 \times 4 \mathrm{~s}$ with no delay in-between exposures) in the High Power mode and $3 \mathrm{~s}$ and $6 \mathrm{~s}(=2 \times 3 \mathrm{~s}$ with no delay in-between exposures) in the Plasma Emulation mode) and exposure distances ( $0 \mathrm{~mm}$ and 7 $\mathrm{mm})$. This resulted in 24 different curing conditions, that have been quantified previously [8]. 


\subsection{Micro-mechanical properties}

The micro-mechanical properties (Vickers Hardness HV and Indentation modulus, E) were assessed on cylindrical specimens (diameter $6 \mathrm{~mm}$, thickness 2 $\mathrm{mm}, \mathrm{n}=5$ ) according to DIN 50359-1:1997-10 [10] For the specimen preparation, a white Teflon mould was used. Immediately after curing, the specimens were removed from the mould and stored in distilled water for 24 hours at $37^{\circ} \mathrm{C}$. Thereafter, the specimens were ground and polished under water with diamond abrasive paper (mean grain sizes: $20 \mu \mathrm{m}$, $13 \mu \mathrm{m}, 6 \mu \mathrm{m}$ ) in a grinding system (EXAKT 400CS, Exakt, Norderstedt, Germany) and transfered to an automatic universal testing device (Fischerscope H100C, Fischer, Sindelfingen, Germany). Measurements ( $n=6$ per specimen and side) were performed at the top and bottom of each specimen. The test procedure was carried out force-controlled, where the test load increased (within 20s) and decreased (within 20s) with constant speed between $0.4 \mathrm{mN}$ and $500 \mathrm{mN}$. The load and penetration depth of the indenter (Vickers pyramid: diamond right pyramid with a square base and an angle of $a=136^{\circ}$ between the opposite faces at the vertex) were continuously measured during the load-unload hysteresis. Universal hardness is defined as the test force divided by the apparent area of indentation under the applied test force.

From a multiplicity of measurements stored in a database supplied by the manufacturer, a conversion factor (0.0945) between Universal hardness and HV was calculated by the manufacturer and entered into the software, so that the measurement results were indicated in the more familiar HV units. E was calculated from the slope of the tangent adapted at the beginning (at maximum force) of the non-linear indentation depth curve upon unloading.

\subsection{Statistical Analysis}

A Shapiro-Wilk test verified the normal distribution of the data. The results were compared using one and multiple-way ANOVA and Tukey HSD post hoc-test $(a=0.05)$. A multivariate analysis (general linear model) assessed the effect of the parameters exposure time, incident irradiance, incident radiant exposure (varying among 0.99 and $47.0 \mathrm{~J} / \mathrm{cm}^{2}[8]$ ), exposure distance $(0 \mathrm{~mm}$ and $7 \mathrm{~mm})$ and measuring position (top-bottom) on $\mathrm{HV}$ and $\mathrm{E}$.

The partial eta-squared statistical data report the practical significance of each term, based on the ratio of the variation accounted for by the effect. Larger values of partial eta-squared indicate a greater amount of variation accounted for by the model effect, to a maximum of 1. Correlation analyses (Pearson correlation) between $\mathrm{HV}$ and $\mathrm{E}$ were performed within each RBC. In all statistical tests, p-values < 0.05 were considered statistically significant when using SPSS Inc. (Version 24.0, Chicago, IL, USA).

\section{Results}

The exposure time $\left(p<0.05, \eta P^{2}=0.899\right.$ for $E$ and 0.872 for HV) and the location of the measurement (top-bottom; $\mathrm{p}<0.05, \eta \mathrm{P}^{2}=0.849$ for $\mathrm{E}$ and 0.867 for $\mathrm{HV}$ ) strongly influenced the micro-mechanical properties measured in the Filtek Supreme XTE flow spec- imens. With a lower, but significant influence, there followed the factor incident irradiance $\left(p<0.05, n P^{2}\right.$ $=0.399$ for $E$ and 0.251 for HV), while the impact of exposure distance was very low $\left(\mathrm{p}<0.05, \eta \mathrm{P}^{2}=0.038\right.$ for $\mathrm{E}$ and 0.030 for $\mathrm{HV}$ ). The impact of the incident radiant exposure was significant as well $\left(p<0.05, n_{p}^{2}\right.$ $=0.607$ for $\mathrm{E}$ and 0.498 for HV), but lower compared to the individual effect of exposure time.

The impact of the above-mentioned factors was even stronger in the higher filled methacrylate-based nano RBC Filtek Supreme XTE. It follows the sequence: exposure time $\left(\mathrm{p}<0.05, \eta \mathrm{P}^{2}=0.972\right.$ for $\mathrm{E}$ and 0.973 for HV), location of measurement (top-bottom) $\left(\mathrm{p}<0.05, n \mathrm{P}^{2}=0.993\right.$ for $\mathrm{E}$ and 0.996 for HV), irradiance $\left(p<0.05, \eta P^{2}=0.126\right.$ for $E$ and 0.128 for $\left.H V\right)$ and exposure distance $\left(p<0.05, \eta P^{2}=0.037\right.$ for $E$ and 0.031 for HV). The impact of the incident radiant exposure was significant as well $\left(p<0.05, \eta_{p}{ }^{2}=0.248\right.$ for E and 0.182 for $\mathrm{HV}$ ).

In Filtek Silorane, the impact of the above-mentioned factors follow the same sequence as above: exposure time $\left(p<0.05, \eta P^{2}=0.932\right.$ for $E$ and 0.903 for HV), location of measurement (top-bottom) $\left(p<0.05, \eta P^{2}=0.903\right.$ for $E$ and 0.932 for HV), incident irradiance $\left(p<0.05, \eta P^{2}=0.760\right.$ for $E$ and 0.637 for $H V)$ and exposure distance $\left(p<0.05, n P^{2}=0.033\right.$ for $E$ and 0.041 for HV). The impact of the incident radiant exposure was significant as well $\left(p<0.05, \eta_{p}{ }^{2}=0.476\right.$ for $\mathrm{E}$ and 0.401 for HV).

Considering all curing conditions and both specimen sides (both top and bottom), the micro-mechanical parameters, HV and E, were lower in Filtek Supreme Flow $\left(p<0.05 ; E=8.09 \mathrm{GPa}, \mathrm{HV}=54.34 \mathrm{~N} / \mathrm{mm}^{2}\right)$, while Filtek Silorane and Filtek Supreme showed statistically similar values $(p=0.138$ for $E(11.18 \mathrm{GPa}$ and $10.47 \mathrm{GPa})$ and 0.283 for HV $\left(75.34 \mathrm{~N} / \mathrm{mm}^{2}\right.$ and 79.95 $\mathrm{N} / \mathrm{mm}^{2}$ ). Considering the specimen surfaces individually, the material sequence for the top surface was, in statistically significant decreasing order of the measured micro-mechanical properties (Filtek Supreme $>$ Filtek Silorane $>$ Filtek Supreme Flow, with $\mathrm{E}=15.11 \mathrm{GPa}$; $13.22 \mathrm{GPa}$; $9.19 \mathrm{GPa}$; and $\mathrm{HV}=124.03$ $\mathrm{N} / \mathrm{mm}^{2} ; 93.71 \mathrm{~N} / \mathrm{mm}^{2} ; 64.59 \mathrm{~N} / \mathrm{mm}^{2}$ ). For the bottom surface, significant higher values were identified in Filtek Silorane specimens $(p<0.05)$, while both methacrylate RBCs performed statistically similarly $(p=$ 0.078 for $E$ and 0.065 for HV). The values measured at the bottom of the specimens in the sequence Filtek Silorane, Filtek Supreme Flow and Filtek Supreme were $\mathrm{E}=9.15 \mathrm{GPa}$; $.00 \mathrm{GPa}$ and $5.83 \mathrm{GPa} ; \mathrm{HV}=56.98$ $\mathrm{N} / \mathrm{mm}^{2} ; 44.08 \mathrm{~N} / \mathrm{mm}^{2} ; 35.87 \mathrm{~N} / \mathrm{mm}^{2}$ ). The individual values for all materials and curing conditions are summarized in Table 2 and illustrated in Fig 1.

An excellent correlation was calculated between HV and $E$ within each material (Pearson correlation coefficient $=0.985$ for Filtek Supreme XTE, 0.977 in Filtek Silorane and 0.973 in Filtek Supreme XTE Flow).

\section{Discussion}

Although constantly improvement in the last decades, the demand for shortening the exposure time for curing dental RBCs, to allow for faster and more economical clinical work, is still valid nowadays. For this purpose manufacturers do not stray from the development of LCUs with continuously 

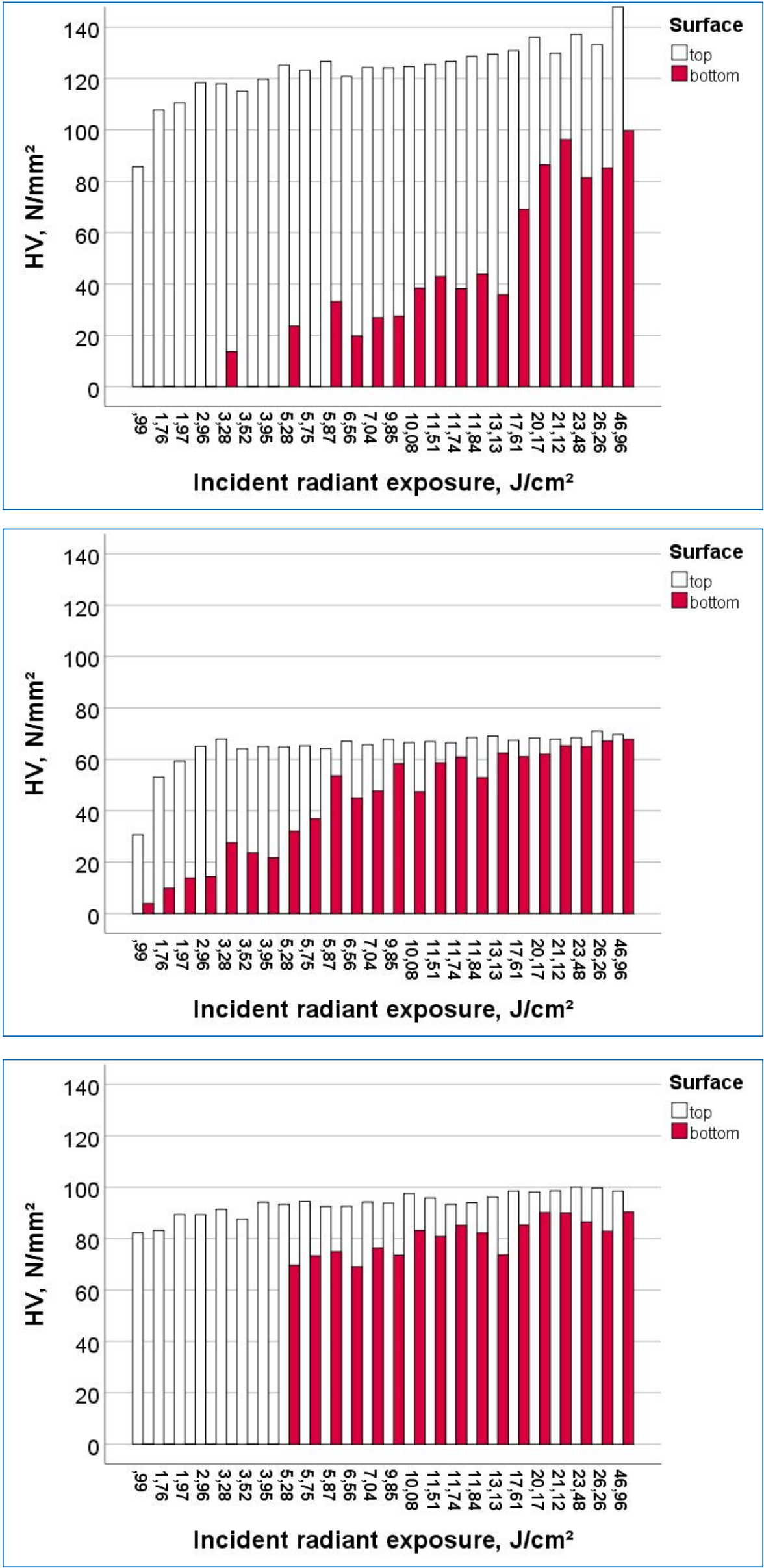

Figure 1. Variation in Vickers Hardness as a function of radiant exposure measured on top and bottom of 2-mm thick specimens made out by the RBC: a) Filtek Supreme XTE; b) Filtek Supreme XTE flow; c) Filtek Silorane; corresponding irradiance, exposure time and distance are presented in Table 2. 
higher radiant emittance. This trend was motivated in the concept of "exposure reciprocity" that is based on the opinion that a RBC needs a certain amount of energy to be adequately cured, while the way in which photons are supplied is supposed to be of minor importance. The term radiant exposure $\left(\mathrm{J} / \mathrm{cm}^{2}\right)$ characterizes the amount of energy supplied by the LCU and is calculated as the product of the radiant emittance $\left(\mathrm{mW} / \mathrm{cm}^{2}\right)$ and exposure time (s). The "exposure reciprocity" concept assumes a similar effect when exposing the RBC to a given radiant exposure, irrespective if the radiant emittance is enhanced to the detriment of the exposure time or vice versa.

This simple construct sounds useful in a clinical situation but it is not universally valid [2]. Musanje et al. [2] identified no lower limit of radiant emittance for an effective polymerization, up to $25 \mathrm{~mW} / \mathrm{cm}^{2}$, but the very long exposure time needed for appropriate curing is no longer relevant for practical use. Numerous studies in recent years have clearly shown that efficient polymerization, especially in depth, is achieved with LCUs of a radiant emittance about $1200 \mathrm{~mW} / \mathrm{cm}^{2}$ and exposure times of at least $20 \mathrm{~s}$ [11]. The radiant exposure levels required for a RBC to be adequately polymerized depend to a large extent on the composition of the RBC [2] and consequently each product must be individually analyzed. The present study attaches particular attention to the effect of the different composition of the organic matrix (silorane vs. methacrylate) at a comparable filler volume amount (55\%).

With the limitation of using commercially available materials with a small difference in their organic matrix (Table 1), the study also analyzes the effect of the filler volume amount at a given composition of the organic matrix. Confirming the data of Musanje et al. $[2,3]$, the analyzed RBCs reacted differently to the variation in radiant exposure. The analyzed flowable RBC (Filtek Supreme XTE flow) showed only minor differences in micro-mechanical properties at a sharp variation of radiant exposure levels, while the higher viscous RBCs (Filtek Supreme XTE and Filtek Silorane) reacted with a higher variation in the measured properties.

The present study also identified that the exposure time and the irradiance itself, and not only their connection as radiant exposure (time $\mathrm{x}$ irradiance), has an influence on the polymerization of the analyzed RBC, thus confirming again previous studies [2,3]. Moreover, the study identified that in all analyzed materials, it was the exposure time showing the highest impact higher partial eta-squared values) on the measured properties, while irradiance played a minor role. In general, the best results were identified in all RBCs at the longest exposure time (40 s) and lowest LCU's radiant emittance $\left(1174 \mathrm{~mW} / \mathrm{cm}^{2}\right)$. Note, however, that the lowest irradiance used in the present study has a comparatively high value and involves a modern, well-functioning LCU.

The highest radiant emittance employed in the present study was delivered by the program "plasma", with a value of $3361.5 \mathrm{~mW} / \mathrm{cm}^{2}$. A 3s curing in this mode, based on the data of the present study must be considered as insufficient for all analyzed materials and should be avoided clinically. When doubling the exposure time (6-s) in the same curing mode, the properties improved, but to a different extent. The silorane-based material showed properties that were statistically similar to a 20 s or 40 s exposure in the standard mode, and thus similar to the highest achievable properties in this material.

For the methacrylate-based RBCs, the 6-s exposure might be considered as sufficient only for the top surface. At the bottom surface, the recorded values were comparable to a 20-s exposure in the standard mode but significant lower as a 40-s exposure in the same mode. The differentiation among materials accentuates even more when the clinically relevant exposure distance of $7 \mathrm{~mm}$ is additionally considered. The silorane-based material still performed well at both top and bottom sides, the flowable methacrylate-based RBC reached comparable values with a 20-s polymerization in the standard mode, but the values measured at the bottom of the regular methacrylate-based material are very low, indicating insufficient polymerization.

Under these conditions, a fast, 6-s polymerization at the highest analyzed radiant emittance can be unrestrictedly recommended only for the siloranebased RBC and unconditionally banned for the analyzed regular methacrylate-based RBCs. The results confirm the failure recorded earlier with the $\mathrm{P}\left({ }_{\text {plasma }}\right)$ $A\left({ }_{\text {arc }}\right) C\left(_{\text {curing }}\right)$-LCUs, which were advocated for a rapid, 3 -second curing, as being equivalent to that of a 40 or 60-s s exposure from a QTH (Quartz Tungsten Halogen) light [12].

Numerous studies attested insufficient polymerization $[12,13]$, emphasizing the need for multiple 3 -s exposures to achieve a clinically adequate performance $[12,14]$. Enhancing LCU's radiant emittance alone is thus insufficient in curing currently available RBCs. Modern attempts conjunct a fast curing (3-s) at high radiant emittance $\left(>3000 \mathrm{~mW} / \mathrm{cm}^{2}\right)$ with altering the polymerization mechanism of methacrylate-based RBCs. The latest one involves a reversible addition-fragmentation chain transfer (RAFT) polymerization and has been so far incorporated in two commercial available bulk-fill RBCs $[15,16]$.

The proof for the clinical success of a 3-s curing of materials with a RAFT polymerization is missing for the moment. This is not least due to the recent launch (2019) of the products. Note, however, that curing with high radiant emittance increases the risk to over-heat the pulp or to injure the soft tissues. Besides, curing fast at high irradiances will leave no room to relieve internal stresses accumulated during shrinkage [17].

To simulate clinically relevant curing conditions, the LCU was placed either directly on or at a distance of $7 \mathrm{~mm}$ from the specimen's surface. This distance was chosen based on the observation of Price at al.[18] that the distance between the LCU and the cavity bottom is $6.3 \mathrm{~mm}$ (standard deviation 0.7) in a standard class II cavity.

Note that the irradiance in the simulated curing conditions of the present study amounted at an exposure distance of $7 \mathrm{~mm}$ only $43 \%$ to $49 \%$ of the values at a direct contact to the surface [8]. It should also be noted that the curing times recommended by the manufacturer are mainly based on the assumption 
Table 2. Vickers hardness [N/mm²] and Indentation modulus (GPa) measured on specimen's top and bottom at $0 \mathrm{~mm}$ and $7 \mathrm{~mm}$ exposure distance. Superscripts indicate statistically homogeneous subgroups within a column (Tukey's HSD test, $a=0.05)$.

\section{a) Filtek ${ }^{\mathrm{TM}}$ Supreme XTE}

Vickers hardness $\mathrm{HV}\left[\mathrm{N} / \mathrm{mm}^{2}\right]$

\begin{tabular}{|c|c|c|c|c|c|c|c|c|c|c|c|c|c|}
\hline \multirow{3}{*}{$\begin{array}{c}\text { Curing } \\
\text { mode }\end{array}$} & \multirow{3}{*}{$\begin{array}{c}\begin{array}{c}\text { Exposure } \\
\text { time }[\mathrm{s}]\end{array} \\
5\end{array}$} & \multicolumn{6}{|c|}{ 0mm- exposure distance } & \multicolumn{6}{|c|}{$7 \mathrm{~mm}$-exposure distance } \\
\hline & & \multicolumn{3}{|c|}{ top } & \multicolumn{3}{|c|}{ bottom } & \multicolumn{3}{|c|}{ top } & \multicolumn{3}{|c|}{ bottom } \\
\hline & & 126.6 & CD & (2.1) & 33.1 & CD & (2.7) & 117.9 & c & (1.2) & 0.0 & a & $(0.0)$ \\
\hline & 10 & 126.6 & CD & (3.5) & 38.1 & D & (2.5) & 120.8 & cdef & (2.5) & 19.7 & $\mathrm{~b}$ & (2.7) \\
\hline & 15 & 130.8 & DEF & (2.6) & 69.0 & $\mathrm{E}$ & (5.7) & 124.1 & efg & (2.1) & 27.4 & c & (2.7) \\
\hline & 20 & 137.2 & $\mathrm{~F}$ & (2.8) & 81.4 & $\mathrm{~F}$ & (5.0) & 129.4 & hi & (2.4) & 35.9 & d & (2.3) \\
\hline & 40 & 155.9 & G & (3.8) & 99.8 & G & (2.9) & 133.1 & $\mathrm{i}$ & (1.1) & 85.1 & $\mathrm{f}$ & (4.5) \\
\hline High & 1 & 107.7 & A & (3.7) & 0.0 & A & $(0.0)$ & 85.7 & a & (3.5) & 0.0 & a & $(0.0)$ \\
\hline \multirow[t]{4}{*}{ Power } & 2 & 115.1 & B & (4.5) & 0.0 & A & $(0.0)$ & 110.5 & $\mathrm{~b}$ & (3.6) & 0.0 & a & $(0.0)$ \\
\hline & 3 & 125.2 & CD & (3.4) & 23.5 & B & (2.7) & 118.4 & $c d$ & (2.2) & 0.0 & a & $(0.0)$ \\
\hline & 4 & 124.4 & c & (2.1) & 26.9 & BC & (4.0) & 119.7 & cde & (3.2) & 0.0 & a & $(0.0)$ \\
\hline & 12 & 129.8 & CDE & (4.6) & 96.2 & G & (5.6) & 128.6 & ghi & (2.1) & 43.7 & e & (1.1) \\
\hline Plasma & 3 & 124.7 & $C D$ & (1.8) & 38.3 & D & (3.4) & 123.2 & def & (2.9) & 0.0 & a & $(0.0)$ \\
\hline Emulation & 6 & 135.9 & EF & (3.2) & 86.4 & $\mathrm{~F}$ & (4.9) & 125.5 & fgh & (2.8) & 42.8 & e & (2.1) \\
\hline
\end{tabular}

$0=$ not measurable, material was not cured

Indentation Modulus, E [GPa]

\begin{tabular}{|c|c|c|c|c|c|c|c|c|c|c|c|c|c|}
\hline \multirow{3}{*}{$\begin{array}{c}\begin{array}{c}\text { Curing } \\
\text { mode }\end{array} \\
\text { Standard }\end{array}$} & \multirow{2}{*}{$\begin{array}{c}\text { Exposure } \\
\text { time }[s]\end{array}$} & \multicolumn{6}{|c|}{ 0mm- exposure distance } & \multicolumn{6}{|c|}{$7 \mathrm{~mm}$-exposure distance } \\
\hline & & \multicolumn{3}{|c|}{ top } & \multicolumn{3}{|c|}{ bottom } & \multicolumn{3}{|c|}{ top } & \multicolumn{3}{|c|}{ bottom } \\
\hline & 5 & 14.6 & BC & $(0.7)$ & 6.2 & $B C$ & $(0.3)$ & 14.3 & c & $(0.5)$ & 0.0 & $a$ & $(0,3)$ \\
\hline & 10 & 15.0 & BC & $(0.2)$ & 6.4 & $B C$ & $(0.5)$ & 14.9 & cde & $(0.6)$ & 4.8 & b & $(0,3)$ \\
\hline & 15 & 16.0 & DEF & $(0.4)$ & 10.5 & 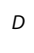 & $(0.6)$ & 15.8 & def & $(0.5)$ & 5.4 & c & $(0,5)$ \\
\hline & 20 & 16.7 & $\mathbf{F}$ & $(0.3)$ & 12.1 & E & $(0.4)$ & 15.8 & ef & $(0.4)$ & 6.4 & d & $(0,2)$ \\
\hline & 40 & 17.7 & G & (0.3) & 13.4 & $F$ & $(0.5)$ & 16.2 & $\mathrm{f}$ & $(0.5)$ & 11.9 & $g$ & $(0,5)$ \\
\hline High & 1 & 12.9 & A & (0.4) & 0.0 & A & $(0.0)$ & 10.3 & a & $(0.3)$ & 0.0 & a & $(0,0)$ \\
\hline \multirow[t]{4}{*}{ Power } & 2 & 14.3 & B & (0.4) & 0.0 & A & $(0.0)$ & 13.0 & b & (0.6) & 0.0 & a & $(0,0)$ \\
\hline & 3 & 14.8 & BC & $(0.2)$ & 5.6 & B & $(0.5)$ & 14.9 & cd & (0.4) & 0.0 & a & $(0,0)$ \\
\hline & 4 & 15.3 & CD & $(0.2)$ & 6.3 & $B C$ & (0.6) & 15.2 & cde & $(0.4)$ & 0.0 & a & $(0,0)$ \\
\hline & 12 & 16.2 & EF & (0.4) & 12.9 & EF & $(0.4)$ & 15.8 & def & $(0.2)$ & 8.2 & e & $(0,1)$ \\
\hline Plasma & 3 & 15.8 & DE & $(0.3)$ & 6.5 & c & $(0.2)$ & 15.1 & cde & (0.7) & 0.0 & a & $(0,0)$ \\
\hline Emulation & 6 & 16.4 & EF & $(0.2)$ & 12.2 & E & $(0.6)$ & 15.4 & def & $(0.4)$ & 7.3 & $f$ & $(0,4)$ \\
\hline
\end{tabular}

$0=$ not measurable, material was not cured 


\section{b) Filtek ${ }^{\mathrm{TM}}$ Supreme XTE flow}

Vickers hardness, $\mathrm{HV}\left[\mathrm{N} / \mathrm{mm}^{2}\right]$

\begin{tabular}{|c|c|c|c|c|c|c|c|c|c|c|c|c|c|}
\hline \multirow{3}{*}{$\begin{array}{c}\text { Curing } \\
\text { mode }\end{array}$} & \multirow{3}{*}{$\begin{array}{c}\text { Exposure } \\
\text { time [s] } \\
5\end{array}$} & \multicolumn{6}{|c|}{ 0mm- exposure distance } & \multicolumn{6}{|c|}{ 7mm-exposure distance } \\
\hline & & \multicolumn{3}{|c|}{ top } & \multicolumn{3}{|c|}{ bottom } & \multicolumn{3}{|c|}{ top } & \multicolumn{3}{|c|}{ bottom } \\
\hline & & 64.3 & B & (4.6) & 53.6 & $\mathrm{E}$ & $(2.8)$ & 67.9 & $\mathrm{~cd}$ & $(1,1)$ & 27.5 & $d$ & (3.2) \\
\hline & 10 & 66.5 & B & (2.6) & 60.9 & $\mathrm{~F}$ & $(2.1)$ & 67.0 & $c d$ & (1.9) & 44.9 & $f$ & (3.2) \\
\hline & 15 & 67.4 & B & $(1.0)$ & 61.0 & $\mathrm{~F}$ & $(2.1)$ & 67.7 & $c d$ & $(2.0)$ & 58.4 & $\mathrm{~h}$ & $(1.5)$ \\
\hline & 20 & 68.4 & B & (1.5) & 64.9 & F.G & (1.5) & 69.1 & $c d$ & $(2.1)$ & 62.4 & hi & $(0.9)$ \\
\hline & 40 & 69.7 & B & $(2.0)$ & 67.8 & G & $(1.2)$ & 71.0 & $d$ & (1.6) & 67.2 & $i$ & $(2.8)$ \\
\hline High & 1 & 53.1 & A & (2.3) & 9.8 & A & (1.9) & 30.6 & a & (1.5) & 3.9 & a & $(0.5)$ \\
\hline \multirow[t]{4}{*}{ Power } & 2 & 64.1 & B & (2.9) & 23.5 & B & (1.4) & 59.3 & b & (3.2) & 13.8 & b & (1.4) \\
\hline & 3 & 64.8 & B & (4.9) & 32.0 & c & (3.2) & 65.1 & c & (4.0) & 14.4 & b & $(2.5)$ \\
\hline & 4 & 65.7 & B & (3.8) & 47.7 & D & (3.5) & 65.0 & c & (3.8) & 21.6 & c & $(1.2)$ \\
\hline & 12 & 67.9 & B & (1.6) & 65.2 & F.G & $(0.1)$ & 68.5 & $c d$ & (1.6) & 52.9 & g & (3.1) \\
\hline Plasma & 3 & 66.5 & B & (3.2) & 47.3 & D & (2.4) & 65.2 & c & (1.3) & 36.8 & e & $(4.2)$ \\
\hline Emulation & 6 & 68.3 & B & $(2.2)$ & 62.0 & $\mathrm{~F}$ & (2.8) & 66.9 & $c d$ & (1.5) & 58.7 & $\mathrm{~h}$ & (2.5) \\
\hline
\end{tabular}

Indentation Modulus, E [GPa]

\begin{tabular}{|c|c|c|c|c|c|c|c|c|c|c|c|c|c|}
\hline \multirow{3}{*}{$\begin{array}{c}\begin{array}{c}\text { Curing } \\
\text { mode }\end{array} \\
\text { Standard }\end{array}$} & \multirow{3}{*}{$\begin{array}{c}\text { Exposure } \\
\text { time }[\mathrm{s}]\end{array}$} & \multicolumn{6}{|c|}{ Omm- exposure distance } & \multicolumn{6}{|c|}{ 7mm-exposure distance } \\
\hline & & \multicolumn{3}{|c|}{ top } & \multicolumn{3}{|c|}{ bottom } & \multicolumn{3}{|c|}{ top } & \multicolumn{3}{|c|}{ bottom } \\
\hline & & 9.6 & $C D$ & $(0.3)$ & 8.5 & $\mathrm{DE}$ & $(0.5)$ & 9.0 & $c d$ & $(0.1)$ & 5.9 & d & $(0.5)$ \\
\hline & 10 & 9.7 & $C D$ & $(0.4)$ & 8.7 & $\mathrm{EF}$ & $(0.2)$ & 9.3 & cde & $(0.2)$ & 7.6 & $f$ & $(0.3)$ \\
\hline & 15 & 9.8 & $C D$ & $(0.3)$ & 9.3 & FG & $(0.3)$ & 9.5 & def & $(0.3)$ & 8.9 & gh & $(0.2)$ \\
\hline & 20 & 9.9 & D & $(0.1)$ & 9.3 & FG & $(0.3)$ & 9.8 & ef & $(0.1)$ & 8.8 & gh & (0.3) \\
\hline & 40 & 10.1 & D & $(0.2)$ & 9.9 & G & $(0.3)$ & 9.9 & $f$ & $(0.3)$ & 9.4 & $\mathrm{~h}$ & $(0.2)$ \\
\hline High & 1 & 7.3 & A & $(0.2)$ & 2.2 & A & $(0.3)$ & 5.0 & a & $(0.2)$ & 1.0 & a & $(0.1)$ \\
\hline \multirow[t]{4}{*}{ Power } & 2 & 8.5 & B & $(0.6)$ & 4.6 & B & $(0.3)$ & 8.2 & b & $(0.6)$ & 2.8 & $\mathrm{~b}$ & $(0.1)$ \\
\hline & 3 & 9.1 & $B C$ & $(0.7)$ & 5.9 & c & $(0.6)$ & 8.8 & bc & $(0.4)$ & 3.3 & b & (0.3) \\
\hline & 4 & 9.4 & $C D$ & $(0.4)$ & 7.8 & D & $(0.4)$ & 9.2 & $c d$ & $(0.3)$ & 4.5 & c & $(0.1)$ \\
\hline & 12 & 9.7 & $C D$ & $(0.5)$ & 8.7 & $\mathrm{EF}$ & $(0.2)$ & 9.5 & def & $(0.3)$ & 8.4 & g & (0.3) \\
\hline Plasma & 3 & 9.7 & $C D$ & $(0.2)$ & 7.9 & D & $(0.5)$ & 9.3 & cde & $(0.2)$ & 6.6 & e & (0.4) \\
\hline Emulation & 6 & 10.1 & D & $(0.3)$ & 9.4 & FG & $(0.4)$ & 9.5 & def & (0.3) & 9.0 & $\mathrm{~h}$ & (0.4) \\
\hline
\end{tabular}




\section{c) Filtek ${ }^{\mathrm{TM}}$ Silorane}

\section{Vickers hardness, $\mathrm{HV}\left[\mathrm{N} / \mathrm{mm}^{2}\right]$}

\begin{tabular}{|c|c|c|c|c|c|c|c|c|c|c|c|c|c|}
\hline \multirow{3}{*}{$\begin{array}{c}\begin{array}{c}\text { Curing } \\
\text { mode }\end{array} \\
\text { Standard }\end{array}$} & \multirow{3}{*}{$\begin{array}{l}\text { Exposure } \\
\text { time [s] } \\
5\end{array}$} & \multicolumn{6}{|c|}{ Omm- exposure distance } & \multicolumn{6}{|c|}{ 7mm-exposure distance } \\
\hline & & \multicolumn{3}{|c|}{ top } & \multicolumn{3}{|c|}{ bottom } & \multicolumn{3}{|c|}{ top } & \multicolumn{3}{|c|}{ bottom } \\
\hline & & 92.5 & BC & (4.3) & 74.9 & BC & (1.9) & 91.4 & bc & (2.9) & 0.0 & a & $(0.0)$ \\
\hline & 10 & 93.4 & $\mathrm{BCD}$ & (2.7) & 85.1 & DE & (6.3) & 92.6 & bc & (3.2) & 69.0 & b & (4.8) \\
\hline & 15 & 98.5 & DE & (2.2) & 85.3 & DE & (3.0) & 93.9 & bc & (1.7) & 73.6 & b & (2.3) \\
\hline & 20 & 98.5 & DE & (2.2) & 86.5 & DE & (1.4) & 96.2 & cd & (2.5) & 73.8 & b & (3.3) \\
\hline & 40 & 100.0 & E & (3.4) & 90.3 & E & (1.4) & 99.7 & d & $(1.0)$ & 82.9 & c & (1.8) \\
\hline High & 1 & 83.2 & A & $(4.0)$ & 0.0 & A & $(0.0)$ & 82.3 & a & (5.7) & 0.0 & a & $(0.0)$ \\
\hline \multirow[t]{4}{*}{ Power } & 2 & 87.6 & $A B$ & (4.3) & 0.0 & A & $(0.0)$ & 89.4 & $\mathrm{~b}$ & $(2.2)$ & 0.0 & a & $(0.0)$ \\
\hline & 3 & 93.4 & $\mathrm{BCD}$ & (2.1) & 69.7 & в & (4.8) & 89.4 & b & (2.1) & 0.0 & a & $(0.0)$ \\
\hline & 4 & 94.3 & $C D$ & (2.7) & 76.4 & c & (1.9) & 94.1 & bc & (2.3) & 0.0 & a & $(0.0)$ \\
\hline & 12 & 98.7 & DE & (2.4) & 90.0 & $\mathrm{E}$ & (3.5) & 94.2 & bcd & (2.4) & 82.3 & c & (3.1) \\
\hline Plasma & 3 & 97.6 & CDE & (2.2) & 83.3 & D & (2.8) & 95.8 & bcd & (3.6) & 73.4 & b & (4.0) \\
\hline Emulation & 6 & 98.2 & CDE & (2.4) & 90.2 & E & (3.0) & 95.8 & $\mathrm{~cd}$ & (3.6) & 80.9 & c & (4.1) \\
\hline
\end{tabular}

$0=$ not measurable, material was not cured

Indentation Modulus, E [GPa]

\begin{tabular}{|c|c|c|c|c|c|c|c|c|c|c|c|c|c|}
\hline \multirow{3}{*}{$\begin{array}{c}\begin{array}{c}\text { Curing } \\
\text { mode }\end{array} \\
\text { Standard }\end{array}$} & \multirow{3}{*}{$\begin{array}{c}\text { Exposure } \\
\text { time [s] }\end{array}$} & \multicolumn{6}{|c|}{ Omm- exposure distance } & \multicolumn{6}{|c|}{$7 \mathrm{~mm}$-exposure distance } \\
\hline & & \multicolumn{3}{|c|}{ top } & \multicolumn{3}{|c|}{ bottom } & \multicolumn{3}{|c|}{ top } & \multicolumn{3}{|c|}{ bottom } \\
\hline & & 12.3 & AB & $(0.5)$ & 12.0 & B & $(0.2)$ & 13.1 & cde & $(0.3)$ & 0.0 & a & $(0.0)$ \\
\hline & 10 & 13.7 & CDE & $(0.4)$ & 12.3 & B & $(0.8)$ & 13.0 & bcd & $(0.2)$ & 12.5 & b & (0.7) \\
\hline & 15 & 14.1 & DE & $(0.5)$ & 12.4 & B & $(0.3)$ & 13.5 & def & $(0.1)$ & 13.1 & bc & (0.3) \\
\hline & 20 & 14.1 & DE & $(0.5)$ & 13.5 & c & $(0.4)$ & 13.5 & def & $(0.3)$ & 13.0 & bc & $(0.2)$ \\
\hline & 40 & 14.3 & $\mathrm{E}$ & $(0.5)$ & 13.8 & c & $(0.5)$ & 14.3 & $\mathrm{f}$ & $(0.5)$ & 13.5 & c & (0.3) \\
\hline High & 1 & 11.7 & A & $(0.6)$ & 0.0 & A & $(0.0)$ & 11.2 & a & (1.2) & 0.0 & a & $(0.0)$ \\
\hline \multirow[t]{4}{*}{ Power } & 2 & 13.2 & $B C D$ & $(0.2)$ & 0.0 & A & $(0.0)$ & 12.1 & $a b c$ & (1.0) & 0.0 & a & $(0.0)$ \\
\hline & 3 & 13.2 & BCD & $(0.2)$ & 11.8 & B & (0.9) & 12.0 & ab & (0.5) & 0.0 & a & $(0.0)$ \\
\hline & 4 & 13.6 & CD & $(0.4)$ & 12.1 & B & $(0.2)$ & 13.4 & de & $(0.3)$ & 0.0 & a & $(0.0)$ \\
\hline & 12 & 13.7 & CDE & $(0.8)$ & 13.8 & c & $(0.5)$ & 14.2 & ef & $(0.3)$ & 12.7 & b & $(0.8)$ \\
\hline Plasma & 3 & 12.9 & BC & $(0.5)$ & 13.3 & c & $(0.3)$ & 13.2 & def & $(0.7)$ & 12.8 & $\mathrm{~b}$ & (0.4) \\
\hline Emulation & 6 & 13.5 & CDE & (0.4) & 13.5 & c & $(0.2)$ & 13.6 & def & (0.4) & 13.5 & c & $(0.2)$ \\
\hline
\end{tabular}

$0=$ not measurable, material was not cured

that the LCU is placed directly and perpendicularly on the restoration, which would be considered an ideal situation. Compared to the effect of the exposure time or location of measurement (top-bottom) the effect of the exposure distance was low in all materials.

This effect corroborates well with the identified low effect of the exposure distance on the transmitted irradiance through the same materials and specimen geometries [8]. Moreover, the influence of the exposure distance was lower at the surface than at the bottom, and larger in the higher filled RBC Filtek

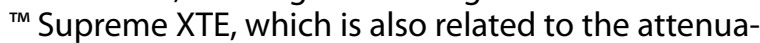
tion of light [8].

A further aspect analyzed in the present study is the effect of the chemical composition of the organic matrix at a given filler amount or the viscosity of the material at a given chemical composition of the organic matrix, on the material's susceptibility to different curing conditions. To analyze this aspect, all 
RBCs were chosen in the same shade, A3. This supposes that differences in the material reaction to different curing conditions are related to the chemical composition of the individual ingredients, the filler size and the proportional relation between filler and organic matrix.

A further component that may have an influence on the amount of light transmitted in the depth of the specimen is the initiator. While there is less information about the amount and exact composition of the initiator system, it is likely that both methacrylatebased RBCs are based on the same initiator, a camphorquinone/amine system. As for the silorane material, the initiator is camphorquinone as well, but it contains in addition an iodonium salt and aromatic amines [19] that may have an effect in light transmission as well.

The lower filler amount in the flowable RBC lead to the significant highest light transmission at the bottom of the specimens [8] when compared to the higher filled methacrylate-based RBC. This fact is clearly reflected in the present study in a lower susceptibility of the flowable material to variations in light exposure. A difference of 8.3 vol. \% in filler amount resulted in significantly lower light transmittance and a ca. 50\% higher absorbance in the higher filled methacrylate-based RBC [8].

This is directly related to the identified insufficient polymerization at the bottom of the $2-\mathrm{mm}$ thick specimens of the last-mentioned material, also at high exposure times.

At a given filler amount, $55 \mathrm{vol}-\%$, the silorane-based RBCs was less translucent than the flowable methacrylate-based RBCs, but the difference in the light transmittance and absorbance characteristics of both materials was lower compared to the differences related to the higher filled methacrylate-based $\mathrm{RBC}$ [8].

The reasons for the different light transmittance at a similar filler volume amount is related, besides the abovementioned differences in the type of initiator, to the monomer reactivity and differences in refractive index between fillers and organic matrix as well as to the filler size and chemical composition $[20,21]$. It must also be emphasized that the micromechanical properties measured in the silorane material were superior to the values measured in the flowable methacrylate-based flowable material at a similar filler volume content. This may also be related, besides the filler type, to the high crosslinking

\section{References}

1. Park J, Chang J, Ferracane J, Lee IB. How should composite be layered to reduce shrinkage stress: incremental or bulk filling? Dent Mater. 2008;24(11):1501-1505.

[Full text links] [CrossRef] [PubMed] Google Scholar

2. Musanje L, Darvell BW. Polymerization of resin composite restorative materials: exposure reciprocity. Dent Mater. 2003;19(6):531-541.

[Full text links] [CrossRef] [PubMed] Google Scholar Scopus

3. Musanje L, Darvell BW. Curing-light attenuation in filled-resin restorative materials. Dent Mater. 2006;22(9):804-817.

[Full text links] [CrossRef] [PubMed] Google Scholar Scopus

4. Rueggeberg FA, Caughman WF, Curtis JW, Jr. Effect of light intensity and exposure duration on cure of resin composite. Oper Dent. 1994;19(1):26-32.

[PubMed] Google Scholar Scopus density of the final silorane-polymer, as the silorane monomer, which was obtained from the reaction of oxirane and siloxane molecules, is a four-branched monomer [19].

The presented data allow rejecting all specified null hypothesis.

\section{Conclusions}

The analyzed RBCs react differently to the analyzed curing conditions depending on their structure and composition. It can therefore be concluded that:

- The susceptibility to various curing conditions is material-dependent, while less filled methacrylate-based as well as the silorane micro-hybrid seems to be more robust to these variations.

- The indentation modulus, $E$, reacts more sensitively to variations in curing conditions then the hardness, HV, thus being a better indicator in the characterization of changes in polymerization.

- Within the bounds of this study, exposure time has a significant stronger effect on the micro-mechanical properties than irradiance. The influence of radiant exposure, which is the product of exposure time and irradiance, was lower compared to the effect of exposure time. The effect of exposure distance was by comparison much lower.

- Fast polymerization (3s) with high irradiance is not recommended for the analyzed materials. The doubled exposure time (6s) at high irradiance proved to be insufficient for the methacrylate based RBCs, while acceptable for the silorane material.

- On the basis of these findings, under comparable clinical conditions, a curing time of at least 20 s at moderate irradiance is likely to be recommended for the majority of the tested materials, providing clinical conditions are comparable to those in the described study.

\section{Author Contributions}

$\mathrm{NI}$ : designed the study, provided the infrastructure (devices, materials), developed the measurement methods, supervised the experiment, performed statistics, and wrote the manuscript. EP: performed the experiments and recorded the data.

5. Sobrinho LC, Goes MF, Consani S, et al. Correlation between light intensity and exposure time on the hardness of composite resin. J Mater Sci Mater Med. 2000;11(6):361-364. [PubMed] Google Scholar

6. Ilie N, Hilton TJ, Heintze SD, et al. Academy of Dental Materials guidance-Resin composites: Part I-Mechanical properties. Dent Mater. 2017;33(8):880-894.

[Full text links] [CrossRef] [PubMed] Google Scholar Scopus

7. Ferracane JL, Hilton TJ, Stansbury JW, et al. Academy of Dental Materials guidance-Resin composites: Part II-Technique sensitivity (handling, polymerization, dimensional changes). Dent Mater 2017:33(11):1171-1191.

[Full text links] [CrossRef] [PubMed] Google Scholar

8. Ilie N, Plenk E. Light transmission through resin composites. Stoma Edu J. 2018;5(3):148-154. [CrossRef] 
9. Ilie N, Furtos G. A comparative study of light transmission through various dental restorative materials and the tooth structure. Oper Dent - in revision. 2019.

10. DIN-50359-1. Testing of metallic materials - Universal hardness test - Part 1: Test method. 1997.

11. Ilie N, Bauer H, Draenert M, Hickel R. Resin-based composite light-cured properties assessed by laboratory standards and simulated clinical conditions. Oper Dent. 2013;38(2):159-167.

[Full text links] [CrossRef] [PubMed] Google Scholar Scopus

12. Rueggeberg FA. State-of-the-art: dental photocuring--a review. Dent Mater. 2011;27(1):39-52.

[Full text links] [CrossRef] [PubMed] Google Scholar Scopus

13. Deb S, Sehmi H. A comparative study of the properties of dental resin composites polymerized with plasma and halogen light. Dent Mater. 2003;19(6):517-522.

[Full text links] [CrossRef] [PubMed] Google Scholar Scopus

14. Kim JW, Jang KT, Lee SH, et al. Effect of curing method and curing time on the microhardness and wear of pit and fissure sealants. Dent Mater. 2002;18(2):120-127.

[Full text links] [CrossRef] [PubMed] Google Scholar Scopus

15. Joly GD, Abuelyaman AS, Fornof AR, et al. Dental compositions comprising addition-fragmentation agents. US Patent 9414996B2. 2016.
16. Ilie N. Sufficiency of curing in high-viscosity bulk-fill resin composites with enhanced opacity. Clin Oral Investig. 2019;23(2):747-755.

[Full text links] [CrossRef] [PubMed] Google Scholar Scopus

17. Ilie $N$, Jelen $E$, Hickel $R$. Is the soft-start polymerisation concept still relevant for modern curing units? Clin Oral Investig. 2011;15(1):21-29.

[Full text links] [CrossRef] [PubMed] Google Scholar

18. Price RB, Derand T, Sedarous M, et al. Effect of distance on the power density from two light guides. J Esthet Dent. 2000;12(6):320327.

[CrossRef] [PubMed] Google Scholar Scopus

19. Weinmann W, Thalacker C, Guggenberger R. Siloranes in dental composites. Dent Mater. 2005;21(1):68-74.

[Full text links] [CrossRef] [PubMed] Google Scholar Scopus

20. Palin WM, Leprince JG, Hadis MA. Shining a light on high volume photocurable materials. Dent Mater. 2018;34(5):695-710.

[Full text links] [CrossRef] [PubMed] Google Scholar Scopus

21. Shortall AC, Palin WM, Burtscher P. Refractive index mismatch and monomer reactivity influence composite curing depth. J Dent Res. 2008;87(1):84-88.

[Full text links] [CrossRef] [PubMed] Google Scholar Scopus

Nicoleta ILIE
Dipl. Eng, PhD, Professor
Department of Operative/Restorative Dentistry, Periodontology and Pedodontics
Faculty of Medicine
Ludwig-Maximilians University of Munich, Munich, Germany

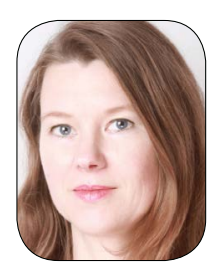

Dipl. Eng. Nicoleta llie studied technical chemistry at the Department of Technology of silicates and high-temperature oxides at the Traian Vuia University, Timişoara, Romania (1989-1993). She studied material sciences with a focus on glass and ceramics at the Friedrich Alexander University, Erlangen-Nuremberg, Germany (1994-1999). She got her doctoral degree in material sciences from the Ludwig-Maximilians University, Dental School, Munich, Germany (1999-2004), followed by her postdoctoral lecture qualification (habilitation) at the same university (2004-2009). Since 1999, she has been assistant professor, associated professor (2009) and tenured professor (2014) of biomaterials at the Dental School of the Ludwig-Maximilians University in Munich. 


\section{Questions}

\section{The highest influence on the micro-mechanical properties of a light cured resin-based composite ( $R B C)$ is exerted by:}

Da. Exposure time;

ab. Exposure distance;

口c. Incident irradiance;

口d. LCU's irradiance.

\section{When curing a $R B C$, following in valid:}

$\square$ a. Fast polymerization (3s) with high irradiance is recommended, to speed up the restoration procedure; ab. A curing time of at least $20 \mathrm{~s}$ at moderate irradiance;

ac. A lower increment can only be pre-cured for few seconds, since it will receive sufficient light while curing the upper increments;

$\square$ d. All RBCs react similar to variations in radiant exposure.

\section{What are "Silorane"?}

$\square$ a. Resin-based composites with particular glass ionomer filler;

b. Resin-based composites designed to release ions like F;

ac. Four branched monomer obtained from the reaction of oxirane and siloxane molecules;

ad. A sort of ceramic.

4. At a given composition of the filler and matrix in a RBC, an enhanced filler amount will result in:

$\square$ a. Higher mechanical properties;

ab. Higher light transmittance;

ac. Lower susceptibility to variation in irradiation;

$\square$ d. Better polymerization at the bottom of the $2 \mathrm{~mm}$ increments. 


\section{EFFECTS OF ETCHING MODE ON BOND STRENGTH OF UNIVERSAL ADHESIVES}

Andre Figueiredo Reis ${ }^{1{ }^{*}}$, Paula Maria Mendes Alves ${ }^{2 b}$, Rose Yakushijin Kumagai ${ }^{2 c}$

'Department of Restorative Dental Sciences, Division of Operative Dentistry, College of Dentistry

University of Florida, Gainesville, FL, USA

2Department of Restorative Dentistry, Dentistry Clinic, Guarulhos University, Guarulhos, SP, Brazil

${ }^{2} D D S$, MS, PhD, Clinical Associate Professor

bDS, Master student

'DDS, MS, PhD student

Introduction: The aim of this study was to analyze the bond strength to dentin produced by new universal adhesive systems used in self-etch and etch-and rinse application modes.

Materials and Methods: Sixty human teeth were divided into 6 groups according to the different universal adhesive systems: Scotchbond Universal (SBU - 3M ESPE), Clearfil Universal (CFU - Kuraray), Futurabond U (FBU - VOCO) Xeno Select (XS - Dentsply De Trey), Prime\&Bond Elect (PBE - Dentsply Caulk) and All Bond Universal (ABU, Bisco). Then, the teeth were subdivided into 2 subgroups, according to the application mode: etchand-rinse or self-etch. Composite crowns were built after application of the adhesive systems and the restored teeth were sectioned in both " $X$ " and " $Y$ " directions into sticks with a cross-sectional bonded area of approximately $1 \mathrm{~mm}^{2}$. The microtensile test was carried on a universal testing machine operated at a crosshead speed of $1 \mathrm{~mm} / \mathrm{min}$. Bond strength values were statistically evaluated using two-way ANOVA and the Tukey post-hoc test.

Results: $\mathrm{SBU}, \mathrm{XS}$ and $\mathrm{ABU}$ presented significantly higher bond strength values when applied on the etch-and-rinse mode $(p<0.05)$. CFU, FBU and PBE presented no significant difference in bond strength values between etch-and-rinse and self-etching groups ( $p>$ 0.05).

Conclusion: The adhesive performance of Universal Adhesives was similar or higher when they were used in the etch-and-rinse mode in comparison with the self-etching mode.

Keywords: Acid etching; Dental; Bond strength; Dental bonding; Universal adhesives.

OPEN ACCESS This is
Oan Open Access article under
the CC BY-NC 4.0 license.
Peer-Reviewed
Article
Citation: Reis AF, Alves PMM,
Kumagai RY. Effects of etching
mode on bond strength of universal
adhesives.
Stoma Edu J. 2019;66(2):1111-117
Received: March 19, 2019
Revised: April 16, 2019
Accepted: May 10, 2019
Published: May 15, 2019

*Corresponding author:
Andre Figueiredo Reis, DDS, MS, PhD,
Clinical Associate Professor,
Department of Restorative Dental
Sciences, Division of Operative
Dentistry, University of Florida,1395
Center Drive, Room D9-6, P.O. Box
100415, Gainesville, FL 32610-
0415, USA
Phone: +1(352)273-5850;
Fax: +1(352)846-1643;
e-mail: AReis@dental.ufl.edu
Copyright: @ 2019
the Editorial Council for the
Stomatology Edu Journal.

\section{Introduction}

Bonding to enamel and dentin is mainly accomplished by micromechanical interlocking between synthetic, naturally degradable polymers, and enamel or dentin collagen fibrils [1]. Effective, long-lasting bonding to dentin has been a challenge to dental clinicians, because in order to promote adhesion to dentin, the mineral phase needs to be totally or partially removed, and substituted by an adhesive solution, that will permeate this collagenrich layer, and polymerize in situ, forming what has been called the hybrid layer [1-3].

Different approaches, with different numbers of steps and degrees of sensitivity have been used to bond resin-based materials to enamel and dentin [4-6]. Efforts have been directed to reduce the number of steps and technique sensitivity. Onebottle self-priming etch-and-rinse systems, as well as single-step self-etching adhesives are simplified versions of their multiple-step precursors, and have been recently combined and marketed as Universal adhesives [7,8]. These multimodal adhesives may be used in etch-and-rinse mode, self-etch mode or selective-etch mode, depending on the clinician's preference $[9,10]$.

Although recent studies reported that universal adhesives applied using either the etch-andrinse or the self-etch mode produce excellent immediate bond strength to bonding substrates [11], limited information is available on the newest universal adhesives recently introduced by different manufacturers. Thus, the aim of this study was to evaluate the bond strength to dentin produced by six universal adhesives applied either on the etchand-rinse or self-etching mode. The tested null hypothesis was that there is no difference in bond strength produced by universal adhesives applied on the etch-and-rinse or self-etching mode. 
Table 1. Universal adhesives short name, manufacturer, $\mathrm{pH}$, composition, and application instructions.

\begin{tabular}{|c|c|c|c|c|}
\hline $\begin{array}{c}\text { Adhesive, } \\
\text { (Batch Number) }\end{array}$ & pH & Composition & Self-Etch & Etch-and-Rinse \\
\hline $\begin{array}{l}\text { Scotchbond } \\
\text { Universal (SBU) } \\
3 \mathrm{M} \text { Espe, St } \\
\text { Paul, MN, USA } \\
\text { (554836) }\end{array}$ & 2.7 & $\begin{array}{l}\text { 2-HEMA, 10-MDP, } \\
\text { dimethacrylate resins, } \\
\text { VitrebondTM copolymer, } \\
\text { silane, filler, ethanol, water, } \\
\text { iniciators }\end{array}$ & $\begin{array}{l}\text { 1. Apply the adhesive to the } \\
\text { prepared tooth and rub in } \\
\text { for } 20 \mathrm{~s} \\
\text { 2. Gently air-dry the } \\
\text { adhesive for } 5 \mathrm{~s} \text { for the sol- } \\
\text { vent to evaporate } \\
\text { 3. Light cure for } 10 \mathrm{~s}\end{array}$ & $\begin{array}{l}\text { 1. Apply etchant for } 15 \mathrm{~s} \\
\text { 2. Rinse for } 10 \mathrm{~s} \\
\text { 3. Air dry } 2 \mathrm{~s} \\
\text { 4. Apply adhesive as for } \\
\text { the self-etch mode }\end{array}$ \\
\hline $\begin{array}{c}\text { Clearfil } \\
\text { Universal Bond } \\
\text { (CFU) } \\
\text { Kuraray, Tokyo, } \\
\text { Japan (C40001) }\end{array}$ & 2.3 & $\begin{array}{l}\text { HEMA, MDP, Bis-GMA, } \\
\text { ethanol, camphorquinone, } \\
\text { hydrophilic aliphatic dimeth- } \\
\text { acrylate, } \\
\text { silane coupling agent, } \\
\text { colloidal silica, water, and } \\
\text { accelerators }\end{array}$ & $\begin{array}{l}\text { 1. Apply bond and rub for } \\
20 \mathrm{~s} \text { or } 40 \mathrm{~s} \\
\text { 2. Dry by blowing mild air } \\
\text { for } 5 \mathrm{~s} \\
\text { 3. Light cure for } 10 \mathrm{~s}\end{array}$ & $\begin{array}{l}\text { 1. Apply etchant for } 10 \mathrm{~s} \\
\text { 2. Rinse thoroughly } \\
\text { 3. Dry } \\
\text { 4. Apply adhesive as for } \\
\text { the self-etch mode }\end{array}$ \\
\hline $\begin{array}{l}\text { Futurabond U } \\
\text { (FBU) } \\
\text { VOCO, } \\
\text { Cuxhaven, } \\
\text { Germany } \\
(1333352)\end{array}$ & 2.3 & $\begin{array}{l}\text { 2-HEMA, Bis-GMA, HEMA, } \\
\text { acidic adhesive monomer, } \\
\text { urethane dimethacrylate, } \\
\text { catalyst, silica nanoparticles, } \\
\text { ethanol }\end{array}$ & $\begin{array}{l}\text { 1. Activate single dose } \\
\text { adhesive package } \\
\text { 2. Apply adhesive to the } \\
\text { cavity surface using the } \\
\text { Voco Single Tim brush and } \\
\text { rub adhesive in for } 20 \mathrm{~s} \\
\text { 3. Dry adhesive with dry, } \\
\text { oil-free air for at least } 5 \mathrm{~s} \\
\text { 4. Light cure for } 10 \mathrm{~s}\end{array}$ & $\begin{array}{l}\text { 1. Apply etchant for } 15 \mathrm{~s} \\
\text { 2. Rinse for } 10 \mathrm{~s} \\
\text { 3. Air dry } 2 \mathrm{~s} \\
\text { 4. Apply adhesive as for } \\
\text { the self-etch mode }\end{array}$ \\
\hline $\begin{array}{l}\text { Xeno Select } \\
\text { (XS) } \\
\text { Dentsply De } \\
\text { Trey, Konstanz, } \\
\text { Germany } \\
\text { (1402000636) }\end{array}$ & 1.3 & $\begin{array}{l}\text { Bifunctional acryl resin with } \\
\text { amide functions, } \\
\text { Acryloylamino alkylsulfonic } \\
\text { acid, "inverse" } \\
\text { functionalized phosphoric } \\
\text { acid ester, Camphorquinone, } \\
\text { Coinitiator, Butylated } \\
\text { benzenediol, Water, } \\
\text { tert-Butanol }\end{array}$ & $\begin{array}{l}\text { 1. Apply the adhesive to the } \\
\text { prepared tooth and rub in } \\
\text { for } 20 \mathrm{~s} \\
\text { 2. Gently air-dry the } \\
\text { adhesive for } 5 \mathrm{~s} \text { for the } \\
\text { solvent to evaporate } \\
\text { 3. Light cure for } 10 \mathrm{~s}\end{array}$ & $\begin{array}{l}\text { 1. Apply etchant for } 15 \mathrm{~s} \\
\text { 2. Rinse for } 10 \mathrm{~s} \\
\text { 3. Air dry } 2 \mathrm{~s} \\
\text { 4. Apply adhesive as for } \\
\text { the self-etch mode }\end{array}$ \\
\hline $\begin{array}{l}\text { Prime\&Bond } \\
\text { Elect (PBE) } \\
\text { Dentsply Caulk, } \\
\text { Milford, DE, USA } \\
\text { (141008) }\end{array}$ & 2.5 & $\begin{array}{l}\text { Mono-, di- and trimethacry- } \\
\text { late resins, PENTA, diketone; } \\
\text { organic phosphine oxide, } \\
\text { cetylamine hydrofluoride, } \\
\text { acetone, water, self-cure } \\
\text { activator }\end{array}$ & $\begin{array}{l}\text { 1. Apply generous amounts } \\
\text { of adhesives to thoroughly } \\
\text { wet all tooth surfaces } \\
\text { 2. Agitate applied adhesive } \\
\text { for } 20 \mathrm{~s} \text {. Re-apply to coat } \\
\text { preparation for the entire } \\
20 \text { s period } \\
\text { 3. Remove excess solvent } \\
\text { by gentle dryingwith clean, } \\
\text { dry air for at least } 5 \mathrm{~s} \\
\text { 4. Light cure for } 10 \mathrm{~s}\end{array}$ & $\begin{array}{l}\text { 1. Condition enamel for } \\
\text { at least } 15 \text { seconds and } \\
\text { dentin for } 15 \text { seconds } \\
\text { or less. } \\
\text { 2. Rinse for } 15 \mathrm{~s} \\
\text { 3. Dry } \\
\text { 4. Apply adhesive as for } \\
\text { the self-etch mode }\end{array}$ \\
\hline $\begin{array}{l}\text { All Bond Univer- } \\
\text { sal (1300006652) }\end{array}$ & 3.2 & $\begin{array}{l}\text { 2-HEMA, 10-MDP, Bis-GMA, } \\
\text { ethanol, water, initiators }\end{array}$ & $\begin{array}{l}\text { 1. Apply two separate coats } \\
\text { of adhesive with agitation } \\
\text { for } 10-15 \text { s per coat } \\
\text { 2. Evaporate solvent by } \\
\text { thorough air-drying for } \\
\text { least } 10 \mathrm{~s} \text {. } \\
\text { No visible movement of } \\
\text { adhesive } \\
\text { 3. Surface should have a } \\
\text { uniform glossy appearance. } \\
\text { If not, repeat steps } 1 \text { and } 2 \\
\text { 4. Light cure for } 10 \mathrm{~s}\end{array}$ & $\begin{array}{l}\text { 2. Rinse thoroughly } \\
\text { 3. Remove excess water } \\
\text { by blotting surface with } \\
\text { an absorbent pellet or } \\
\text { high volume evacuation } \\
\text { for } 1-2 \text { s, leaving the } \\
\text { preparation visibly moist } \\
\text { 4. Apply adhesive as for } \\
\text { the self-etch mode }\end{array}$ \\
\hline
\end{tabular}

Abbreviations: 2-HEMA, 2-hydroxyethyl methacrylate; 10-MDP, 10-methacryloyloxydecyl dihydrogen phosphate; Bis-GMA, bisphenol A glycidyl methacrylate; PENTA, dipentaerythritol penta acrylate monophosphate. 


\section{Materials and Methods}

Sixty freshly extracted human third molars were used. The teeth were obtained following an approved protocol by the review board of the University of Guarulhos (\# 641.271). After disinfection and removal of soft tissues, the flat coronal dentin surfaces were exposed using 600-grit $\mathrm{SiC}$ paper under running water to create a standardized smear layer.

The teeth were randomly assigned to six experimental groups, which were restored using six commercially available universal adhesive systems: Clearfil Universal (Kuraray), Scotchbond Universal (3M Espe), Futurabond U (Voco), Prime\&Bond Elect (Dentsply Caulk), All Bond Universal (Bisco) and Xeno Select (Dentsply De Trey). The composition, batch number and application instructions are listed in Table 1. The sixty teeth were randomly assigned to 6 test groups, according to the universal adhesives used, and then subdivided into 2 subgroups according to the application mode: etch-and-rinse or self-etching (n $=5$ ). For the etch-and-rinse groups, 35\% phosphoric acid was applied for $15 \mathrm{~s}$, thoroughly rinsed with water, and excess water was removed with cotton pellets. Care was taken not to dehydrate dentin surfaces prior to adhesive application. For the selfetching groups, the dentin surface was dried with an air stream prior to the adhesive application.

After application of the adhesive resins according to the manufacturers' instructions, composite crowns of $5 \mathrm{~mm}$ in height were built up incrementally with composite resin (TPH3, Shade A3, Dentsply Caulk, Milford, DE, USA). A LED light-curing unit (Radii Plus $\mathrm{SDI}$, Victoria, Australia) with a power output of 1,500 $\mathrm{mW} / \mathrm{cm}^{2}$ was used to polymerize all specimens. Each increment (not exceeding $2 \mathrm{~mm}$ thickness) was light cured for 20 seconds. The restored teeth were stored in distilled water at $37^{\circ} \mathrm{C}$ for 24 hours.

Afterwards, the restored teeth were serially sectioned perpendicularly to the adhesive-tooth interface into slabs, and the slabs into beams with a cross-sectional bonded area of approximately 1 $\mathrm{mm}^{2}$ using a diamond saw (Isomet 1000; Buehler, Lake Bluff, IL, USA). Beams were fixed to the grips of a universal testing machine (EZ Test; Shimadzu Corp, Kyoto, Japan) using a cyanoacrylate adhesive (Loctite Super Bonder Gel; Henkel, Düsseldorf, Germany) and tested in tension at a crosshead speed of $1 \mathrm{~mm} /$ min until fracture occurred. The maximum tensile load was divided by specimen cross-sectional area, measured with a digital caliper (Mitutoyo Co., Tokyo, Japan), to express results in units of stress ( $\mathrm{MPa}$ ). Five beams were selected from each restored tooth, and the average value for each tooth was used in the calculations. Bond strength values were statistically evaluated using a two-way ANOVA and the Tukey post-hoc test at a preset significance level of 0.05 . Statistical analyses were performed using a personal computer program (SAS V9, SAS Institute, Cary, NC). Failure modes were determined by visual examination of fractured specimens in a stereomicroscope at a magnification of 50X (PanTec, Panambra Ind. e Tecnica SA, Sao Paulo, Brazil). Failure was classified according to one of four types: cohesive failure in dentin, adhesive failure at the adhesive-dentine interface, cohesive failure in resin composite or mixed failure.

\section{Results}

The mean bond strength values and standard deviation for the different groups are are shown in Table 2. The two-way ANOVA revealed that there were statistically significant differences for the factor "universal adhesive" $(p<0.00021)$ and for the factor "etching mode" $(p=0.00001)$. In addition, it identified a significant interaction between the two factors ( $p=$ $0.00157)$. The Tukey post-hoc test showed significant differences among adhesive systems for the different etching modes $(p<0.05)$.

Scotchbond Universal, Xeno Select and All Bond Universal presented significantly higher bond strength values when applied on the etch-and-rinse mode $(p<0.05)$. Clearfil Universal, Futurabond $U$ and Prime\&Bond Elect presented no significant difference in bond strength values between the etch-and-rinse and self-etchnig groups ( $p>0.05)$. When the etch-and-rinse mode was used, Scotchbond Universal and Xeno Select presented the highest $\mu$ TBS values, with no significant difference between them $(p>0.05)$. However, Xeno Select was not significantly different from the other groups $(p>$ $0.05)$. For the self-ecthing mode groups, the highest $\mu$ TBS values were presented by Futurabond $U$ and Scotchbond Universal, with no significant difference between them $(p>0.05)$. However, Scotchbond Universal was not significantly different from the other Universal Adhesives when used in self-etching mode $(p>0.05)$.

Fig. 1 shows the distribution of fracture patterns for the different groups. The failure mode analysis revealed that the majority of failures were adhesive at the adhesive-dentin interface for most groups, except for Scotchbond Universal and All Bond Universal applied on the etch-and-rinse mode, which presented a high number of cohesive failures in resin composite.

\section{Discussion}

Recently, a new type of single-step self-etching adhesive has been introduced. This type of selfetching adhesive is categorized as "universal" or "multi-mode" as it can be used either with the etch-and-rinse or the self-etching approaches [1215]. Therefore, universal adhesives are used with phosphoric acid pre-etching in the etch-and-rinse or selective-etch approaches, which enhances bond strength to enamel. In addition, it also provides a simplified self-etching approach for dentin substrate [16]. However, this type of adhesive has only recently been introduced to the market, and there is little information as to whether the different etching 
Table 2. Mean bond strength values in MPa (SD) produced by the universal adhesives applied in self-etching and etch-and-rinse modes.

\begin{tabular}{|c|c|c|c|c|}
\hline Universal Adhesives & Etch-and-Rinse & & Self-etching & \\
\hline Scotchbond Universal & $96.8(14.9)$ & $\mathrm{Aa}$ & $47.5(17.6)$ & $\mathrm{ABb}$ \\
\hline Clearfil Universal & $52.2(11.1)$ & $\mathrm{Ba}$ & $36.6(13.0)$ & $\mathrm{Ba}$ \\
\hline Futurabond U & $63.7(14.4)$ & $\mathrm{Ba}$ & $67.5(5.3)$ & $\mathrm{Aa}$ \\
\hline Xeno Select & $76.1(31.5)$ & $\mathrm{ABa}$ & $40.4(10.7)$ & $\mathrm{Bb}$ \\
\hline Prime\&Bond Elect & $56.0(8.4)$ & $\mathrm{Ba}$ & $40.7(7.2)$ & $\mathrm{Ba}$ \\
\hline All Bond Universal & $65.0(7.1)$ & $\mathrm{Ba}$ & $27.6(4.2)$ & $\mathrm{Bb}$ \\
\hline
\end{tabular}

Means followed by different letters (lower case - row, upper case - column) differ among them by Tukey test at $95 \%$ confidence level.

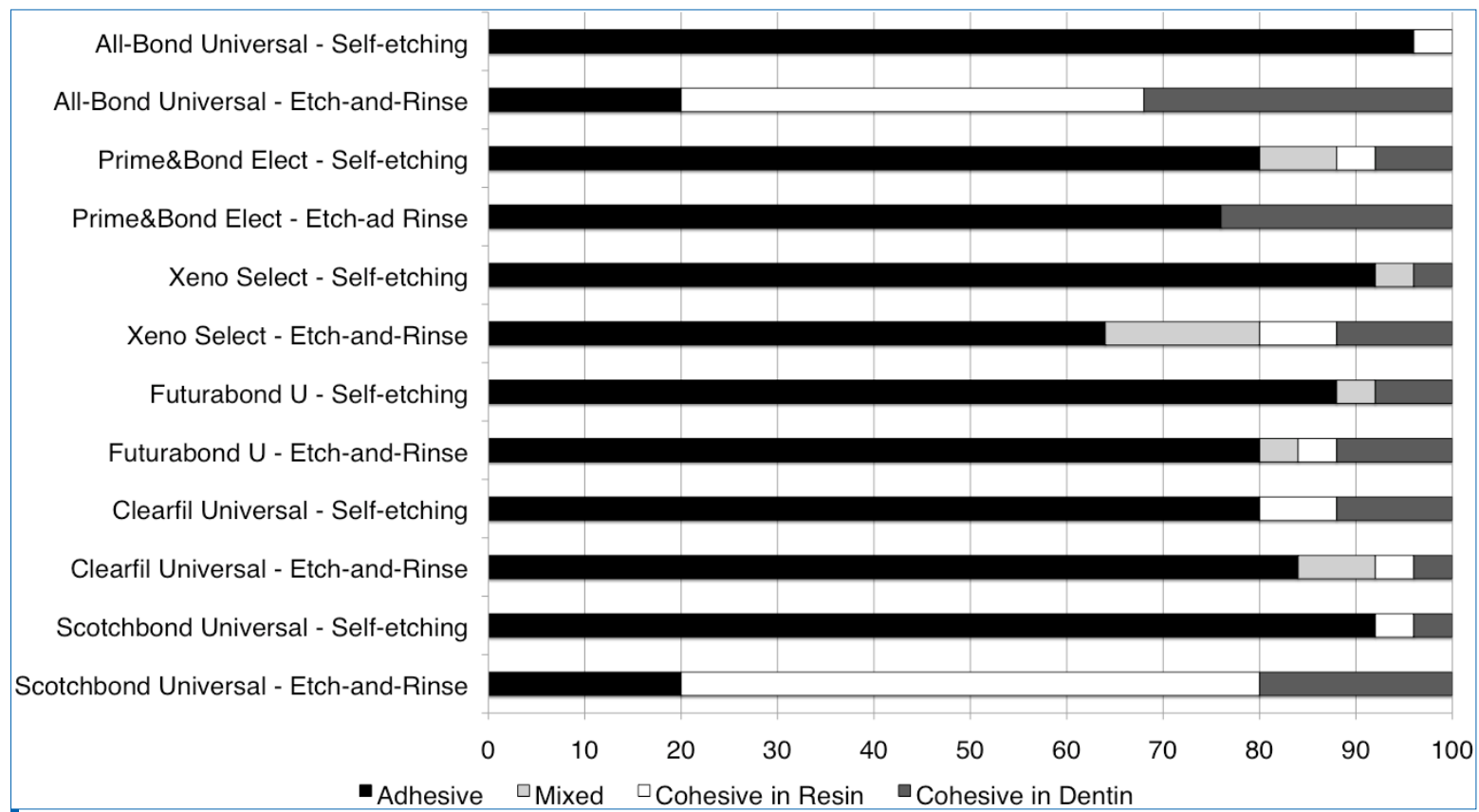

Figure 1. Distribution of failure modes for the different groups.

modes achieve equivalent bonding performance to dentin. Our null hypothesis was rejected, because for three of the tested universal adhesives, bond strength was significantly higher when the etchand-rinse approach was used.

The resin composition as well as the presence and type of fillers might play important roles in bonding effectiveness [17]. Each self-etch adhesive contains its specific functional monomer that, to a large extent, determines its actual adhesive performance [18]. The specific molecular formula of the functional monomer and the dissolution rate of its calcium salt are thought to influence bonding performance. The potential to chemically interact with interfacial hydroxyapatite might be helpful in the adhesion process. This interaction occurs with mild selfetching adhesives that partially demineralize the dentin surface. It has been shown that MDP (10-methacryloxydecyl dihydrogen phosphate) is effective in bonding to hydroxyapatite, and seems to be very stable. Three of the tested adhesives (Clearfil Universal, Scotchbond Universal and All Bond Universal) present MDP as functional monomer. While the components in these materials are similar, there may be differences in the quantities and proportions of water, solvent, MDP, and dimethacrylate resins among the adhesives. There is a possibility that such differences may influence viscosity and wettability of each bonding agent, affecting the ability of resin monomers to penetrate into decalcified dentin [16]. When used in the self-etching mode, these three MDP-containing universal adhesives presented bond strength values that were not significantly different from each other. However, when used on the etch-and-rinse mode, Scotchbond Universal presented significantly higher bond strengths.

More than a decade ago, when single step selfetching adhesives were first introduced to the market, they were not recommended for use in the etch-andrinse mode, because lower bonding performance to dentin was observed when phosphoric acid was used prior to adhesive application $[4,19,20]$. In the present investigation the immediate adhesive performance of the recently introduced universal adhesives was always significantly higher or not significantly different when used in the etch-and- 
rinse mode. Demonstrating that adjustments in the chemical formulation of single-step self-etching adhesives was made so they can also be used in the etch-and-rinse mode. It seems that the problem of the bonding mode incompatibility has been solved by manufacturers through blending less acidic resin monomers in the appropriately reduced concentrations with other resin monomers [21].

Three of the tested adhesives (Scotchbond Universal, Xeno Select and All Bond Universal) presented significantly lower bond strength values when used in the self-etching mode, in comparison with the etchand-rinse groups. This reduction probably occurs due to the higher $\mathrm{pH}$ of these adhesives, classified as ultra-mild systems, in comparison with the other products. The interaction depth with dentin depends on the $\mathrm{pH}$ of the adhesives [21]. Depending on the $\mathrm{pH}$, self-etch adhesives may be classified into ultramild ( $\mathrm{pH}>2.5,0.2-0.5 \mu \mathrm{m}$ interaction depth), mild ( $\mathrm{pH} \approx 2 ; 0.5-1 \mu \mathrm{m}$ interaction depth), intermediate $(\mathrm{pH}, 1-2 ; 1-2 \mu \mathrm{m}$ interaction depth), and strong $(\mathrm{pH}$ $<1,>5 \mu \mathrm{m}$ interaction depth, similar to etching with phosphoric acid) [22]. More aggressive self-etching systems present higher contents of acidic monomers and water, resulting in increased hydrophilicity, which will result in increased water sorption, and consequently, decreased hydrolytic stability [4]. In addition, continued etching along the base of hybrid layers after polymerization of those adhesives can occur [23]. Among the products tested, All Bond Universal presents the highest $\mathrm{pH}$, 3.2. Even though not significantly different, it also presented the lowest bond strength values when used in the self-etching mode. On a study by Chen et al. [21],TEM observations revealed that All Bond Universal presented the shallowest interaction with dentin when used in the self-etching mode, approximately $0.2 \mu \mathrm{m}$. On the other hand, when used in the self-etching mode, Futurabond $U$ presented the highest bond strength values. However, in recent reports on the long-term

\section{References}

1. Nakabayashi N, Kojima K, Masuhara E. The promotion of adhesion by the infiltration of monomers into tooth substrates. $J$ Biomed Mater Res. 1982;16(3):265-273.

[CrossRef] [PubMed] Google Scholar Scopus

2. Hashimoto $M$, Ohno $H$, Kaga $M$, et al. In vivo degradation of resin-dentin bonds in humans over 1 to 3 years. J Dent Res. 2000;79(6):1385-1391.

[Full text links] [CrossRef] [PubMed] Google Scholar Scopus

3. Sano $\mathrm{H}$, Yoshikawa T, Pereira PNR, et al. Long-term durability of dentin bonds made with a self-etching primer, in vivo. J Dent Res. 1999;78(4):906-911.

[Full text links] [CrossRef] [PubMed] Google Scholar Scopus

4. Nagarkar $\mathrm{S}$, Theis-Mahon $\mathrm{N}$, Perdigão J. Universal

dental adhesives: Current status, laboratory testing, and clinical performance. J Biomed Mater Res B Appl Biomater. 2019;107(6):2121-2131.

[Full text links] [CrossRef] [PubMed] Google Scholar Scopus 5. Feitosa VP, Sauro S, Zenobi W, et al. Degradation of adhesivedentin interfaces created using different bonding strategies after five-year simulated pulpal pressure. J Adhes Dent. 2019;21(3):199207.

[Full text links] [PubMed] Google Scholar Scopus

6. Reis AF, Giannini M, Pereira PN. Long-term TEM analysis of the performance of universal adhesives, Zhang et al. [10] and Chen et al. [21] reported remarkable decrease in bond strengths and nanoleakage with signs of water-treeing on resin dentin interfaces produced with Futurabond $U[21,10]$. In fact, all universal adhesives tested in the above-mentioned study of Zhang et al. [10], with the exception or Prime\&Bond Elect and Scotchbond Universal (applied in selfetching mode), presented significant reduction in bond strengths after 12 months of storage. Previous investigations are in accordance with the present study, which demonstrated similar or higher performance, clinically or in vitro, when universal adhesives are applied in the etch-and-rinse mode $[12,13,24]$. Even though the hybrid layer thickness is approximately 10 times thicker when used in the etch-and-rinse mode $(\approx 5 \mu \mathrm{m})$ in comparison with the self-etching approach $(\approx 0.5 \mu \mathrm{m})$, thicker hybrid layers formed in dentin substrates have been shown not to necessarily produce higher bond strengths [25].

\section{Conclusion}

According to the results of the present investigation, the immediate bonding performance of Universal Adhesives was similar or higher when they were used in the etch-and-rinse mode in comparison with the self-etching mode.

\section{Author Contributions}

AR: participated in the study design, statistical analy. PA and RK: participated in the microtensile bond strength test, and manuscript writing. sis and manuscript writing.

\section{Acknowledgments}

There is no conflict of interest for any of the authors of the paper. This research did not receive any specific grant from funding agencies in the public, commercial, or not for-profit sectors. nano leakage patterns in resin-dentin interfaces produced by different bonding strategies. Dent Mater.

2007;23(9):1164-1172.

[CrossRef] Google Scholar

7.Perdigão J, Sezinando A, Monteiro PC. Laboratory bonding ability of a multipurpose dentin adhesive. Am J Dent 2012:25(3):153-158. [PubMed] Google Scholar Scopus

8. Makishi $P$, André CB, Ayres APA, et al. Effect of storage time on bond strength and nanoleakage expression of universal adhesives bonded to dentin and etched enamel. Oper Dent. 41(3):305-317.

[Full text links] [CrossRef] [PubMed] Google Scholar Scopus

9. Rosa WLO, Piva E, Silva AF. Bond strength of universal adhesives: A systematic review and meta-analysis. J Dent. 2015:43(7):765776.

[Full text links] [PubMed] Google Scholar Scopus

10. Zhang Z, Tian F, Niu L, et al. Defying ageing: An expectation for dentine bonding with universal adhesives? J Dent. 2016;45:43-52 [Full text links] [CrossRef] [PubMed] Google Scholar

11. Hanabusa M, Mine A, Kuboki T, et al. Bonding effectiveness of a new 'multi-mode' adhesive to enamel and dentine. J Dent 2012;40(6):475-484

[Full text links] [CrossRef] [PubMed] Google Scholar Scopus

12. Muñoz MA, Luque I, Hass V, et al. Immediate bonding properties 
of universal adhesives to dentine. J Dent. 2013;41(5):404-411.

[Full text links] [CrossRef] [PubMed] Google Scholar Scopus

13. Wagner A, Wendler M, Petschelt A, et al. Bonding performance of universal adhesives in different etching modes. J Dent. 2014;42(7):800-807.

[Full text links] [CrossRef] [PubMed] Google Scholar Scopus

14. Munoz MA, Luque-Martinez I, Malaquias $P$, et al. In vitro longevity of bonding properties of universal adhesives to dentin Oper Dent. 2015;40(3):282-292.

[Full text links] [CrossRef] [PubMed] Google Scholar

15. McLean DE, Meyers EJ, Guillory VL, Vandewalle KS. Enamel bond strength of new universal adhesive bonding agents. Oper Dent. 2015;40(4):410-417.

[Full text links] [CrossRef] [PubMed] Google Scholar

16. Takamizawa T, Barkmeier WW, Tsujimoto A, et al. Influence of different etching modes on bond strength and fatigue strength to dentin using universal adhesive systems. Dent Mater. 2016;32(2):e9-e21.

[Full text links] [CrossRef] [PubMed] Google Scholar Scopus

17. Tay FR, Pashley DH, Yiu C, et al. Nanoleakage types and potential implications: evidence from unfilled and filled adhesives with the same resin composition. Am J Dent. 2004;17(3):182-190.

[PubMed] Google Scholar Scopus

18. Yoshida Y, Nagakane K, Fukuda R, et al. Comparative study on adhesive performance of functional monomers. J Dent Res. 2004;83(6):454-458.
[Full text links] [CrossRef] [PubMed] Google Scholar Scopus 19. Van Landuyt KL, Peumans M, De Munck J, et al. Extension of a one-step self-etch adhesive into a multi-step adhesive. Dent Mater. 2006;22(6):533-544.

[Full text links] [CrossRef] [PubMed] Google Scholar Scopus

20. Torii Y, Itou K, Nishitani Y, et al. Effect of phosphoric acid etching prior to self-etching primer application on adhesion of resin composite to enamel and dentin. Am J Dent. 2002;15(5):305-308. [PubMed] Google Scholar Scopus

21. Chen $C$, Niu LN, Xie H, et al. Bonding of universal adhesives to dentine--Old wine in new bottles? J Dent. 2015;43(5):525-536.

[Full text links] [CrossRef] [PubMed] Google Scholar

22. Van Meerbeek B, Yoshihara K, Yoshida Y, et al. State of the art of self-etch adhesives. Dent Mater. 2011;27(1):17-28.

[Full text links] [CrossRef] [PubMed] Google Scholar Scopus

23. Wang $Y$, Spencer P. Continuing etching of an all-in-one adhesive in wet dentin tubules. J Dent Res. 2005;84(4):350-354. [Full text links] [CrossRef] [PubMed] Google Scholar Scopus

24. Perdigão J, Kose C, Mena-Serrano AP, et al. A new universal simplified adhesive: 18-month clinical evaluation. Oper Dent. 2014;39(2):113-127.

[Full text links] [CrossRef] [PubMed] Google Scholar Scopus

25. Harada N, Yamada T, Inokoshi S, Tagami J. Tensile bond strengths and adhesive interfaces of ten dentin bonding systems. J Med Dent Sci. 1998:45(2):85-96.

[PubMed] Google Scholar Scopus

Andre Figueiredo REIS

DDS, MS, PhD, Clinical Associate Professor Department of Restorative Dental Sciences Division of Operative Dentistry

College of Dentistry, University of Florida

Gainesville, FL, USA

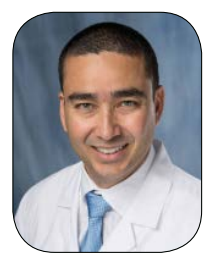

Dr. Andre Reis earned his dental degree in 1999 from the Campinas State University in Sao Paulo, Brazil. He got his Master's degree in Operative Dentistry in 2003 and PhD in 2005. From 2006 to 2018 he was actively involved in teaching and research at the Guarulhos University. Dr. Reis joined the University of Florida in 2018, as a Clinical Associate Professor in the division of Operative Dentistry.

Dr. Reis is the 2005 recipient of the Paffenbarger Award (Academy of Dental Materials), and 2006 recipient of the Hatton Award (IADR). He has presented numerowus lectures and hands-on seminars nationally and internationally. He has published over 70 articles on the study of Adhesive and Esthetic Dentistry materials and techniques. He is involved in patient care devoted to Restorative and Esthetic Dentistry. 


\section{Orestions}

\section{Universal adhesives can be applied in:}

口a. Self-etching mode;

ab. Etch-and-rinse mode;

ac. Selective etching mode;

$\square$ d. All the answers are correct.

\section{What are the advantages of using the self-etching mode when applied on deep dentin?}

$\square$ a. Lower post-operative sensitivity, due to maintenance of smear plugs and shallower demineralization in comparison with $35 \%$ phosphoric acid etching;

ab. Higher bond strengths;

c. Self-etching adhesives don't need to be light-cured;

ad. Better esthetics.

3. Depending on the $\mathrm{pH}$, self-etch adhesives may be classified into ultra-mild ( $\mathrm{pH}>\mathbf{2 . 5}, \mathbf{0 . 2}-0.5$ $\mu \mathrm{m}$ interaction depth), mild ( $\mathrm{pH} \approx 2 ; 0.5-1 \mu \mathrm{m}$ interaction depth), intermediate $(\mathrm{pH}, 1-2 ; 1-2$ $\mu \mathrm{m}$ interaction depth), and strong ( $\mathrm{pH}<1,>5 \mu \mathrm{m}$ interaction depth, similar to etching with phosphoric acid). About the adhesives/ $\mathrm{pH}$, it is correct to say that:

$\square$ a. Lower $\mathrm{pH}$ results in more aggressive demineralization;

b. Lower $\mathrm{pH}$ results in higher hydrophilicity;

ac. For ultra-mild and mild self-etching adhesives, enamel selective etching with phosphoric acid is recommended;

$\square$ d. All the answers are correct.

4. The potential to chemically interact with interfacial hydroxyapatite might be helpful in the adhesion process. This interaction occurs with mild self-etching adhesives that partially demineralize the dentin surface. It has been shown that MDP (10-methacryloxydecyl dihydrogen phosphate) is effective in bonding to hydroxyapatite, and seems to be very stable. It is correct to say that:

$\square$ a. All functional monomers are the same;

ab. The specific molecular formula of the functional monomer and the dissolution rate of its calcium salt are thought to influence bonding performance;

ac. MDP is the only functional monomer available in the market;

$\square d$. All Universal Adhesives present MDP in their composition.

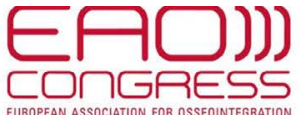

$28^{\text {th }}$ Annual Scientific Meeting of the European Association for Osseointegration 26-28 September

www.eao.org

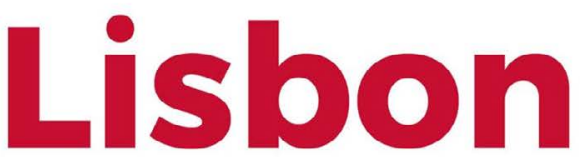

26-28 September 2019

The bridge to the future
In collaboration with

SOPIO SPERO

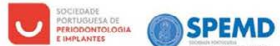

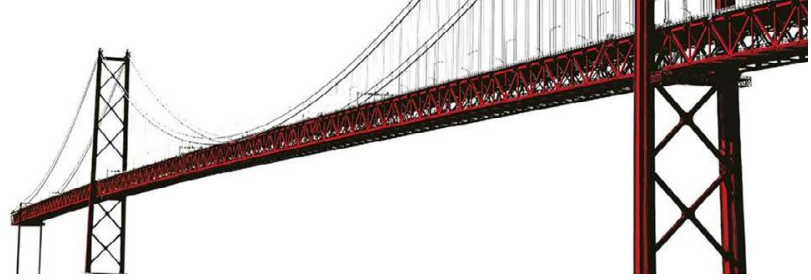




\title{
EFFECT OF PLATELET-RICH PLASMA ON CHRONIC ODONTOGENIC MAXILLARY SINUS- ITIS:A PILOTSTUDY
}

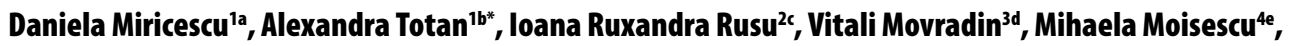

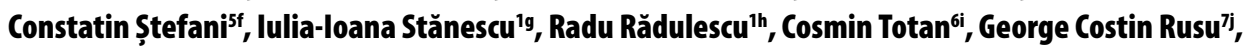 \\ Maria Greabu' ${ }^{\text {1k }}$ \\ 1. Department of Biochemistry, Faculty of Dental Medicine, "Carol Davila"University of Medicine and Pharmacy Bucharest, Bucharest, Romania \\ 2.Department of Anatomy and Embryology, Faculty of Medicine, "Carol Davila"University of Medicine and Pharmacy Bucharest, Bucharest, Romania \\ 3. Private Dental Practice, Bucharest \\ 4. Center for Excellence in Biophysics and Cellular Biotechnology Research, "Carol Davila” University of Medicine and Pharmacy \\ 5. Department of Family Medicine, Faculty of Medicine, "Carol Davila"University of Medicine and Pharmacy, Bucharest, Romania, "Carol Davila" University \\ Central Emergency Military Hospital, Bucharest, Romania \\ 6. Department of Oral Maxillofacial Surgery, Faculty of Dental Medicine, "Carol Davila” University of Medicine and Pharmacy Bucharest, Bucharest, Romania \\ 7. Department of Modern Languages, Faculty of Medicine, "Carol Davila"University of Medicine and Pharmacy Bucharest, Bucharest, Romania
}

aChem, MSc, PhD, Lecturer

${ }^{b} \mathrm{DMD}, \mathrm{PhD}$, Associate Professor

'DMD, PhD, Lecturer

'DMD

eDMD, PhD, Lecturer

'DMD, PhD, Lecturer

פDMD, PhD, Assistant Professor

"DMD, PhD, Assistant Professor

'DMD, PhD, Lecturer

iDMD, PhD, Lecturer

kDMD, PhD, Professor, Head

Introduction: Chronic odontogenic maxillary sinusitis (CMOS) is a frequent inflammatory process pertaining to the oro-maxilo-facial pathology. Platelet-rich plasma (PRP) is a natural source of growth factors, which have the potential to stimulate and accelerate the wound healing process.

The aim of this study is to observe the effects of the PRP growth factors in patients with CMOS.

Methodology: Inflammatory oral mucosa was collected from five patients diagnosed with CMOS, and it was incubated with $2 \mathrm{~mL}$ PRP for 7 days. PRP was obtained from venous blood collection from each patient. The control samples were represented by inflammatory sinus mucosa without adding PRP. The following biomarkers were measured using cell lysate: insulin receptor (IR) and insulin-like growth factor 1 receptor (IGF-1R), glycogen synthase kinase 3 beta (GSK3 $\beta)$, glycogen synthase kinase 3 alfa (GSK3a) performed by Multiplex technology.

Results: The results revealed statistically increased levels for all four parameters in patients with CMOS versus controls $(p<0.05)$. Growth factors from PRP bind to receptors with tyrosine kinase activity, cellular event being correlated with cell proliferation. The radiological control of patients 10 months after PRP administration revealed a decrease in the thickness of the sinus lining up to 3 times.

Conclusions: The growth factors released from platelets should be regarded as a positive effect source in the case of patients diagnosed with CMOS. These growth factors should activate the oligopotente stem cells which will finally lead to sinus mucosa regeneration. Future studies are needed to understand the molecular mechanisms that occur at the sinus level.

Keywords: Inflammation; Platelet-rich plasma (PRP); Sinusitis; Chronic odontogenic maxillary sinusitis (CMOS).

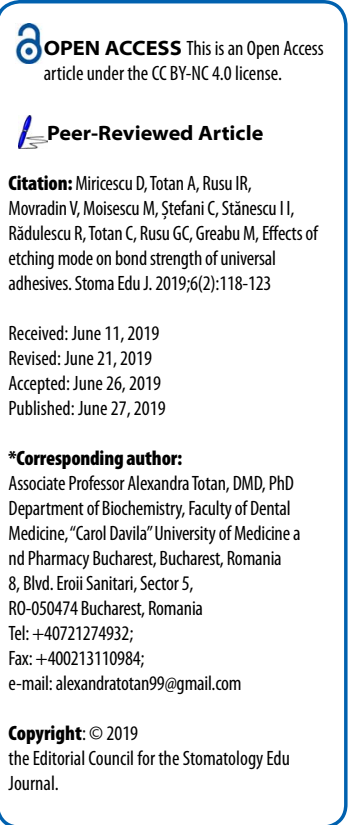




\section{Introduction}

CMOS is an inflammation of the maxillary sinus caused by dental infection. Patients with chronic periodontitis have an increased risk of developing maxillary sinusitis caused by intra-antral foreign bodies or by oroantral fistulas after tooth extraction $[1,2]$. According to the literature in the field, the incidence of this disease in the adult population is $10-12 \%$, but according to the latest studies, the incidence increased to $41 \%$ [3-5]. So far, there is no gold standard in choosing the most suitable treatment method for this inflammatory process. Until now, specialized literature suggests 3 main clinical methods to treat CMOS: the Caldwell-Luc operation, functional endoscopic sinus surgery and finally dental extraction or dental treatment. Using these surgical methods presents several disadvantages: bleeding, infraorbital nerve damage, facial swelling, pain, and significant hemorrhage may appear. These treatment methods require patient hospitalization and general anesthesia with possible complications [6,7]. Platelet-rich-plasma (PRP) is a natural source of growth factors being considered an endogenous therapeutic technology used in many medical fields. PRP has the potential to stimulate and accelerate the healing process $[8,9,14]$. The main aim of this pilot study was to observe the effects of PRPrelated growth factors in patients diagnosed with CMOS.

\section{Materials and Methods}

The pilot study included five patients (4 men and 1 woman aged 40-64) diagnosed with CMOS following a dental exam and computer tomography (CT) (Fig.1). PRP was obtained by venous blood collection in tubes containing separating gel with an inert polymer necessary to ensure the separation between

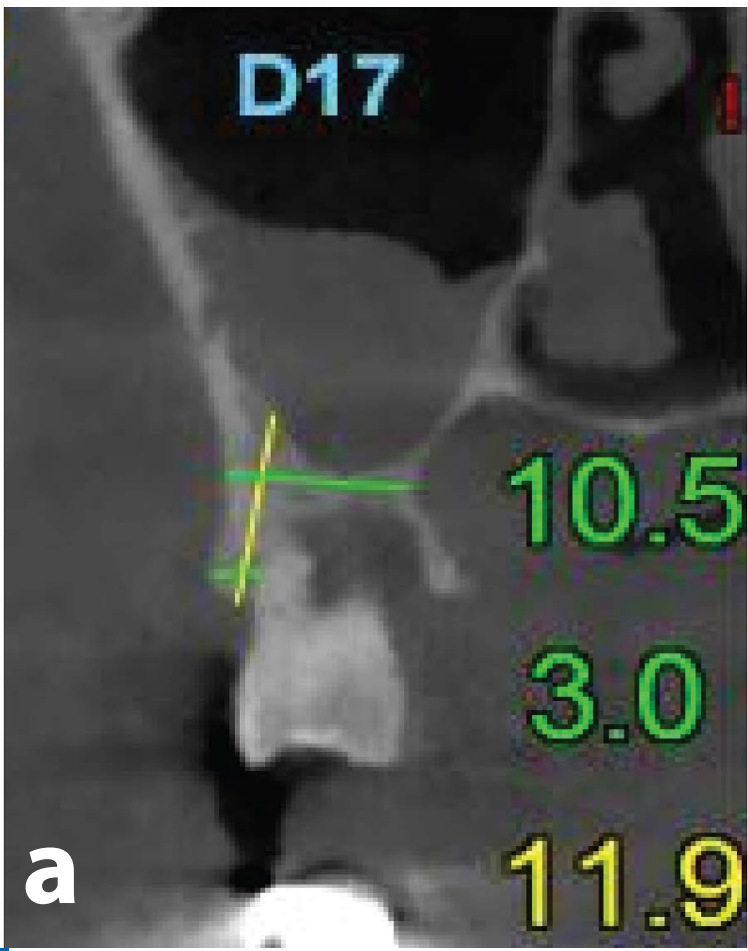

Figure 1. Computer tomography from a patient included in the study:

a. Coronal CT dental scan showing. Opacified right maxillary sinus - before PRP treatment;

b. Opacity of right maxillary sinus reduced after PRP intrasinusal infiltration(Used with permission of pacient) - after PRP treatment erythrocytes and platelers. Sodium citrate was used as anticoagulant to prevent the initiation of the coagulation cascade. The samples were centrifuged at $4000 \mathrm{rpm}$ for 5 minutes. Using the trepanation technique, inflammatory sinus mucosa was collected from the maxillary sinus in sterile tubes and was incubated with PRP for 7 days. PRP was injected in the inflammatory maxillary sinus PRP was injected in all patients based on a clinical chart.

Along with the clinical study, lab study was conducted in order to underline the PRP procedure on the mucus, to prove the effect of growth factors implied in the local healing process. The control samples were represented by the inflammatory mucosa that were not treated with PRP and were collected in sterile tubes containing phosphate-buffered aline solution (pH 7.2). The samples were sonicated on ice $(10 \mathrm{~min}$, Sonoplus HD 2070, BANDELIN electronic $\mathrm{GmbH}$ \& Co. KG, Berlin, Germany) and the lysate was stored at $-80^{\circ} \mathrm{C}$. All patients signed an informed consent and agreed to participate in the study. Insulin receptor (IR), insulin-like growth factor 1 receptor (IGF-1R) glycogen synthase kinase 3 beta (GSK3 $\beta$ ) and glycogen synthase kinase 3 alfa (GSK3a) were detected using Luminex technology and Magnetic Bead-Based Multiplex assays (Akt/mTOR, Total protein 11-plex Magnetic Bead kit, 96 well plate, 48-612 MAG). This method can detect all the mentioned biomarkers from the same sample.

\subsection{Statistical analysis}

The statistical analysis was performed using student $\mathrm{t}$-test and $\mathrm{p}$-value less then 0.05 was considered statistically significant.

\section{Results}

The results of our study reveled statistically increased levels of IR, IGF-1, GSK3 $\beta$ and GSK3a for mucosa samples treated with PRP compared with mucosa

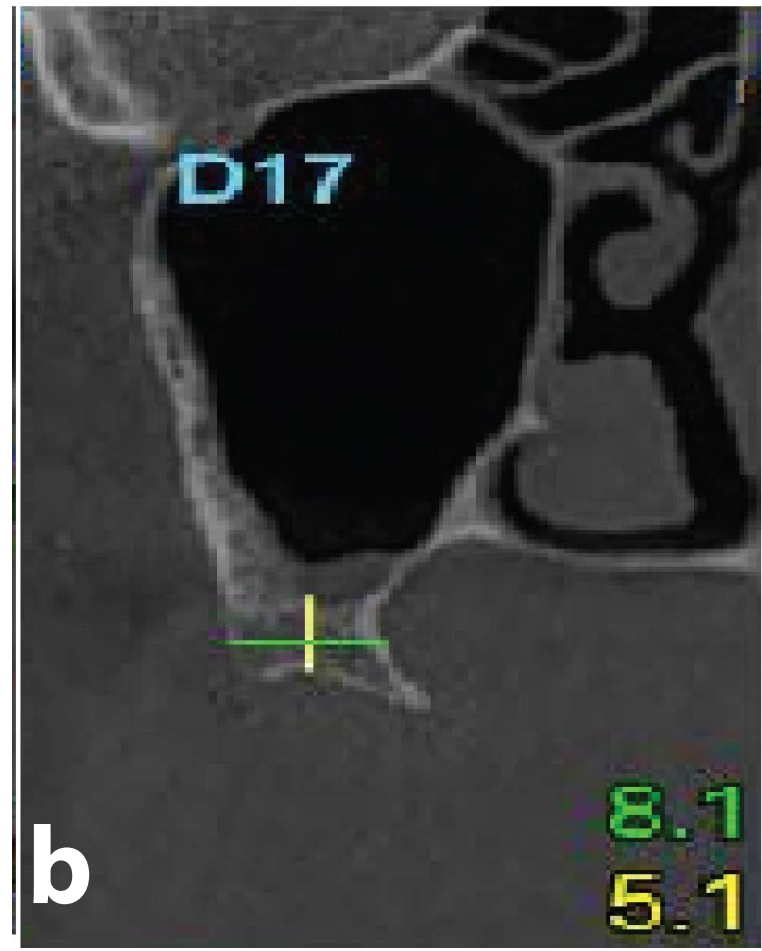


Table 1. Mean values for all four parameters detected.

\begin{tabular}{|c|c|c|c|}
\hline Parameters (MFI) & Patients & Controls & p \\
\hline IGF-1R & $142.33 \pm 16.7$ & $63.37 \pm 16.7$ & $<0.05$ \\
\hline IR & $204.5 \pm 8.23$ & $78.97 \pm 8.23$ & $<0.05$ \\
\hline GSK3 $\beta$ & $70.625 \pm 20.44$ & $30 \pm 20.44$ & $<0.05$ \\
\hline GSK3a & $111.75 \pm 43.12$ & $40.375 \pm 43.12$ & $<0.05$ \\
\hline
\end{tabular}

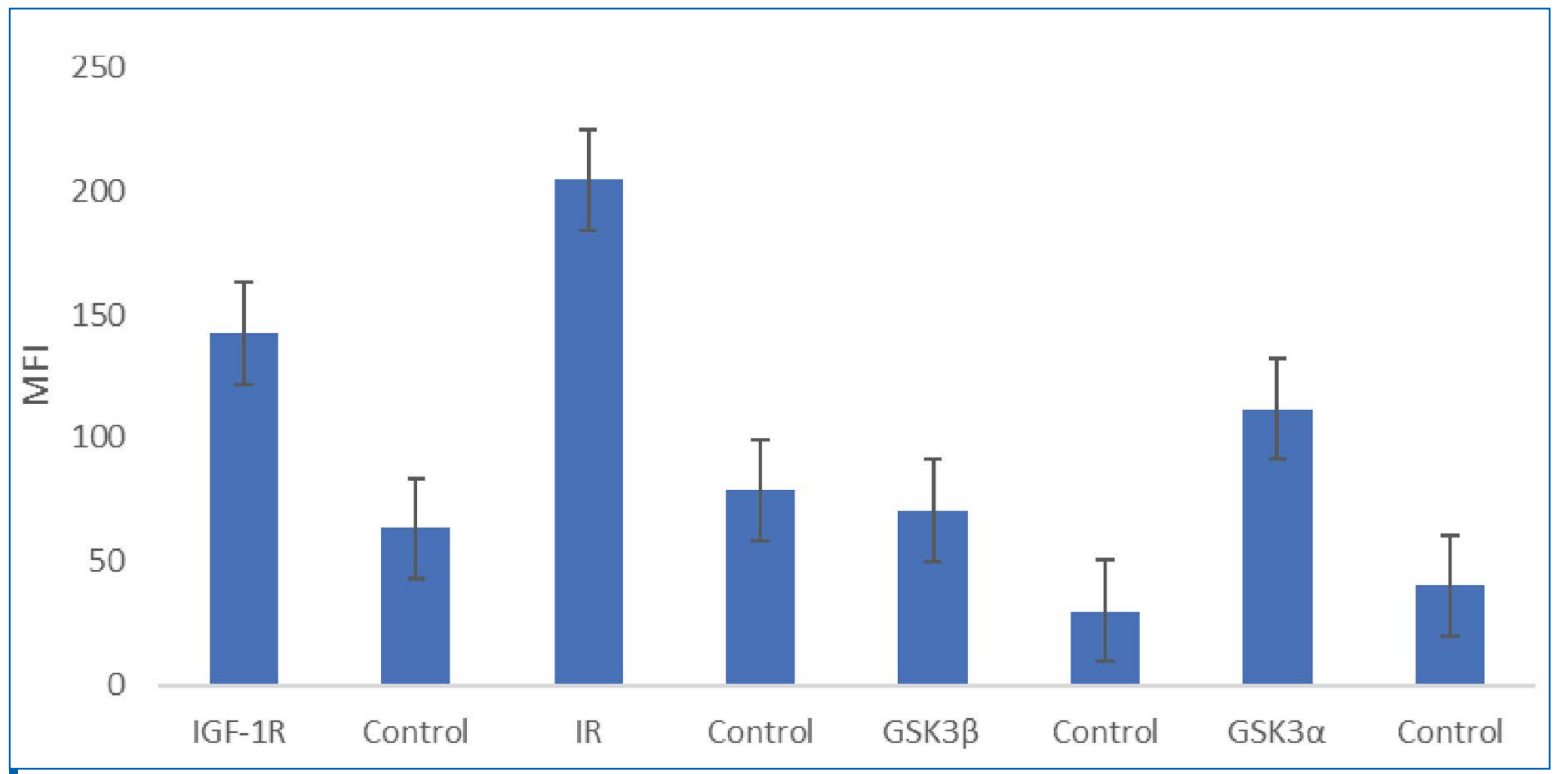

Figure 2. Graphic represenation of all 4 studied parameters versus their controls

samples that did not received PRP. Our results are presented in Table 1 and Fig. 2.

\section{Discussions}

PRP is currently used in many medical fields such as orthopedic, pediatric, maxillofacial and plastic surgery, sport medicine, and cosmetic and dental implant surgery [9-13]. FDA (Food and Drug Administration) has classified PRP as a minimally manipulated tissue and an autologous blood product with multiple benefits for patients [14]. Growth factors play key roles in the complex process of tissue healing and regeneration, being signaling proteins that influence the metabolism of other cells $[15,16]$. Transforming growth factor (TGF- $\beta$ ), platelet-derived growth factor (PDGF), vascular endothelial growth factor (VEGF), insulin-like growth factor-1 (IGF-1) and epidermal growth factor (EGF) are present in PRP [10-16]. PDGF is secreted by platelets, macrophages, keratinocytes, endothelial and muscle cells. PDGF is one of the growth factors that are secreted when an injury occurs, stimulating many metabolic processes such as protein and collagen synthesis. It also promotes the proliferation and migration of endothelial cells, exerting angiogenic effects, stimulates the production of TGF- $\beta$ that initiates collagen synthesis and stimulates the production of IGF-1. The positive effects of PDGF were seen in the treatment of the ulcerous foot in diabetic patients $[17,18]$. Platelets, macrophages, fibroblasts and mesenchimal stem cells secrete EGF, which is released at a high concentration at the beginning of the healing process. EGF plays important roles in the proliferation, differentiation, growth and migration of keratinocytes and epithelial cells $[14,15]$.

IGF is secreted by fibroblasts and is involved mainly in the inflammatory and proliferative phase II, 58, 72. Decreased IGF concentrations were observed in diabetic patients with chronic wounds. Clinical trials conducted on laboratory animals such as diabetic and healthy rats, or rabbits showed that the exogenous IGF application accelerates the healing process [16-18]. In combination with other growth factors such as PDGF and EGF, IGF exhibits much more powerful biological effects promoting keratinocyte migration and enhancing tissue repair [19-21]. VEGF is secreted by plateles, keratinocytes, macrophages and fibroblasts and manifests strong paracrine effects on endothelial cells, promotes and supports the process of wound angiogenesis. It is the main growth factor that initiates the angiogenesis process in granulation tissue [21,22]. VEGF growth factors are implicated in the physiological and pathological processes of vasculogenesis, angiogenesis, vascular 
permeability and lymhangiogenesis $[22,23]$.

Clinical and experimental studies conducted on diabetic mice and dogs, as well as diabetic patients reported very good results by applying VEGF, which accelerate healing by increasing epithelialization, angiogenesis and granulation tissue formation [2427]. Many cell types secrete TGF $\beta$ such as platelets, $T$ lymphocytes, macrophages, keratinocytes, fibroblasts, muscle and endothelial cells. TGF $\beta$ induces synthesis of collagen and fibronectin due to chemotactic effects on macrophages and inhibits the activity of metalloproteases [25]. IGF-1R, IR, GSK3a, GSK $3 \beta$, detected in our pilot study are part of the signaling cascade called Akt/mTOR or protein kinase B. This signaling pathway plays a central role in numerous cellular processes such as cell proliferation regulation, survival and glucose metabolism. Akt is activated by insulin, which presents the receptor with tyrosine kinase activity [28]. By binding the insulin to the extracellular domain of the receptor there occurs the autophosphorylation of the receptor that is recognized by the IRS (insulin receptor substrate), and further there is a series of cascade phosphorylates with Akt activation that will lead to cell growth and proliferation. Akt may be activated by many growth factors such as those found in PRP or cytokines [28]. The results of the current study reflect statistically significant increased levels for IGF$1 R, I R, G S K 3 a, G S K 3 \beta$ in the case of PRP-treated oral mucosa versus oral mucosa without PRP treatment. Growth factors from PRP bind to receptors with tyrosine kinase activity, such as the insulin receptor, actives Akt signaling pathway, promotes increase

\section{References}

1. Lima CO, Devito $\mathrm{KL}$, Vasconcelos LRB, et al. Correlation between endodontic infection and periodontal disease and their association with chronic sinusitis: A clinical-tomographic study. $J$ Endod. 2017:43(12):1978-1983.

[Full text links] [CrossRef] [PubMed] Google Scholar Scopus 2. Philipsen BB, Ghawsi S, Kjeldsen AD. Odontogenic sinusitis among patients surgically treated for maxillary sinus disease. Rhinology Online. 2018;1:60-66.

[CrossRef] Google Scholar

3. Vidal F, Coutinho TH, Ferreira DC, et al. Odontogenic sinusitis: a comprehensive review. Acta Odontol Scand 2017-75(8):623-633. [Full text links] [CrossRef] [PubMed] Google Scholar Scopus 4. Wang KL, Nichols BG, Poetker DM, et al. Odontogenic sinusitis: a case series studying diagnosis and management. Int Forum Allergy Rhinol. 2015;5(7):597-601.

[Full text links] [CrossRef] [PubMed] Google Scholar Scopus

5. Fadda GL, Berrone M, Crosetti $E$, et al. Monolateral sinonasal complications of dental disease or treatment : when does endoscopic endonasal surgery require an intraoral approach? Acta Otorhinolaryngol Ital. 2016;36(4):300-309.

Google Scholar Scopus

6. Workman AD, Granquist EJ, Adapp ND. Odontogenic sinusitis: developments in diagnosis, microbiology, and treatment. Curr Opin Otolaryngol Head Neck Surg. 2018;26(1):27-33.

[Full text links] [CrossRef] [PubMed] Google Scholar Scopus

7. Akhlaghi F, Esmaeelinejad M, Safai P. Etiologies and treatments of odontogenic maxillary sinusitis: A systematic review. Iran Red Crescent Med J. 2015:17(12):e25536.

[Full text links] [CrossRef] [PubMed] Google Scholar Scopus 8. Anitua, E, Alkhraisat MH, Orive G. Perspectives and challenges in regenerative medicine using plasma rich in growth factors. $J$ Control Release. 2012;157(1):29-38.

[Full text links] [CrossRef] [PubMed] Google Scholar Scopus 9. Agrawal AA. Evolution, current status and advances in application of platelet concentrate in periodontics and implantology. World J Clin Cases. 2017;5(5):159-171.

[Full text links] [CrossRef] [PubMed] Google Scholar in protein translation and cell growth. The results of the biochemical evaluations are correlated with the findings of CT performed at 10 months after the PRP injection, according to Fig. 1.

\section{Conclusions}

In conclusion, the growth factors released from platelets should be regarded as a positive effect source in the case of patients diagnosed with CMOS. These growth factors should activate the oligopotent stem cells which will finally lead to sinus mucosa regeneration. Future studies are needed to understand the molecular mechanisms that occur at the sinus level.

\section{Author Contributions}

All authors equally contributed to the present manuscript. DM: participated in sample analysis and manuscript writing; AT: participated in sample analysis and manuscript writing, IRR: participated in study design, data collection; VM: participated in the study design and sample collection, being the OMF surgeon to produce the clinical samples; MM: participated in sample analysis, CS: participated in manuscript writing; IIS: manuscript writing; RR: manuscript writing; CT: participated in manuscript writing; GCR: translation of the text, proposing and managing the whole work; MG: participated in critical review of the manuscript.

\section{Acknowledgments}

This work was proposed and managed by The Hospitallers Knights' Club - Knights of Malta.

10. Hussain $\mathrm{N}$, Johal $\mathrm{H}$, Bhandari $\mathrm{M}$. An evidence-based evaluation on the use of platelet rich plasma in orthopedics-A review of the literature. SICOT J. 2017;3:57.

[Full text links] [CrossRef] [PubMed] Google Scholar

11. Salarinia R, Sadeghnia HR, Alamdari $\mathrm{DH}$, et al. Platelet rich plasma: Effective treatment for repairing of spinal cord injury in rat. Acta Orthop Traumatol Turc. 2017;51(3):254-257.

[Full text links] [Free PMC Article] [CrossRef] [PubMed] Google Scholar Scopus

12. Ahmed M, Reffat SA, Hassan A, et al. Platelet-rich plasma for the treatment of clean diabetic foot ulcers. Ann Vasc Surg. 2017;38:206-211.

[Full text links] [CrossRef] [PubMed] Google Scholar Scopus 13. Ronci C, Ferraro AS, Lanti A, et al. Platelet-rich plasma as treatment for persistent ocular epithelial defects. Transfus Apher Sci. 2015;52(3):300-304

[Full text links] [CrossRef] [PubMed] Google Scholar Scopus

14. Chahla J, Cinque ME, Piuzzi NS, et al. A call for standardization in platelet-rich plasma preparation protocols and composition reporting: A systematic review of the clinical orthopaedic literature. J Bone Joint Surg Am. 2017;99(20):1769-1779.

[Full text links] [CrossRef] [PubMed] Google Scholar Scopus 15. Qian Y, Han O, Chen W, et al. Platelet-rich plasma derived growth factors contribute to stem cell differentiation in musculoskeletal regeneration. Front Chem. 2017:5(89):1-8.

[Full text links] [Free PMC Article] [CrossRef] [PubMed] Google Scholar

16. Tsai $H C$, Chang GL, Fan $H C$, et al. A mini-pig model for evaluating the efficacy of autologous platelet patches on induced acute full thickness wound healing. BMC Vet Res. 2019;15(1):191. [Full text links] [Free PMC Article] [CrossRef] [PubMed] Google Scholar Scopus

17. Zubair M, Ahmad J. Role of growth factors and cytokines in diabetic foot ulcer healing: A detailed review. Rev Endocr Metab Disord. 2019;20(2):207-217.

[Full text links] [CrossRef] [PubMed] Google Scholar Scopus 
18. Botusan IR, Zheng X, Narayanan S, et al. Deficiency of liverderived insulin-like growth factor-I (IGF-I) does not interfere with the skin wound healing rate. PLoS One. 2018;13(3):e0193084. [CrossRef] Google Scholar

19. Cieszkowski J, Warzecha Z, Ceranowicz P, et al. Therapeutic effect of exogenous ghrelin in the healing of gingival ulcers is mediated by the release of endogenous growth hormone and insulin-like growth factor-1. J Physiol Pharmacol. 2017;68(4):609617.

[Full text links] [PubMed] Google Scholar Scopus

20. Bai $Y, X u R$, Zhang $X$, et al. Differential role of rapamycin in epidermis-induced IL-15-IGF-1 secretion via activation of Akt/ mTORC2. Cell Physiol Biochem 2017;42(5):1755-1768.

[Full text links] [CrossRef] [PubMed] Google Scholar Scopus

21. Mayo $T$, Conget $P$, Becerra-Bayona $S$, et al. The role of bone marrow mesenchymal stromal cell derivatives in skin wound healing in diabetic mice. PLoS One. 2017;12(6):e0177533.

[Full text links] [CrossRef] [PubMed] Google Scholar Scopus 22. Ong HT, Dilley RJ. Novel non-angiogenic role for mesenchymal stem cell-derived vascular endothelial growth factor on keratinocytes during wound healing. Cytokine Growth Factor Rev. 2018:44:69-79.

[Full text links] [CrossRef] [PubMed] Google Scholar Scopus 23. Robering JW, Weigand A, Pfuhlmann R, et al. Mesenchymal stem cells promote lymphangiogenic properties of lymphatic endothelial cells. J Cell Mol Med. 2018;22(8):3740-3750.
[Full text links] [Free PMC Article] [CrossRef] [PubMed] Google Scholar Scopus

24. Mansoub NH, Gürdal M, Karadadaș E, et al. The role of PRP and adipose tissue-derived keratinocytes on burn wound healing in diabetic rats. Bioimpacts. 2018;8(1):5-12.

[Full text links] [CrossRef] [PubMed] Google Scholar Scopus

25. Karayannopoulou M, Papazoglou LG, Loukopoulos $P$, et al. Locally injected autologous platelet-rich plasma enhanced tissue perfusion and improved survival of long subdermal plexus skin flaps in dogs. Vet Comp Orthop Traumatol. 2014;27(5):379-386.

[CrossRef] Google Scholar Scopus

26. Ding $Q$, Sun $P$, Zhou H, et al. Lack of endogenous parathyroid hormone delays fracture healing by inhibiting vascular endothelial growth factor-mediated angiogenesis. Int $\mathrm{J} \mathrm{Mol} \mathrm{Med.}$ 2018:42(1):171-181.

[CrossRef] Google Scholar Scopus

27. Chen Z, Fu S, Wu Z, et al. Relationship between plasma angiogenic growth factors and diabetic foot ulcers. Clin Chim Acta. 2018:482:95-100.

[Full text links] [CrossRef] [PubMed] Google Scholar Scopus

28. Yu JSL, Cui W. Proliferation, survival and metabolism: the role of PI3K/AKT/mTOR signalling in pluripotency and cell fate determination. Development. 2016;143(17):3050-3060.

[Full text links] [CrossRef] [PubMed] Google Scholar Scopus

\section{Daniela MIRICESCU \\ Chem, MSc, PhD, Lecturer Department of Biochemistry \\ Faculty of Dental Medicine „Carol Davila" University of Medicine and Pharmacy Bucharest Bucharest, Romania

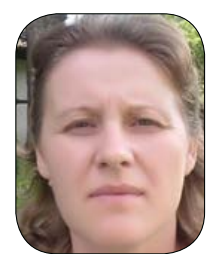

Daniela Miricescu graduated from the Faculty of Chemistry (Biochemistry Department) in 2006, in 2008 she obtained her Master's of Biochemistry and Molecular Biology (Biology Faculty) and in 2012 she obtained her PhD from the "Carol Davila" University of Medicine and Pharmacy Bucharest, Romania.

Since 2016 she has been a lecturer at Department of Biochemistry, Faculty of Dental Medicine „,Carol Davila” University of Medicine and Pharmacy Bucharest.

Her research field includes salivary studies on oxidative stress in various oral pathologies, the effects of obesity on laboratory animals, the effects of PLGA nanoparticles both in vivo and in vitro, the effects of plasma-rich plasma in patients diagnosed with chronic maxillary sinusitis, and the study of Akt (protein kinase B) signaling pathways in health and disease. 


\section{Ouestions}

\section{PRP is:}

Da. Natural source of growth factors

ab. Natural source of proinflammatory agents

ac. Natural source of antiinflammatory agents

ad. Natural source of stem cells

\section{PRP may be used in:}
Da. Ortopedic surgery
ab. Dental implant surgery
ac. Plastic surgery
ad. Cosmetic

\section{IGF:}

$\square$ a. Is secreted by fibroblasts

ab. Is involved in proliferative phase

D. Promotes keratinocytes migration

ad. Promotes tissue repair

\section{Akt (protein kinase B) is implicated in:}

口a. Cell proliferation

ab. Glucose metabolism

ac. Celular survival

ad. Necrosis

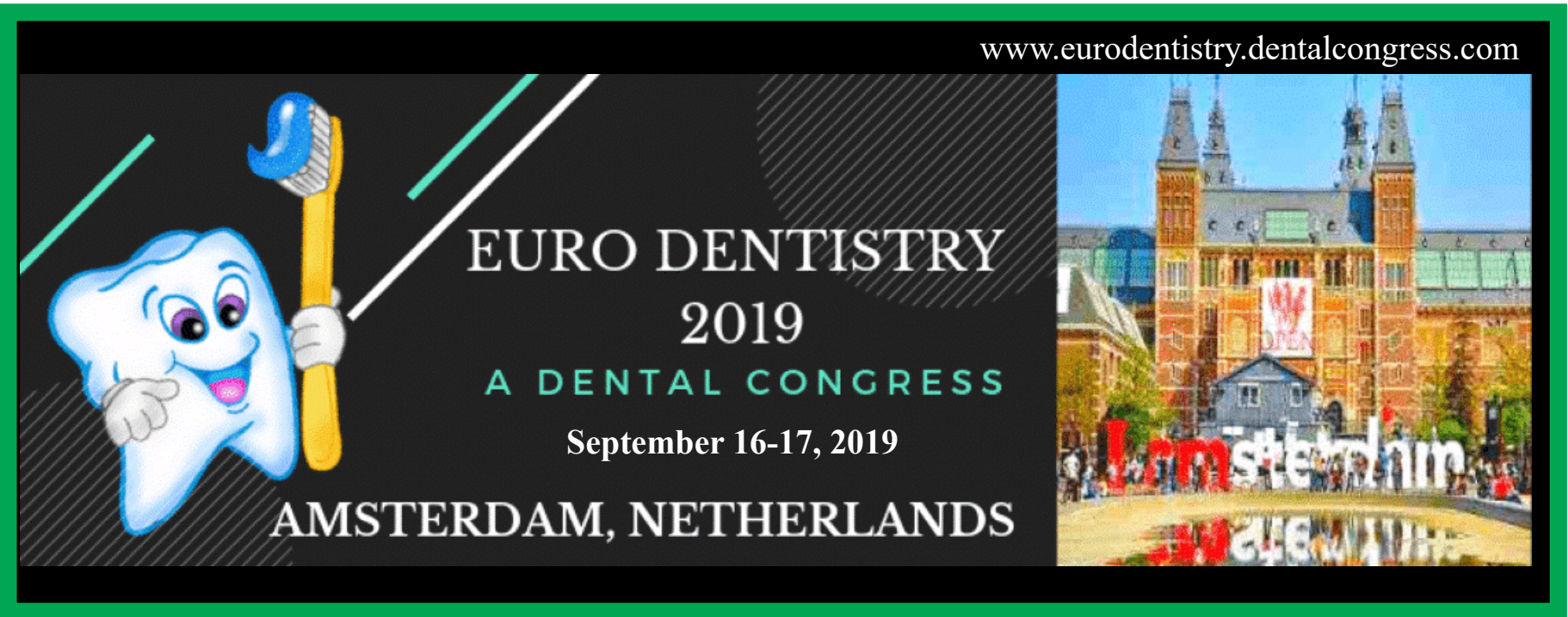





\title{
ROOT TIP MIGRATION INTO THE INFUNDIBULUM OF THE MAXILLARY SINUS AFTER COMPLICATED FIRST MOLAR EXTRACTION
}

\author{
Isabel Miclotte ${ }^{1,2 a}{ }^{(\mathbb{D})}$ Laurence Verstraete $^{1,2 a}{ }^{(\mathbb{D})}$, Constantinus Politis ${ }^{1,2 b}$ \\ 1OMFS-IMPATH Research Group, Department of Imaging and Pathology, KU Leuven, Leuven, Belgium \\ 2Department of Oral and Maxillofacial Surgery, University Hospitals Leuven, Leuven, Belgium
}

${ }^{\mathrm{a} M D, D D S}$

${ }^{b} M D, D D S$, MHA, MM, PhD, Professor, Head

Aim: To show how an unsuccessful retrieval attempt of a broken root tip of an upper molar could lead to dislocation into the maxillary sinus and and end up at the ostium of the maxillary sinus, necessitating a FESS procedure for retrieval.

Summary: An upper right first molar was removed with forcesp extraction. The extraction was complicated with a root fracture. Manipulating the residual root tip resulted in root tip dislocation into the maxillary sinus. It was decided to leave the root tip at the bottom of the sinus, but in the following months the root tip migrated and got stuck into the ostium of the maxillary sinus. There, it was retrieved using functional endoscopic sinus surgery (FESS).

Key Learning Points: 1. Manipulating a residual root tip after forceps extraction of an upper molar significantly increases the risk of root tip dislocation into the maxillary sinus. 2. Broken root tips of upper molar roots protruding into the maxillary sinus need not to be removed when it concerns healthy vital pulps. 3. Retrieval attempts of broken root tips can lead to dislocation of the root tip into the maxillary sinus if the roots were protruding into the maxillary sinus or if an insufficient bony barrier separates the maxillary sinus from the alveolar socket. 4 . Cone beam ct is the radiological exam of preference to locate a dislocated root tip in the upper jaw. 5. A root tip stuck at the ostium of the maxillary sinus is best removed with a FESS-procedure.

Keywords: Tooth extraction; Root tip fracture; Functional endoscopic sinus sugery.

\begin{tabular}{l} 
OPEN ACCESS This is an \\
Open Access article under the CC \\
BY-NC 4.0 license. \\
CPeer-Reviewed Article \\
Citation: Miclotte I,Verstraete L, \\
Politis C. Root tip migration into the \\
infundibulum of the maxillary sinus after \\
complicated first molar extraction Stoma \\
Edu J.2019;6(2):125-128 \\
Received: May 06, 2019 \\
Revised: May 22, 2019 \\
Accepted: June 14, 2019 \\
Published: June 18, 2019 \\
*Corresponding author: \\
Prof. Dr. Constantinus Politis \\
Department of Oral and Maxillofacial \\
Surgery, University Hospitals Leuven, \\
Leuven, Belgium \\
Kapucijnenvoer 33, 3000 Leuven, \\
Belgium \\
Tel: / Fax: 0032 (0)163332462, \\
e-mail: constantinus.politis@uzleuven.be \\
Copyright: @ 2019 \\
the Editorial Council for the \\
Stomatology Edu Journal. \\
\hline
\end{tabular}

\section{Introduction}

Extraction of maxillary molars with multiple and separated roots carries a risk of root fracture. Moreover, fractured roots can be displaced into the maxillary sinus, potentially causing oroantral fistula, sinusitis, cellulitis, and subdural empyema [1]. Root displacement into the maxillary sinus can be detected by imaging, which also provides information regarding the root size and location within the sinus.

Some studies suggest that displaced root fragments should be left in the sinus. However, due to the potential development of complications, surgical removal of displaced root tips should always be considered. There are three major methods of removing root tips displaced into the maxillary sinus: a crestal approach, a bone window approach, and a more recently described endoscopic approach [2]. Here we report the case of a displaced root fragment from a first upper molar on the right side, which was located using cone-beam $C T$ imaging (CBCT). Applying an endoscopic approach, the fragment was removed six months after the extraction, after mucosal healing, and in the absence of sinusitis.

\section{Case history}

A 14-year-old female was referred by the orthodontic department for extraction of the four first molars (16, 26, 36, and 46) for orthodontic reasons (Fig. 1). Due to the presence of deep restorations, it was decided to remove the first molars rather than remove four premolars. The deep restorations on teeth 46 and 36 were visible on a panoramic radiograph (Fig. 2). CBCT

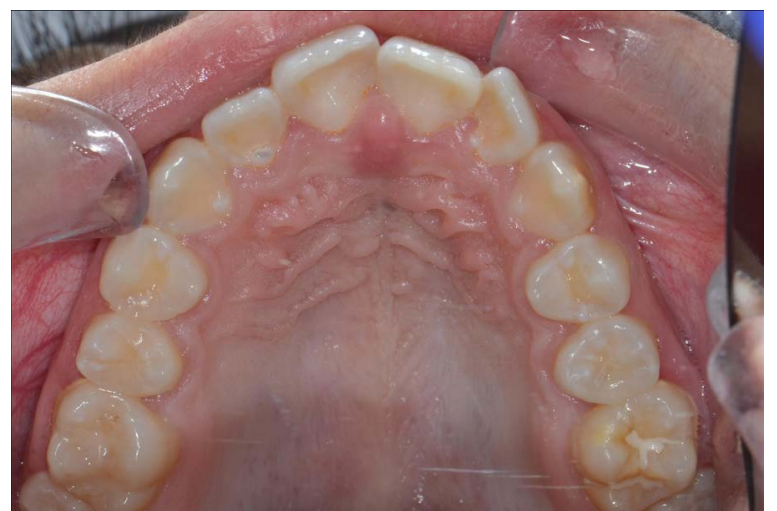

Figure 1. Intra-oral picture of the upper teeth, showing a restored first upper right molar. 


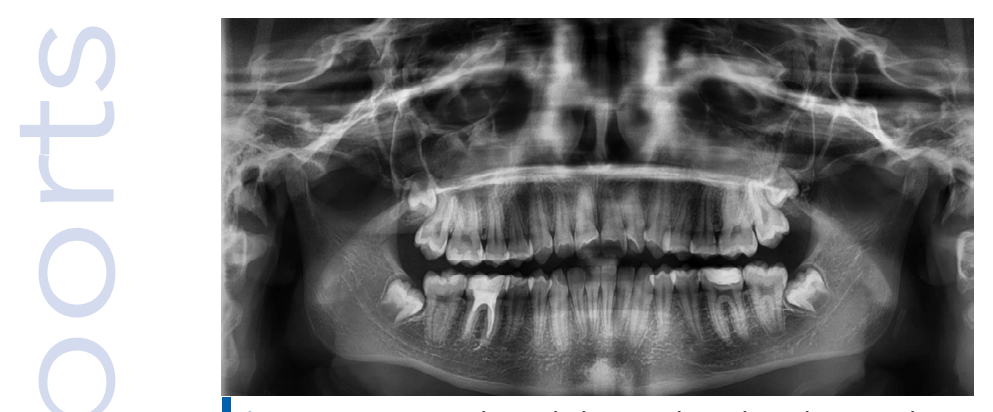

Figure 2. Panoramic radiograph showing close relation between the upper molars and the maxillary sinus.

was not performed prior to extraction. The molars were removed using forceps extraction under local anesthesia, one at a time, in four sessions. The local anesthetic used was articaine $4 \%$ with 1:200,000 epinephrine (Septodont, France). The extractions of elements 26, 46, and 36 were uneventful. However, upon forceps extraction of element 16, the distovestibular root tip was fractured. Efforts were made to remove the displaced root tip using an apical pick instrument, and then with root tip removal forceps. However, the root tip disappeared cranially and could not be retrieved. The root tip was not detected by transalveolar endoscopy or apical X-ray (Fig. 3). CBCT was immediately performed, which revealed the root tip at the base of the maxillary sinus (Fig. 4). This position suggested perforation of the sinus membrane; therefore, the alveolus was filled with four leukocyte-rich and platelet-rich fibrin (L-PRF) membranes. It was decided not to make another immediate attempt to remove the lost root tip, but rather to observe the situation and to reevaluate after four months. Healing was uneventful. Four months later, a new CBCT revealed that the displaced root tip had migrated towards the ostium of the right maxillary sinus (Fig. 5). Despite this position, the maxillary sinus showed no opacification, no mucosal thickening was visualized on CBCT, and the patients were asymptomatic. Two months later, a new CBCT was performed, showing the root tip at the same position. It was then decided to remove the root tip to prevent future complications. Believing that a Caldwell-Luc approach would be too traumatic, a functional endoscopic sinus surgery (FESS) procedure was proposed. The FESS procedure was performed under general anesthesia at the ear, nose, and throat (ENT) department. The root tip was retrieved. Further healing was uneventful. After healing of the four extraction wounds with an uneventful course, orthodontic therapy was immediately restarted.

\section{Discussion}

Dental extractions are a common oral procedure performed in dental and maxillofacial departments. The upper molar removal is sometimes accompanied by root fracture or oro-antral communication. In a series of 2355 dental extractions, the incidence of oro-antral communication was $0.56 \%$ after $\mathrm{M} 3$

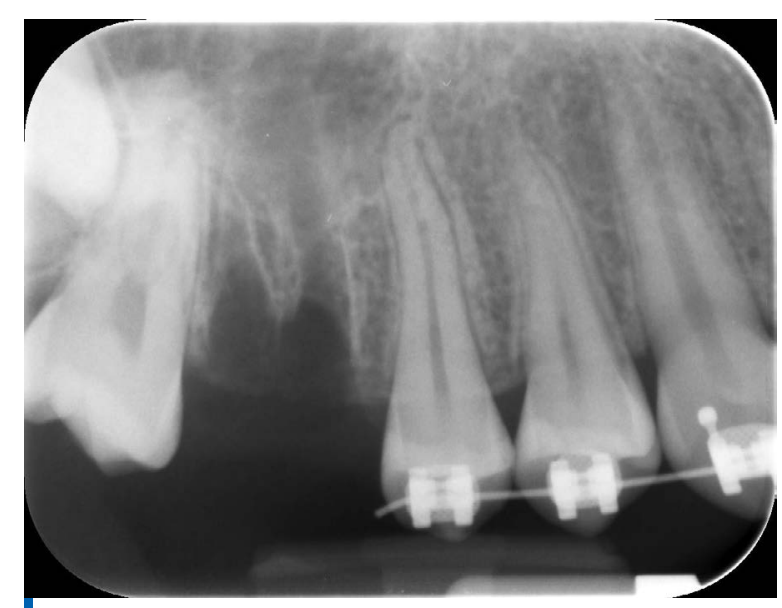

Figure 3. Intra-oral picture of the upper teeth, showing a restored first upper right molar.

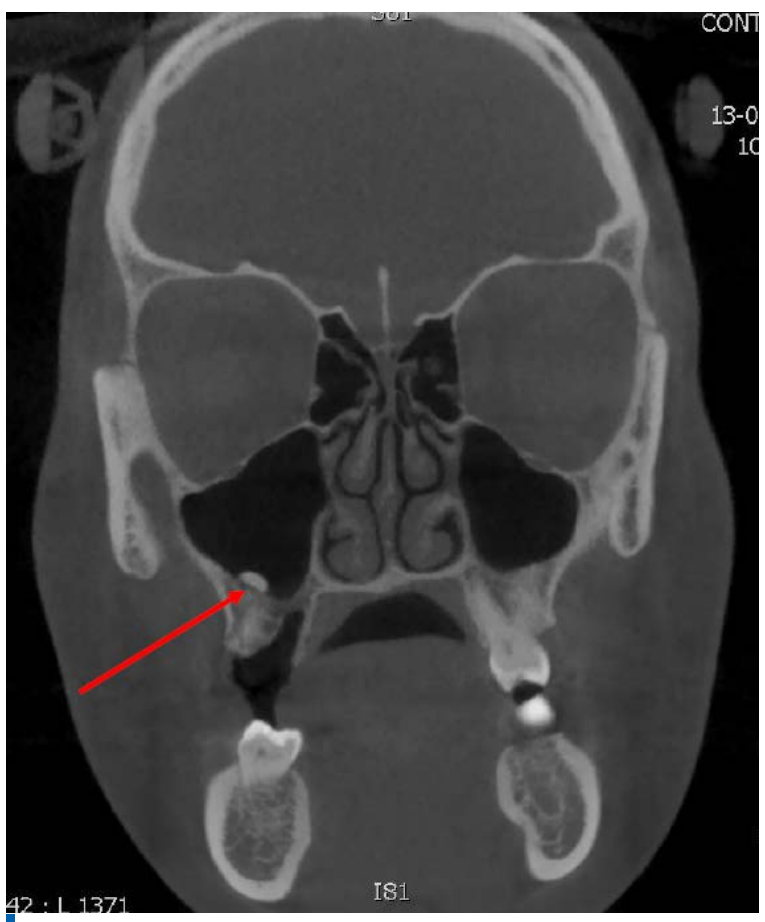

Figure 4. Panoramic radiograph showing close relation between the upper molars and the maxillary sinus.

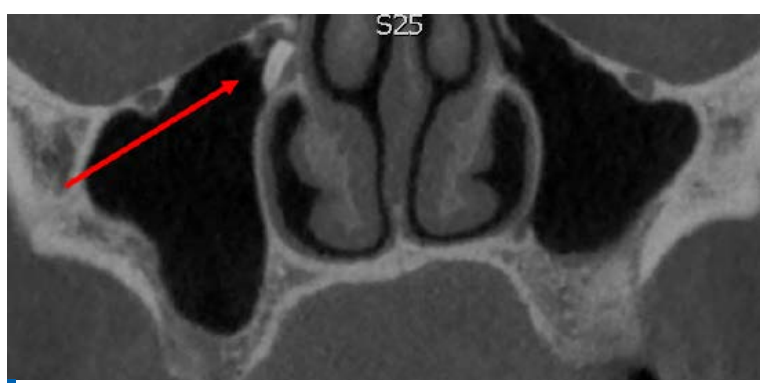

Figure 5. Intra-oral picture of the upper teeth, showing a restored first upper right molar.

extractions and $0.94 \%$ after non-M3 extractions [3]. Rarely, a fractured root migrates into the maxillary sinus. Such displacement depends on several factors, including the surgical technique (elevating roots with excessive force) and the bony interface between the alveolar socket and the sinus membrane. In a series of 1596 maxillary third molar extractions, only one case of tooth or root fragment displacement into 
the maxillary sinus was reported [4]. In another large series, no root tip migration was reported [3].

When a displaced root fragment is detected before alveolar socket healing, a crestal approach can be attempted to remove the fragment. This method involves enlargement of the socket to visualize the fragment or to rinse the maxillary sinus with saline. The disadvantages of this technique include damage to the alveolar bone, which may negatively influence the healing procedure and the residual bone height [2]. Some studies suggest leaving the root fragment in the sinus if it is below $3 \mathrm{~mm}$ in size, and if there is no evidence of sinusitis or other local disease [1]. When a displaced root fragment is diagnosed after mucosal healing, fragment retrieval can be performed using a bone window approach or an endoscopic approach. The traditional method is a Caldwell-Luc (bone window) approach in which fenestration of the anterior wall of the maxillary sinus provides a clear vision and improves the surgical range. However, this procedure is associated with complications, such as severe reactive swelling and nerve damage [2].

Alternatively, endoscopically-assisted procedures are reliable and minimally invasive methods for removing root fragments displaced into the maxillary sinus. Access for an endoscopic procedure can be obtained through the anterior maxillary sinus wall, or through the middle or inferior nasal meatus (FESS) [2]. This technique provides direct visibility of the surgical area and minimal risks of bleeding

\section{References}

1. Huang IY, Chen CM, Chuang FH. Caldwell-Luc procedure for retrieval of displaced root in the maxillary sinus. Oral Surg Oral Med Oral Pathol Oral Radiol Endod. 2011;112(6):e59-e63. [Full text links] [CrossRef] [PubMed] Google Scholar Scopus

2. Wang X, Li S. Removal of the residual roots displaced into the maxillary sinus via endoscopy. J Craniofac Surg. 2018;29(4):10341036.

[Full text links] [CrossRef] [PubMed] Google Scholar Scopus

3. Miclotte I, Agbaje JO, Spaey Y, et al. Incidence and treatment of complications in patients who had third molars or other teeth extracted. Br J Oral Maxillofac Surg. 2018;56(5):388-393.

[Full text links] [CrossRef] [PubMed] Google Scholar Scopus and nerve injury. However, endoscopic procedures require general anesthesia and their success depends on the operator experience.

In the presently reported case, immediate retrieval of the root tip displaced in the maxillary sinus was attempted, but without success. Although the fragment was large, immediate performance of a Caldwell-Luc procedure was considered too invasive in this young patient. After six months of follow-up with repeated CBCT imaging, it was deemed necessary to remove the fragment to avoid future complications. Instead of the Caldwell-Luc procedure, the less invasive FESS approach was performed, with a successful outcome.

\section{Conclusions}

Manipulating a residual root tip after forceps extraction of an upper molar-when little bony interface exists between the alveolar socket and the sinus membrane-significantly increases the risk of root tip dislocation into the maxillary sinus. Migration towards the ostium of the maxillary sinus is rare but possible. A FESS procedure is an efficient approach to retrieving the root tip from the maxillary sinus ostium, while keeping sinus function intact.

\section{Author contributions}

All authors contributed to reporting the case, performing the literature review, and drafting the manuscript.

4. Rothamel D, Wahl G, d'Hoedt B, et al. Incidence and predictive factors for perforation of the maxillary antrum in operations to remove upper wisdom teeth: prospective multicentre study. $\mathrm{Br}$ J Oral Maxillofac Surg. 2007;45(5):387-391.

[Full text links] [CrossRef] [PubMed] Google Scholar Scopus

\section{Isabel MICLOTTE

MD, DDS
OMFS-IMPATH Research Group
Leuven, Belgium
Leurtment of Imaging and Pathology, KU Leuven

Dr. Isabel Miclotte was born in 1986 and was recognised as an OMFS surgeon in 2019. She will become senior resident of the department of Oral and Maxillo Facial Surgery at Leuven University Hospitals as of November 2019. Dr. Miclotte has published on complications of extractions and has elaborated guidelines for dento-alveolar surgery in patients under anticoagulant therapy. Her clinical focus is in orthodontic and orthognathic surgery. 


\section{Questions}

1. Which is the best radiographic exam to find a dislocated roottip of an upper molar tooth?

口a. Apical radiograph;

b. Panoramic radiograph;

口c. MRI;

$\square$ d. Cone-beam CT scan.

2. Which root is most often involved in an oro-antral communication?

口a. Third molar;

ab. Second molar;

ac. First molar;

ad. First premolar.

3. Which is the best technique to retrieve a dislocated root tip of an upper molar tooth at the ostium of the maxillary sinus?

$\square$ a. Denker technique;

b. Caldwell Luc technique;

ac. FESS technique;

ad. Rehrmann flap.

4. Which precaution could be taken to avoid dislocation of a root tip into the maxillary sinus?

$\square$ a. Leaving a broken roottip undistrubed;

$\square$ b. Frequent peroperative repeats of the Valsalva manoeuver;

uc. Performing the extraction in a supine position;

ud. Performing the extraction under general anaesthesia. 


\title{
LARGE ODONTOGENIC KERATOCYST OF THE MANDIBLE: A COMBINED INTRA/EXTRA ORALAPPROACH FOLLOWED BY ENUCLEATION
}

\author{
Maximilien Vercruysse $^{1 a^{*}}$ (D) ,Patricia D'Haeseleire ${ }^{2 b}$, Sidney Kunz $^{2 b}$, Bart Lutin $^{3 c}$ (D) , Constantinus Politis ${ }^{1,4 d}$ (iD \\ 'Department of Oral and Maxillofacial Surgery, University Hospitals Leuven, Leuven, Belgium \\ 2Departments of Oral and Maxillofacial Surgery, AZ Groeninge, Kortrijk, Belgium \\ 3Department of Radiology, AZ Groeninge, Kortrijk, Belgium \\ ${ }^{4}$ Department of Oral and Maxillofacial Surgery, University Hospitals Leuven, Leuven, Belgium; OMFS IMPATH Research Group, Department of Imaging \& \\ Pathology, Faculty of Medicine, University Leuven, Leuven, Belgium
}

${ }^{\mathrm{a} M D}$, Trainee

${ }^{\mathrm{b} M D,}$ DDS

CMD

${ }^{d} M D, D D S, M H A, M M$, PhD, Professor, Head

\begin{tabular}{|c|c|}
\hline DOI: https://doi.org/10.25241/stomaeduj.2019.6(2).art.6 & \\
\hline $\begin{array}{l}\text { he mandible is a benign intraosseus } \\
\text { oy a high recurrence rate. In this case } \\
\text { sis and propose a potential treatment } \\
\text { the ramus of the right mandible near } \\
\text { combined intra/extra- oral approach. } \\
\text { d by extra-oral submandibular access, } \\
\text { leation. } \\
\text { tra oral approach seems a reasonable } \\
\text { ve OKC's in order to avoid pathological } \\
\text { val of the lesion. } \\
\text { lible; WHO classification; Treatment; }\end{array}$ & 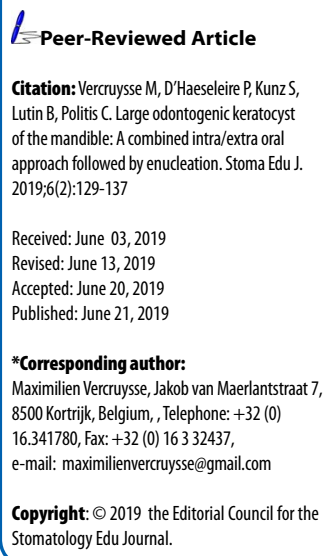 \\
\hline
\end{tabular}

\section{Introduction}

Odontogenic keratocysts (OKC's) of the mandible have been of interest since first presented by Philipsen in $1956[1,17]$. OKC's are considered to be benign intraosseous lesions of odontogenic origin. Evidence suggests that OKC's are to be found posterior to the third molars if offshoots of dental lamina remnants are involved. OKC's occupying the ascending ramus, often present with epithelial island in the mucosa overlying the cyst $[1,2,36]$. The lesions are characterized by a tendency to grow within the medullar space of the mandible/maxilla and have a relatively high recurrence rate. The potential aggressiveness of OKC's is reflected by their potential to extend into soft tissues and bone, although rare. In contrast to ameloblastomas, OKC's cause bone destruction but do not invade through an intact periosteum $[1,33]$. This was questioned by Stoelinga, who cited a few rare instances of keratocysts with soft tissue penetrance $[2,38,43,44,45]$.

OKC's exhibit characteristics of both cysts and benign tumors and were reclassified as odontogenic tumors by the World Health Organization (WHO) in their 2005 Classification of Head and Neck Tumors. In the 2017 classification, the WHO re- categorized the keratocystic odontogenic tumor into the "cyst" category, and the term "odontogenic keratocyst" has been used since. This ambiguity is reflected by their histological characteristics as they present with a cystic architecture but the epithelial lining has a proliferative potential. Histologically the OKC is lined by a regular, keratinized, stratified, squamous epithelium which is 5-10 layers thick and has no rete ridges. The parakeratin surface typically appears corrugated, the basal layer is well defined and frequently palisaded with hyperchromatic nuclei and focal areas showing reversed nuclear polarity. $[3,7,8,41]$. OKC's do not cause metastases or lymph node invasion and do not form tumoral masses. The WHO reclassification could lead to confusion and decreased alertness concerning this lesion. [2,3] When consulting the literature, one must be aware of the different appellations. OKC has a broad age predominance, with a peak incidence in the 2 nd3th decades. In addition, the incidence is higher in male patients, with a male to female ratio of 3:1 [4] Presentation occurs twice as often in the mandible $(70-75 \%)$ as in the maxilla. The posterior body and ascending ramus of the mandible are typical locations. As a consequence, all cysts in the posterior mandibular area have to be treated as if they were OKC's of unicystic ameloblastomas. However, OKC's can also occur in the dentate area of the mandible or maxilla, mimicking ordinary odontogenic cysts. Signs and symptoms can be subtle, but the typical presentation is pain, local swelling, infection and 


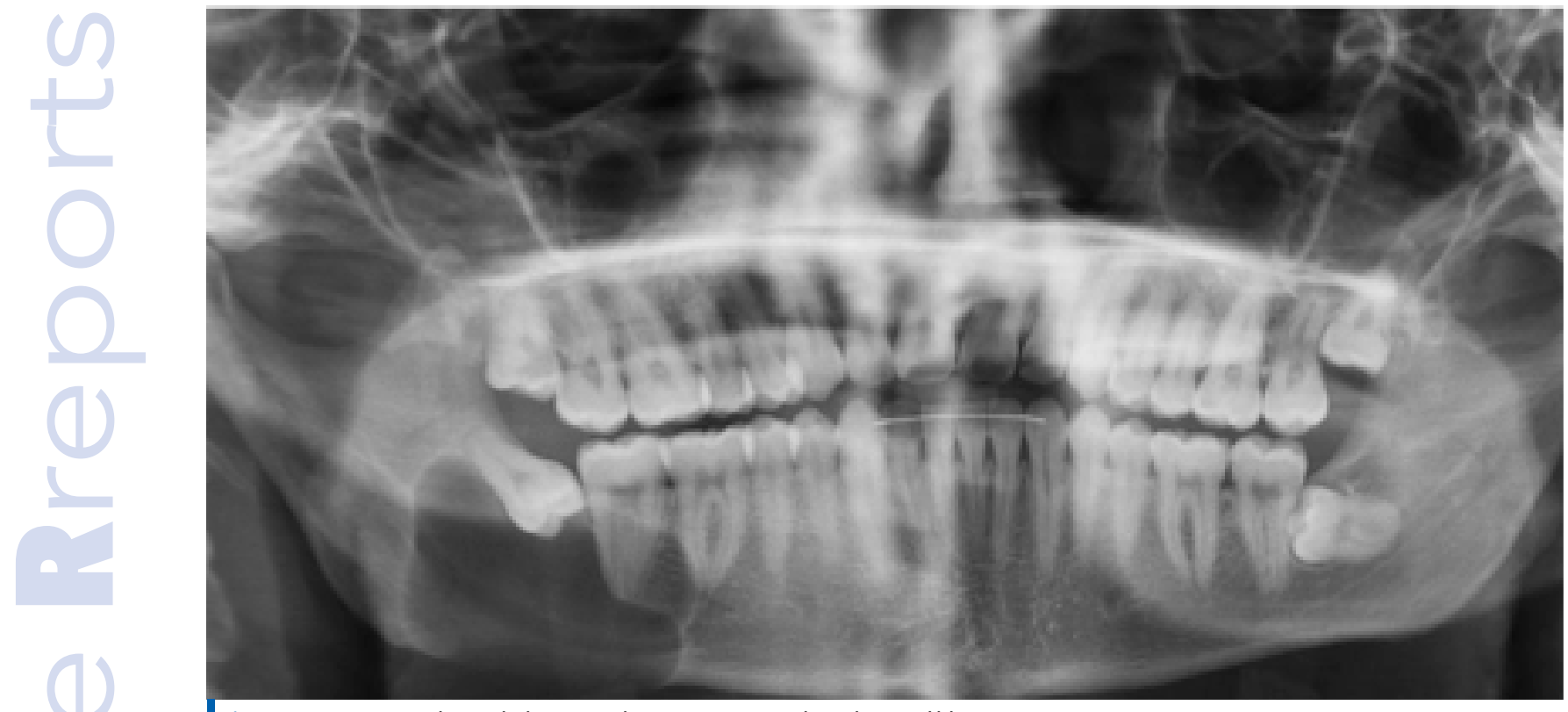

Figure 1. Panoramic radiograph depicting a large cystic mass in the right mandible.

cellulitis $[1,4,6,12,39]$. OKC's are often asymptomatic, probably because they grow in the anteroposterior direction into the intramedullary space, with little cortical expansion. When these lesions reach a large size or perforate the cortical bone, they will often become symptomatic $[9,21,40]$. Of all the cases, 1:3 will be related to an unerupted tooth; the relationship between OKC's and impacted third molars is $10-15 \%$. In addition, growing OKC'scan dislocate away associated teeth [23,24]. OKC's represent approximately $10 \%$ of all cysts of the jaw. They are frequently discovered incidentally by radiographic examination. On radiography, the OKC presents itself as a well-defined radiolucent area. They are commonly unilocular, more rarely multilocular. Often they are not distinguishable from regular odontogenic cysts $[6,9]$. Specific clinical and radiographic characteristics that point to a certain diagnosis pre-operatively are lacking.

The Gorlin Goltz syndrome has to be considered if a patient presents with multiple OKC's. This is an autosomal dominant multisystem disease that leads to multiple OKC's, as well as several nevoid basal cell carcinomas, palmar or plantar pits, calcification of falx cerebri, and skeletal abnormalities. The Gorlin Goltz syndrome is associated with mutations in the PTCH gene situated on $9 q 22.3-q 31$, with described mutation rates of $80-90 \%[1,7,8,16,19,20]$.

The established treatment modalities for OKC's can be divided into radical and conservative treatment options. The radical treatment consists of en bloc resection with negative margins of the segment and has been associated with a recurrence rate of approximately $0 \%$. Knowing the benign nature of this lesion and the morbidity of en bloc resection, this technique has to be reserved for wide, extensive lesions. A retrospective study showed that the main reasons for radical treatment are invasion of the pterygoid muscles and the presence of malignant change $[5,12,13,34]$. The conservative therapies consist of enucleation, but it is generally agreed upon that additional measures for enucleation are crucial to minimize recurrence. The three main techniques are peripheral ostectomy, chemical curettage with application of Carnoy's solution, and cryotherapy. In the literature, there is immense variability in the use of additional techniques, and studies have shown a similar efficacy between peripheral ostectomy and Carnoy's solution. Superior outcomes of cryotherapy have not been described $[6,12,13,21,26]$. Lesions exceeding $3 \mathrm{~cm}$ are not fully suitable for enucleation. In these cases, decompression by marsupialization can reduce the lesion size. The literature has not shown an increased risk of recurrence after decompression [25-27]. It seems advisable to treat each cyst in the mandibular third molar region with possible extension into the ascending ramus by enucleation, with excision of the overlying, attached mucosa if possible. Subsequently, treatment with Carnoy's solution or liquid nitrogen has to be considered. The targeted treatment of the OKC seems achievable, as multiple mutations have been elucidated. Mutations in the PTCH gene or the gene encoding smoothened protein that enhances sonic hedgehog signaling (SMO) can be drug targets. The antimetabolite 5-fluorouracil may affect the sonic hedgehog pathway and has shown lower postoperative morbidity in studies [25,32].

The best treatment for an OKC of the mandible is still a matter of debate, as diagnosis is not straightforward. With this case report, we demonstrate the ambiguity in diagnosis and existing treatment modalities and propose treatment for a large OKC in the right mandible with lingual expansion.

\section{Case presentation}

A 26-year-old Caucasian male was referred to the Department of Oral and Maxillofacial Surgery 

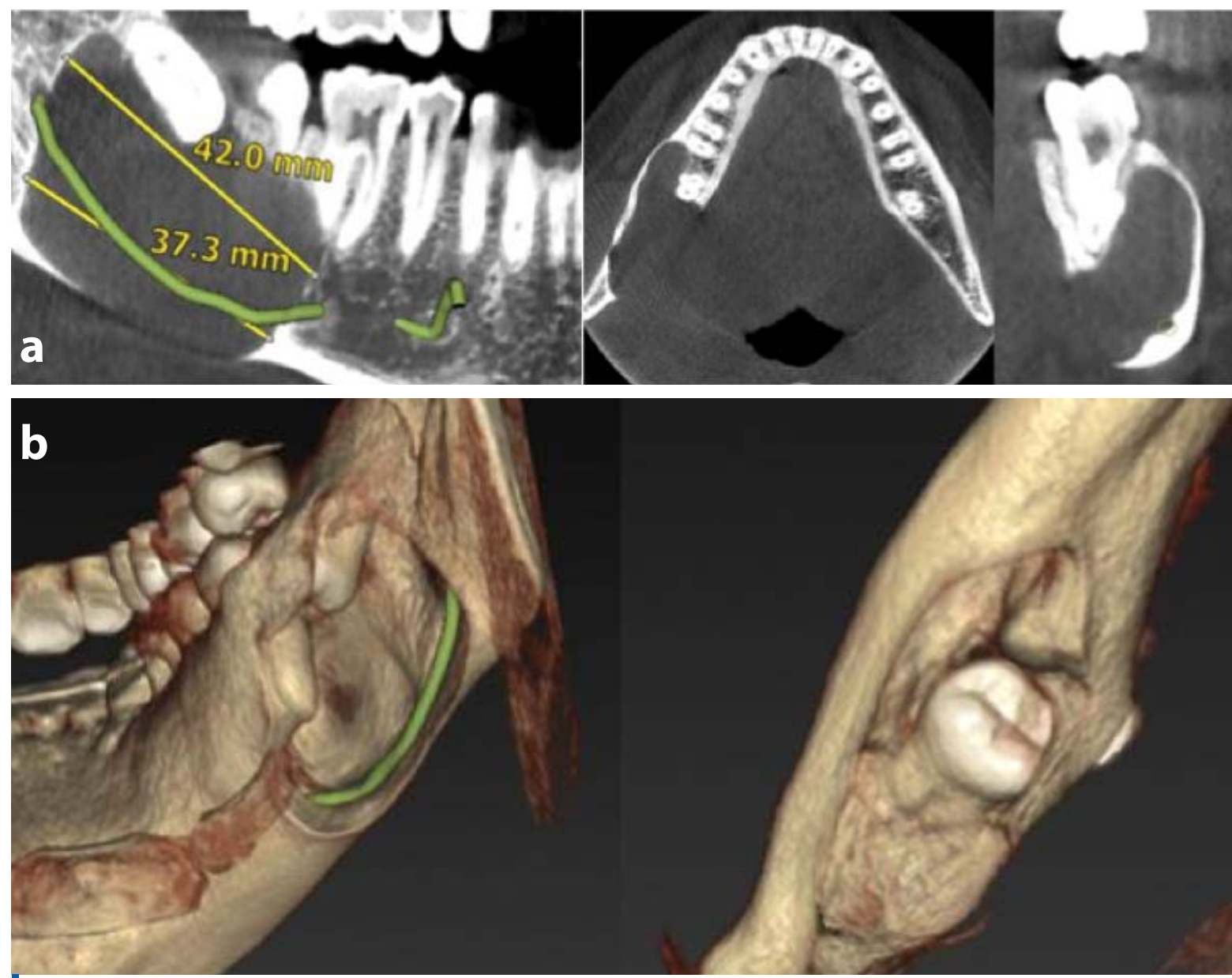

Figure 2. Cone beam computed tomography:

(a) of the right mandible showing a unilocular cystic mass ( $42 \mathrm{~mm} \times 37 \mathrm{~mm}$ )

(b) and 3D volume rendering. The green line indicates the inferior alveolar nerve channel.

complaining of a pain in the right ramus of the mandible, without swelling of this region. Radiographically, there was a unilocular radiolucent lesion with defined borders located in the right mandibular ramus, measuring $42 \mathrm{~mm}$ associated with the retained third molar (Fig. 1). He had no relevant medical history.

Clinical examination did not reveal abnormalities. No regional lymph nodes were palpable and intraoral examination revealed no swelling. Cone beam computed tomography (Fig. 2) showed an expansive, well defined, unilocular cystic lesion longitudinally in the right mandible near the second molar and closely adhering to the third unerupted molar. The lesion had a radiopaque border but caused thinning of the lingual cortex of the mandible with destruction of the cortex at the medial and caudal edge of the mandible. Peri-apical resorption was apparent lateral and posterior to the apex of the second mandibular molar with destruction of the two roots. Neither calcification nor a periosteal reaction wasere identifiable.

On MRI (Fig. 3), were the lesion had homogenous high signal intensity on T2-weighted imaging, low signal intensity on T1-weighted imaging, and homogenous enhancement of the cyst wall after administration of intravenous gadolinium. These characteristics were more suggestive of a benign odontogenic cyst rather than an OKC because of the lack of high intensity on T1-weighted imaging before contrast administration, correlating with ortho/parakeratin or hemorrhage in keratocysts. An ultrasound-guided fine needle biopsy was performed, which was suggestive of an inflammatory follicular or radicular cyst, rather than a keratocyst or ameloblastoma. The surgeons preferred to do a fine needle biopsy instead of an incisional biopsy as it is less invasive and incisional biopsies have the potential for sampling error [42].

A provisional diagnosis of radicular/inflammatory odontogenic cyst was determined. Two weeks later, surgery was performed under general anesthesia. First, a submandibular neck incision $(10 \mathrm{~cm})$ was made, followed by dissection and local excision of the enlarged submandibular lymph nodes. The periosteum was incised over the mandible inferior edge and the mental foramen located. A Martin 2.3 plate was adapted and fixated with 7-9 $\mathrm{mm}$ screws (Fig. 4). The extra oral approach was preferred due to the size of the lesion, the necessity of wide exposure and the fear for a pathological fracture.

Subsequently, teeths 47 and 48 were extracted after preparation of a buccolingual mucoperiosteal flap. Via combined intra/extra-oral access, the cystic mass was exposed. A local posterior gingival resection 


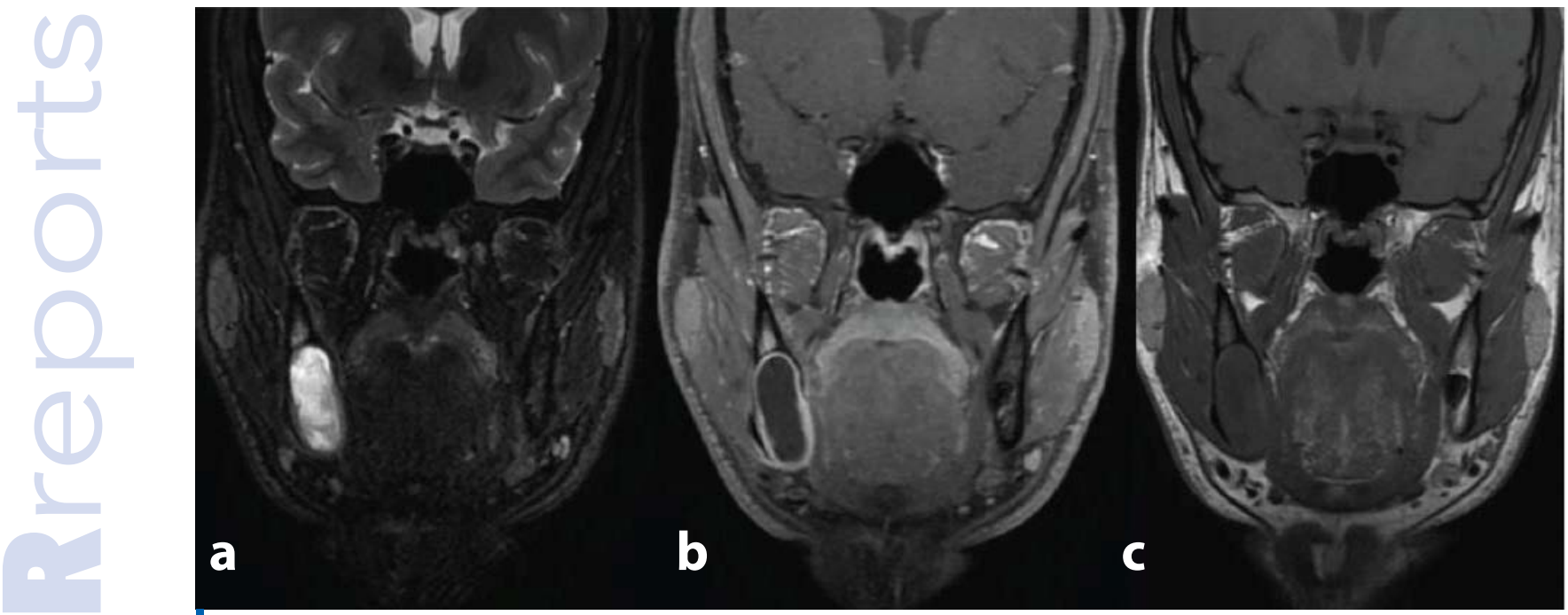

Figure 3. Magnetic resonance imaging:

(a) T2-weighted imaging showing homogenous high signal intensity.

(b) T1-weighted imaging before and

(c) after administration of gadolinium, showing low signal intensity and homogenous enhancement of the cyst wall.

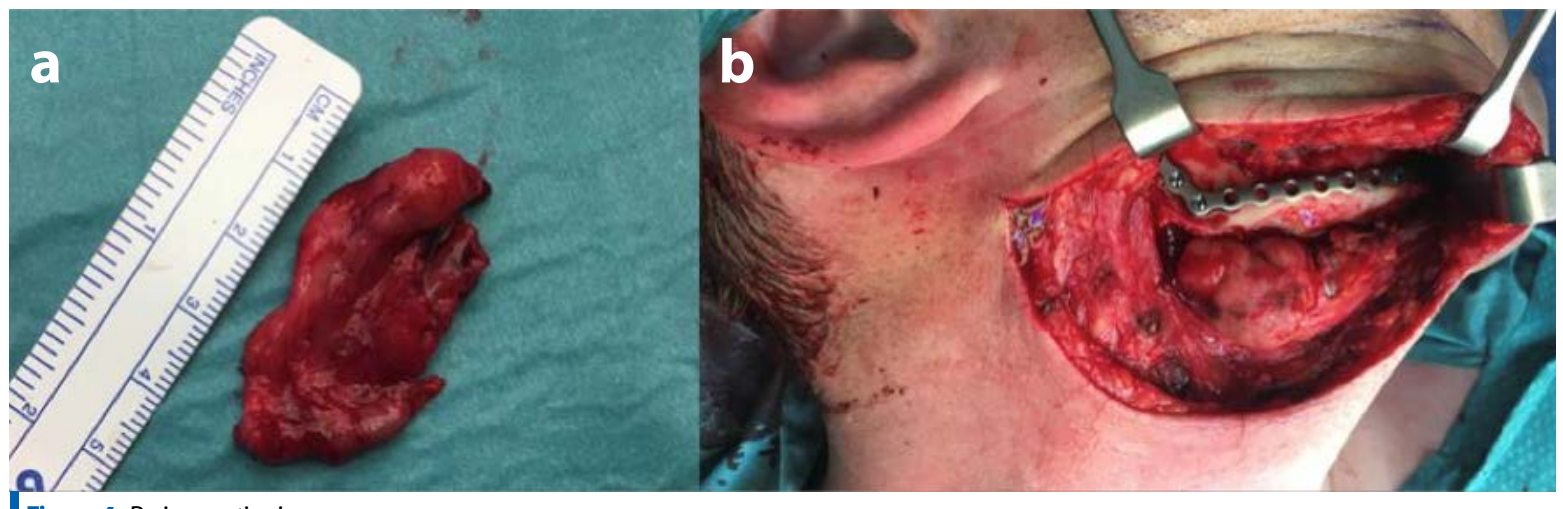

Figure 4. Peri-operative images:

(a) Removed cystic mass and (b) plate osteosynthesis of the right mandible.

was performed by intra-oral access. The inferior alveolar nerve was released of extensive adhesions over $4 \mathrm{~cm}$ without causing a continuity defect. Local bone trepanation was performed to facilitate enucleation while safeguarding bony continuity of the lower border. After flushing, achieving hemostasis, and applying a tetracycline suspension in the intramandibular cavity, intra-oral suturing was performed. The submandibular incision was closed after placing a drain. A postoperative panoramic radiograph showed adequate positioning of the reconstruction plate at the lower border of the right mandible (Fig. 5).

One week after the procedure, the pathology analysis was complete. The microscopic characteristics of the H\&E stained section showed Malpighian epithelium with marked peripheral palisading of the stratum basale. Parakeratosis and orthokeratosis were present with characteristic corrugations of the superficial layer. Some epithelial neutrophilic granulocytes were present and part of the cystic wall was replaced by inflammatory granulation tissue (Fig. 6). Taken together, these findings confirmed the diagnosis of OKC.
Rigorous follow-up was organized with a panoramic radiograph, cephalometric X-ray, and cone beam computed tomography after 6 months, showing no recurrence. The cone beam computed tomography showed a favorable ossifying pattern (Fig. 7). Patient history and clinical examination indicated a favorable healing process (Fig. 8).

\section{Discussion}

The OKC is an expansive, solitary, mostly unilocular (approximately $80 \%$ of cases) jaw lesion thought to arise from remnants of the dental lamina. The active epithelial lining and high proliferation rate reflect a potentially aggressive growth pattern. There is a high recurrence rate, between 25 and $60 \%$, linked to the dental lamina origin and its epithelial islands. Epithelial islands, or micro cysts, can be found in the overlying mucosa in almost $50 \%$ of cases. Research on recurrent OKC's has shown that epithelial islands or micro cysts are present in almost $100 \%$ of recurrent cases [36,37]. The high recurrence rate is attributed to the parakeratotic character of OKC's[8-10]. Most cases of recurrence present within 5 years of treatment, but recurrence after more than 

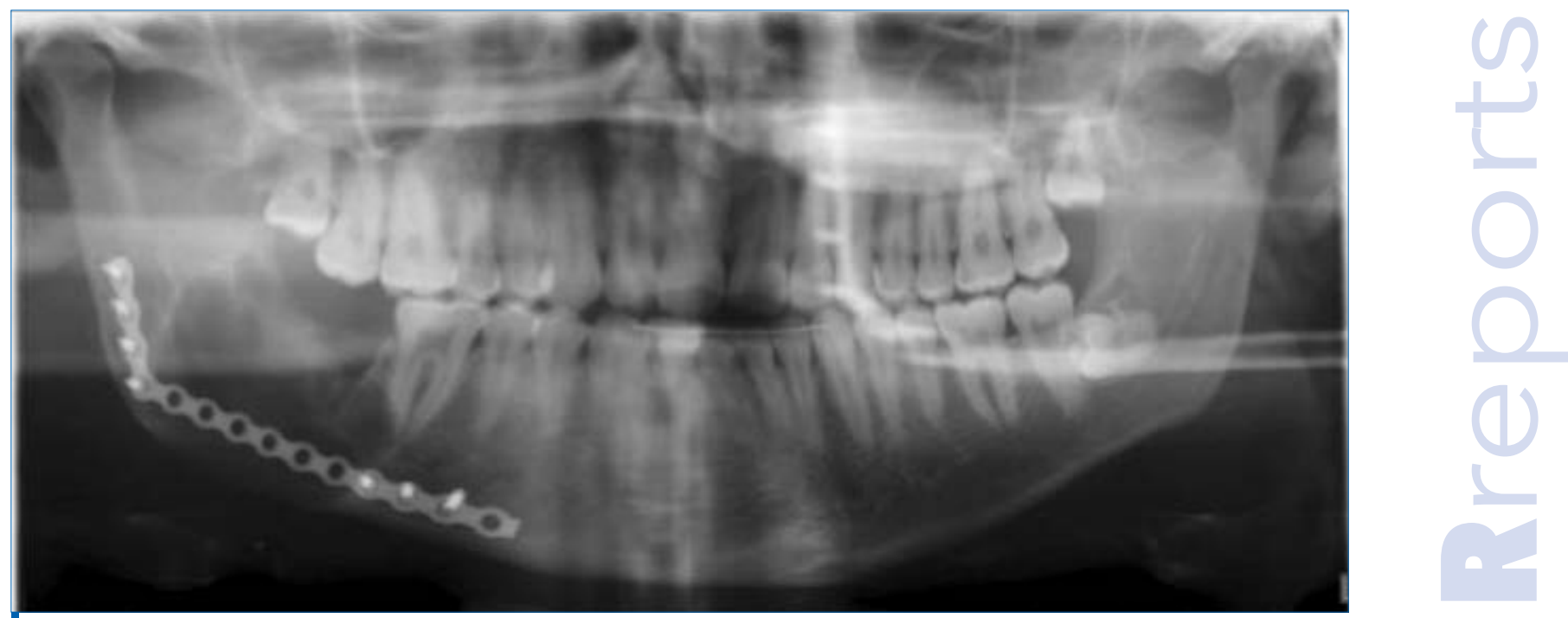

Figure 5. Postoperative panoramic radiograph after removal of the cystic mass and plate osteosynthesis at the lower border of the the right mandible.

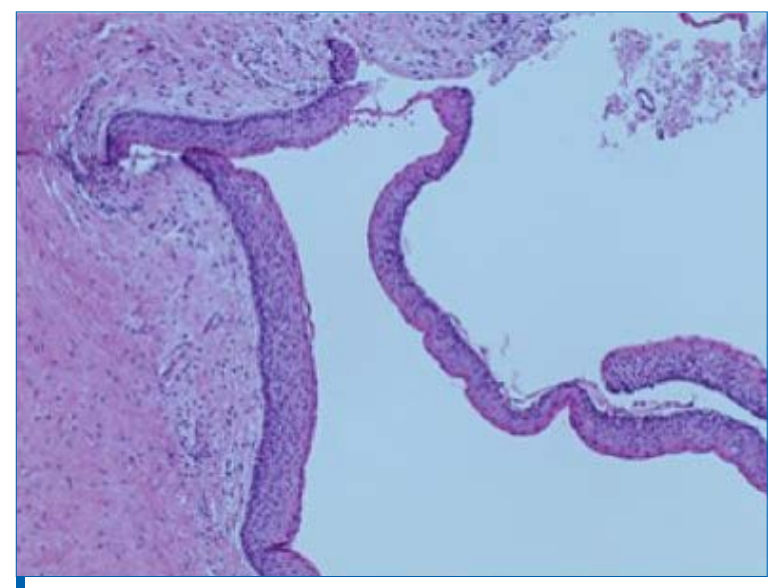

Figure 6. Biopsy of the cystic mandibular mass. Note the wall of the keratocyst with notable palisading and slightly wavy surface.

10 years has been described. Higher recurrence rates have been reported with multilocular lesions and in patients with the Gorlin Goltz syndrome [8$10,14,18,25]$. Our patient consulted with aggravating pain in the right ramus of the mandible and dysgeusia. The dysgeusia was probably caused by a fistula between the lesion and the oral cavity, through which keratin could enter the mouth. Panoramic radiography is helpful in the preliminary assessment, as an OKC will present as a defined radiolucent lesion, mostly unilocular, with smooth and corticated margins [1,3]. Panoramic radiography will show the possible relationship with (impacted) teeth. Cone beam CT should be the next step, as it is considered superior to panoramic radiography because of the possibility to detect bone cortical perforations in the region where the overlying oral mucosa is adhered to the OKC. It is a valuable tool in detecting all dimensions of the lesion with a better identification of the anatomical structures. It has a high spatial resolution but poor contrast resolution, which is not suitable for soft tissue discrimination [1]. Cortical expansion in OKC's will occur more often lingually than buccally. Furthermore, root resorption is rare with $O K C^{\prime}$, in contrast to ameloblastomas, with which root resorption is seen frequently. In our case, the radiolucent lesion caused thinning of the lingual cortex of the mandible and root resorption of the second molar. This highlights that a diagnosis of OKC cannot be made using imaging techniques only. When evaluating a cystic lesion of the mandible, $\mathrm{MRI}$ is a complementary technique to cone beam CT and can be applicable in cases of soft tissue involvement. MRI is superior in illuminating the soft tissue involvement, and a number of studies argue that MRI is crucial in discriminating ameloblastomas from OKC's [28,29]. As such, cone beam CT and $\mathrm{MRI}$, in select cases, are crucial in the diagnosis of OKC's. Some lesions can be indistinguishable from other osteolytic jaw lesions on imaging; therefore, histopathology is always necessary for a definitive diagnosis. A prospective study of 82 OKC's reported that $40 \%$ were not suspected before surgery $[1,22,24]$. The surgeons chose not to execute a preoperative incisional biopsy as it can cause inflammation and interfere in the histopathological analysis of the possurgical specimen.

The differential diagnosis consisted of OKC, ameloblastoma, dentigerous cyst, or radicular cyst. Clinically, these lesions can be indistinguishable, but on imaging they each have typical characteristics. An OKC can be a unilocular or multilocular lesion with few septa and minimal buccolingual expansion. An ameloblastoma typically presents as a multilocular lesion with root resorption and high tendency for buccolingual expansion. A dentigerous cyst will present as a unilocular cyst around the crown of an impacted tooth with possible buccolingual expansion and without septa. Lastly, a radicular/ inflammatory cyst will present as a unilocular lesion connected to the apex of a non-vital tooth [1,24].

Fine needle aspiration biopsy can be considered a safe technique, offering a possibly valuable contribution to pre-operative diagnosis. However, it can be misleading due to inflammation in OKC's. 

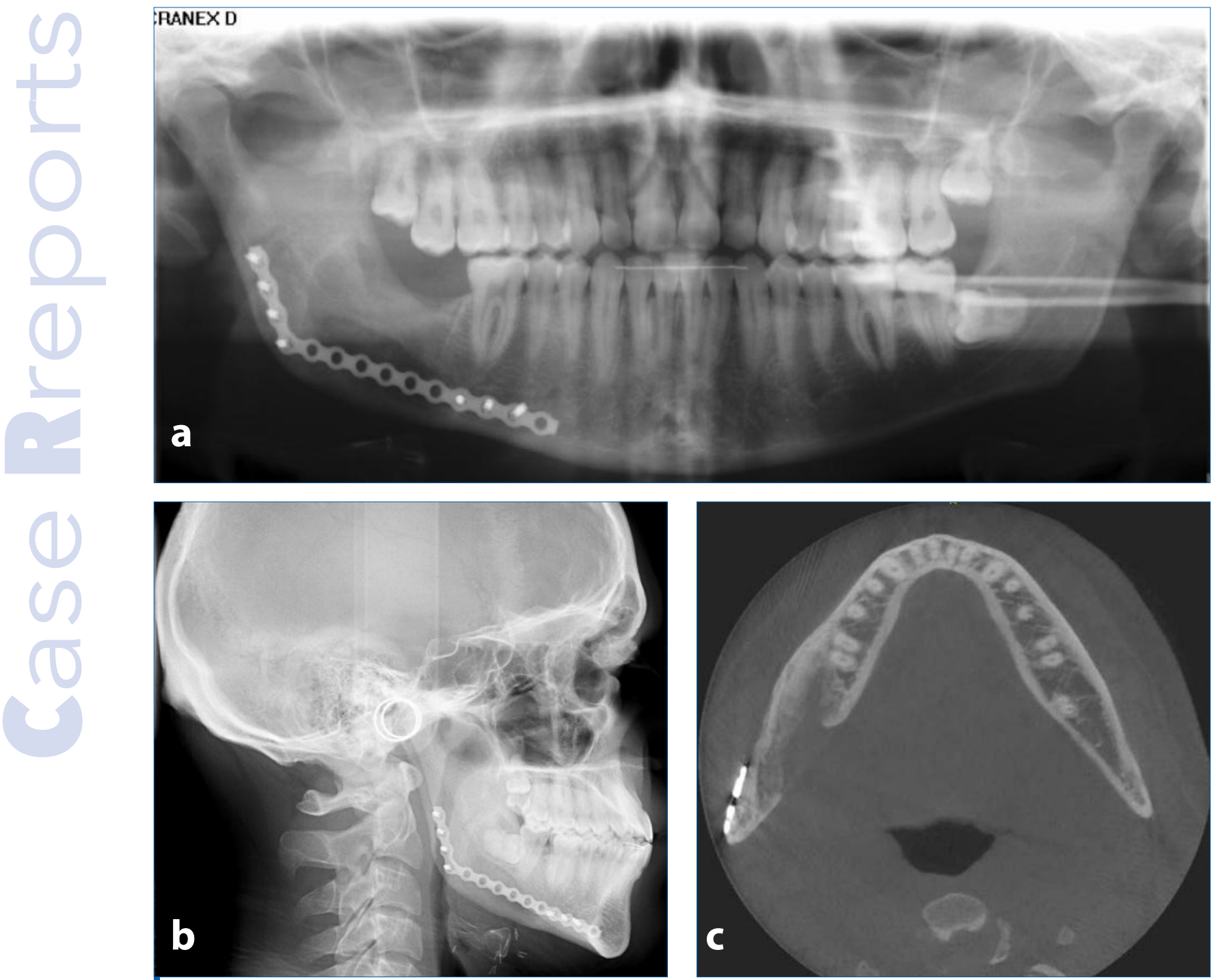

Figure 7. Follow-up 6 months after surgery: (a) Panoramic radiograph, (b) cephalometric X-ray, and (c) cone beam computed tomography.

In addition, a biopsy of an unrepresentative area of the lesion can be misleading. The result can be indicative, but a negative result can never rule out a possible diagnosis of OKC until investigation of the final resection specimen. Baykul et al. showed a correlation of $89.95 \%$ between cytological and histopathological diagnosis for cystic lesions in the maxillofacial region [22,29,30,31].

With this in mind, diagnosis and subsequent treatment of OKC's poses a challenge. The objective is to reduce the recurrence risk as much as possible, while minimizing morbidity. This delicate balance has led to heavy international debate, and no consensus on treatment has been reached.

Conventional treatment modes were described in this article, however, for this specific case an adapted treatment was performed. Because of the size of the lesion and its lingual expansion, there was uncertainty about mandibular stability after enucleation. The location of the lesion with immediate connection to the deep neck soft tissues could not be neglected. The expanded resorption of the lingual cortex with broad fenestration could induce a pathological fracture after enucleation with bone trepanation for removal of teeths 47 and 48 . Therefore, a combined intra/extra-oral technique was applied.

By adapting and fixating a plate before performing the enucleation, we tried to avoid a pathological fracture. With this degree of extended osteolysis, we felt fixation of a plate was necessary. What if mandibular continuity resection is necessary perioperatively? Then, the mandibular bony contour would be guaranteed by using the reconstruction plate. As no clear arguments for OKC were present pre-operatively and peri-operatively, the surgeons decided not to use Carnoy's solution because of the location of the inferior alveolar nerve and the potential neurotoxicity, saving soft tissue as much as possible.

The described technique seems suitable for lesions of this size when pathological fractures are likely. It provides an elegant way to provide mandibular continuity while executing enucleation. We are aware that the short follow-up is a limitation of this case report. 


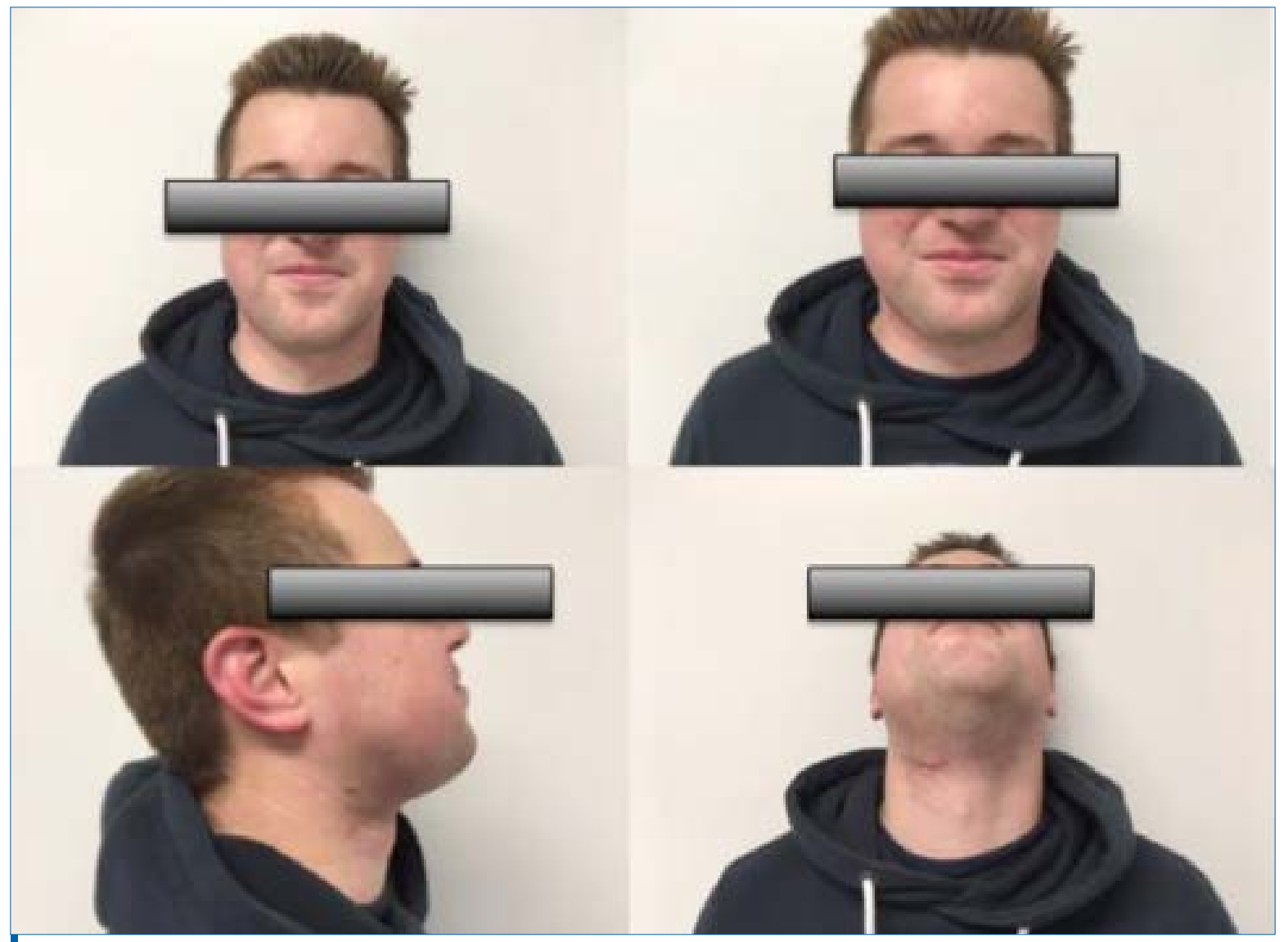

Figure 8. Clinical pictures 6 months after surgery

\section{Conclusion}

With this case report, we tried to point out the difficult diagnosis of OKC and, by extension, all radiolucent lesions of the mandible. Although the lesion does not always present with its typical features, the possibility of OKC must be taken into account when setting up a treatment protocol.

Given the presented case, the combined intra/ extra oral approach is a reasonable technique for the treatment of similar OKC's in order to avoid pathological fractures as well as guaranteeing total removal of the lesion.

\section{Conflicts of interest}

None

\section{Funding}

This research did not receive any specific grant from funding agencies in the public, commercial, or notfor-profit sectors.

\section{Ethical approval}

Not applicable. The present study is not a research study.

\section{Consent}

Written informed consent was obtained from the patient for the publication of this case report and the accompanying images.

\section{Author Contributions}

MV: leading author of the manuscript. PD: critically revising the manuscript. SK: critically revising the manuscript. BL: giving more insight in radiologic aspect of the case report. CP: critically revising the manuscript.

\section{Acknowledgments}

The authors would like to thank all those who were involved in the construction of this article. 


\section{References}

1. Borghesi A, Nardi C, Giannitto C, et al. Odontogenic keratocyst: imaging features of a benign lesion with an aggressive behavior Insights into Imaging. 2018;9(5):883-897.

[Full text links] [Free PMC Article] [CrossRef] [PubMed] Google Scholar

2. Stoelinga PJW. Keratocystic odontogenic tumor (KCOT) has again been renamed odontogenic

keratocyst (OKC). Int J Oral Maxillofac Surg. 2019;48(3):415-416.

[Full text links] [CrossRef] [PubMed] Google Scholar

3. Wright J, Vered M. Update from the 4th Edition of the World Health Organization classification

of head and neck tumors: odontogenic and maxillofacial bone tumors. Head Neck Pathol. 2017;11(1):68-77.

[Full text links] [CrossRef] [PubMed] Google Scholar Scopus

4. De Castro M, Caixeta $C$, de Carli M, et al. Conservative surgical treatments for nonsyndromic odontogenic keratocysts: A systematic review and meta-analysis. Clin Oral Investig. 2017;22(5):2089-2101.

[Full text links] [CrossRef] [PubMed] Google Scholar Scopus

5.ScarfeW, Toghyani S, Azevedo B. Imaging of benign odontogenic lesions. Radiol Clin North Am. 2018;56(1):45-62

[Full text links] [CrossRef] [PubMed]

6. De Molon R, Verzola M, Pires $L$, et al. Five years follow-up of a keratocyst odontogenic tumor treated by marsupialization and enucleation: A case report and literature review. Contemp Clin Dent. 2015; 6(Suppl 1):S106-S110.

[Full text links] [Free PMC Article] [CrossRef] [PubMed] Google Scholar

7. Kamil A, Tarakji B. Odontogenic keratocyst in children: A review. Open Dent J. 2016;10(1):117-123.

[Full text links] [CrossRef] [PubMed] Scopus

8. Pittl T, Meier M, Hakl $\mathrm{P}$, et al. Long-term observation of a large keratocystic odontogenic tumor of the mandible treated by a single enucleation procedure: A case report and literature review. Int J Surg Case Rep. 2017;34:119-122.

[Full text links] [CrossRef] [PubMed] Google Scholar

9. Kebede B, Dejene D, Teka A, et al. Big keratocystic odontogenic tumor of the mandible: A case report. Ethiop J Health Sci. 2016;26(5):491-496.

[Full text links] [PubMed] Google Scholar Scopus

10. Gnanaselvi UP, Kamatchi D, Sekar K, Narayanan BS. Odontogenic keratocyst in anterior mandible:

An interesting case report. J Contemp Dent Pract. 2016;3(1):22-24. [CrossRef] [PubMed] Google Scholar

11. Kurien N, Kumar L, Uma $P$, et al. An extensive swelling in the anterior mandible - A case report.

Ann Med Surg (Lond). 2017;21:30-33.

[Full text links] [CrossRef] [PubMed] Google Scholar Scopus

12. Mosier KM. Keratocystic odontogenic tumor. STATdx [Internet].

2018 [cited 2018 Jan 10].Available from: https://app.statdx com/document/ameloblastoma/53cf7bc7-2f8f-4fdc-8112 519cb50ce74c

13. Mukherjee D, Pati A. Odontogenic keratocyst involving mandible-A Case Report. Int J Adv Res. 2018;6(6):635-641. [CrossRef]

14. Karandikar S, Nilesh K, Dadhich A. Large odontogenic keratocyst of mandible- A case report. JIDA. 2011;5(7):822-824

15. Rajkumar G, Hemalatha M, Shashikala R, Sonal P. Massive keratocystic odontogenic tumor of mandible: A case report and review of literature. Indian J Dent Res. 2011;22(1):181.

[Full text links] [CrossRef] [PubMed] Google Scholar Scopus

16. García de Marcos J, Dean-Ferrer A, Arroyo Rodríguez S, et al.

Basal cell nevus syndrome: clinical and genetic diagnosis. Oral Maxillofac Surg. 2009;13(4):225-230.

[Full text links] [PubMed] Google Scholar Scopus

17. Pogrel MA. The history of the odontogenic keratocyst. Oral Maxillofac Surg Clin North Am. 2003;15(3):311-315.

[CrossRef] [PubMed] Scopus

18. Bell RB, Dierks EJ. Treatment options for the recurrent odontogenic keratocyst. Oral Maxillofac Surg Clin North Am. 2003;15(3):429-446.

[Full text links] [CrossRef] [PubMed] Google Scholar Scopus

19. Li TJ. The odontogenic keratocyst. J Dent Res. 2011;90(2):133-142.

20. Gosau M, Draenert F, Müller S, et al. Two modifications in the treatment of keratocystic odontogenic tumors (KCOT) and the use of Carnoy's solution (CS)--a retrospective study lasting between 2 and 10 years. Clin Oral Investig. 2009;14(1):27-34.

[Full text links] [CrossRef] [PubMed] Google Scholar

21. Menon S. Keratocystic odontogenic tumors: Etiology, pathogenesis and treatment revisited. J Maxillofac Oral Surg. 2014;14(3):541-547.

[Full text links] [CrossRef] [PubMed] Google Scholar

22. Chapelle K, Stoelinga P, de Wilde P, et al. Rational approach to diagnosis and treatment of ameloblastomas and odontogenic keratocysts. Br J Oral Maxillofac Surg. 2004;42(5):381-390. [Full text links] [CrossRef] [PubMed] Google Scholar Scopus 23. Pogrel M. The keratocystic odontogenic tumour (KCOT)-an odyssey. Int J Oral Maxillofac Surg. 2015:44(12):1565-1568. [Full text links] [CrossRef] [PubMed] Google Scholar 24. Vigneswaran AT, Shilpa S. The incidence of cysts and tumors associated with impacted third molars. J Pharm Bioallied Sci. 2015; 7(Suppl 1): S251-S254.

[Full text links] [Free PMC Article] [CrossRef] [PubMed] Google Scholar Scopus

25. Peacock Z. Controversies in Oral and Maxillofacial Pathology. Oral Maxillofac Surg Clin North Am. 2017;29(4):475-486.

[Full text links] [CrossRef] [PubMed] Google Scholar Scopus

26. Ribeiro-Júnior $O$, Borba $A$, Alves $C$, et al. Reclassification and treatment of odontogenic keratocysts: A cohort study. Braz Oral Res. 2017;31:e98.

[Full text links] [CrossRef] [PubMed] Google Scholar Scopus

27. Cakarer S, Isler S, Keskin B, et al. Treatment for the large aggressive benign lesions of the jaws. J Maxillofac Oral Surg. 2017;17(3):372-378

CrossRef] [PubMed] Google Scholar

28. Hisatomi M, Asaumi J, Konouchi $\mathrm{H}$, et al. MR imaging of epithelial cysts of the oral and maxillofacial region. Eur J Radiol 2003;48(2):178-182.

[Full text links] [CrossRef] [PubMed] Google Scholar

29. Vargas P, da Cruz Perez D, Mata G, et al. Fine needle aspiration cytology as an additional tool in the diagnosis of odontogenic keratocyst. Cytopathology. 2007;18(6):361-366.

[Full text links] [CrossRef] [PubMed] Google Scholar Scopus 30. Goyal S, Sharma S, Kotru M, Gupta N. Role of FNAC in the diagnosis of intraosseous jaw lesions. Med Oral Patol Oral Cir Bucal. 2015;20(3):e284-e291.

[Full text links] [CrossRef] [PubMed] Google Scholar Scopus

31. Timucin Baykul O. The value of aspiration cytology in cystic lesions of the maxillofacial region [Internet]. PubMed Central (PMC). 2018 [cited 2018 Dec 19]. Available from: https://www. ncbi.nlm.nih.gov/pmc/articles/PMC2798782/

32. Ledderhof $N$, Caminiti M, Bradley G, Lam D. Topical 5 -fluorouracil is a novel targeted therapy for the keratocystic odontogenic tumor. J Oral Maxillofac Surg. 2017;75(3):514-524.

[Full text links] [CrossRef] [PubMed] Google Scholar Scopus

33. Shear $M$. The aggressive nature of the odontogenic keratocyst: is it a benign cystic neoplasm? Part 1. Clinical and early experimental evidence of aggressive behavior. Oral Oncol. 2002;38(3):219-226.

[Full text links] [CrossRef] [PubMed] Google Scholar

34. Warburton G, Shihabi A, Ord R. Keratocystic odontogenic tumor (KCOT/OKC)-Clinical guidelines for resection. J Maxillofac Oral Surg. 2015;14(3):558-564.

[Full text links] [CrossRef] [PubMed] Google Scholar

35. Stoelinga P. The management of aggressive cysts of the jaws. $J$ Maxillofac Oral Surg. 2012;11(1):2-12

[Full text links] [CrossRef] [PubMed] Google Scholar 36. Stoelinga PJW. Keratocystic odontogenic tumour (KCOT) has again been renamed odontogenic keratocyst (OKC). Int J Oral Maxillofac Surg. 2019:48(3):415-416.

[Full text links] [CrossRef] [PubMed] Google Scholar

37. Stoelinga PJ. The treatment of odontogenic keratocysts by excision of the overlying, attached mucosa, enucleation, and treatment of the bony defect with Carnoy solution. J Oral Maxillofac Surg. 2005;63(11):1662-1666.

[Full text links] [CrossRef] [PubMed] Google Scholar Scopus

38. Stoelinga PJ. Long-term follow-up on keratocysts treated according to a defined protocol. J Oral Maxillofac Surg. 2001;30(1):14-25.

[Full text links] [CrossRef] [PubMed] Google Scholar Scopus

39. Slusarenko da Silva $Y$, Stoelinga $P$, Naclério-Homem $M$. The presentation of odontogenic keratocysts in the jaws with an emphasis on the tooth-bearing area: a systematic review and meta-analysis. Oral Maxillofac Surg. 2019;23(2):133-147.

[Full text links] [CrossRef] [PubMed] Google Scholar Scopus

40. Slusarenko da Silva Y, Naclério-Homem MG. Conservative treatment of primary and nonsyndromic odontogenic keratocyst: an overview of the practice. Int J Oral Dent Health. 2018;4(2):1-6. Google Scholar

41. Shear M, Speight PM. Cysts of the oral and maxillofacial regions. 4th Edition. Oxford, UK: Blackwell Publishing Ltd; 2007. Google Scholar

42. Padilla $R$, Murrah V. The potential for sampling error in incisional biopsies of odontogenic keratocysts. Oral Surg Oral Med Oral Pathol Oral Radiol Endod. 2004;98(2):202.

Google Scholar 
43. Worrall S. Recurrent odontogenic keratocyst within the temporalis muscle. Br J Oral Maxillofac Surg. 1992;30(1):59-62.

[PubMed] Google Scholar Scopus

44. Abé T, Maruyama S, Yamazaki M, et al. Intramuscular keratocyst

as a soft tissue counterpart of keratocystic odontogenic tumor:

differential diagnosis by immunohistochemistry. Hum Pathol.

2014;45(1):110-118.

[Full text links] [CrossRef] [PubMed] Google Scholar Scopus
45. Makarla S, Bavle R, Muniswamappa S, Narasimhamurthy S. A Large extragnathic keratocystic odontogenic tumour. Case Rep Pathol. 2015;2015:1-7.

[Full text links] [CrossRef] [PubMed] [PMC] Google Scholar

Maximilien VERCRUYSSE

MD, Trainee

Department of Oral and Maxillofacial Surgery

University Hospitals Leuven Leuven, Belgium

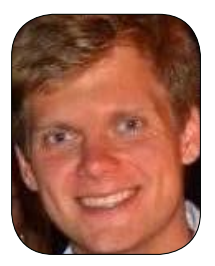

Maximilien Vercruysse is a trainee at the Department of Oral and Maxillofacial Surgery, University Hospitals Leuven, Leuven, Belgium.

\section{Questions}

1. What percentage of the cases present the odontogenic keratocyst in the mandible (approximately)?

ㅁ. $10 \%$;

ab. $20 \%$;

ac. $40 \%$;

ad. $70 \%$.

2. Which syndrome is strongly associated with a higher rate of OKC's?

Da. Pierre robin syndrome;

ab. Gorlin Goltz syndrome;

Dc. Neurofibromatosis;

ad. Treacher Collins Syndrome.

3. Recurrence rate after $\mathbf{5}$ year follow up of a surgically treated non-syndromal keratocyst is approximately?

Da. $0-5 \%$;

ab. $0-20 \%$;

ac. $20-40 \%$;

ad. $60-80 \%$.

\section{Male to female ratio of OKC's can be estimated at?}

ㅁ. 3:1;

ab. 1:1;

口c. 1:2;

ad. 1:3. 
Global Experts Meeting on Frontiers in Advanced Dentistry \& Dental Materials

Date: 15 - 17 July, 2019

Location: London, UK

Event types: Conference, Exhibition

Visit event website: https://frontiersmeetings.com/

conferences/eurodentistry/contact-us

3rd Annual Congress on Endodontics and

Prosthodontics

Date: 24 - 25 July, 2019

Location: Melbourne, Australia

Event types: Conference, Workshop, Exhibition

Visit event website: https://endodontics.conferenceseries. com

32nd International Conference on Dental Science

\& Advanced Dentistry

Date: 29 - 30 July, 2019

Location: Chicago, USA

Event types: Conference, Workshop, Exhibition

Visit event website: https://www.emedevents.com/c/ medical-conferences-2019/32nd-international-

conference-on-dental-science-advanced-dentistry

31 st International Conference \& Exhibition on Dental Medicine \& Dentistry

Date: 29 - 30 July, 2019

Location: Chicago, USA

Event types: Conference, Workshop, Exhibition

Visit event website: https://chicago.eventful.com/

events/31st-international-conference-exhibition-dental-/

E0-001-125418427-3

40thWorld Dental Science and Oral Health Congress

Date: 21 - 22 August, 2019

Location: Singapore, Singapore

Event types: Conference, Workshop, Exhibition

Visit event website: https://dentalscience.dentalcongress.

com/scientific-program

26th International Conference on Dentistry

\& Oral Care

Date: 26 - 27 August, 2019

Location: Vienna, Austria

Event types: Conference, Exhibition

Visit event website: http://kindcongress.com/congress/

dental-treatment-2019/

ADA FDI World Dental Congress 2019

Date: 04 - 08 September, 2019

Location: San Francisco, USA

Event types: Conference, Workshop, Hands on, Exhibition

Visit event website: https://www.world-dental-congress.

org/registration

39th Annual Conference on Dental Practice and Oral Health

Date: 16 - 17 September, 2019

Location: Kyoto, Japan

Event types: Conference, Workshop, Exhibition

Visit event website: https://dentistry.dentalcongress.com/ 40th Asia Pacific Dental and Oral Care Congress

Date: 16 - 17 September, 2019

Location: Osaka, Japan

Event types: Conference, Workshop, Exhibition

Visit event website: https://dentalcare.conferenceseries. com/scientific-program

28th Euro Dentistry Congress

Date: 16 - 17 September, 2019

Location: Amsterdam, Netherlands

Event types: Conference, Workshop, Exhibition

Visit event website: https://eurodentistry.dentalcongress. com/

3rd Polish Dentistry Union Congress

Date: 19 - 21 September, 2019

Location: Poznan, Poland

Event types: Conference, Workshop, Exhibition

Visit event website: https://www.cede.pl/2019/en/

congress/polish-dentistry-union-congress-programme/

24th International Conference on Dentistry and Dental Materials

Date: 23 - 24 September, 2019

Location: Copenhagen, Denmark

Event types: Conference, Workshop, Exhibition

Visit event website: https://dentalmaterials.

dentistryconferences.com/scientific-program

19th Annual Meeting on Oral Care \& Oral Cancer

Date: 23 - 24 September, 2019

Location: Toronto, Canada

Event types: Conference, Workshop, Exhibition

Visit event website: https://www.myconferencepass. com/events/19th-annual-meeting-on-oral-care-oralcancer-1550457389

37th International Conference on Dentistry and Dental Marketing

Date: 25 - 26 September, 2019

Location:Toronto, Canada

Event types: Conference, Workshop, Exhibition

Visit event website: https://dentalmarketing.

conferenceseries.com/scientific-program

EAO 28th Annual Scientific Meeting

Date: 26 - 28 September, 2019

Location: Lisbon, Portugal

Event types: Conference, Workshop, Hands on, Exhibition Visit event website: https://www.dental-tribune.com/ event/eao-28th-annual-scientific-meeting/

World Congress of Esthetic Dentistry

- IFED SEPES BCN2019

Date: October 10-12, 2019

Location: Barcelona, Spain

Visit event website: http://www.sepes-ifed2019.sepes.

org/eng_index.php

stuttgart-2019/ 


\section{Improving the realization of individualized prostheses by optical measurement of mandibular kinematics}

To improve the dental prostheses of their patients, more and more practitioners make individualized prostheses by measuring mandibular kinematics.

At the IDS 2019 I had the opportunity to examine several devices which measure mandibular kinematics. Out of all these, I have chosen to present to you the new measurement system produced by the renowned company Zebris Medical $\mathrm{GmbH}$. While at the company stand, Eng. Wolfgang Brunner, one of the owners of the company, made a very detailed presentation of the Optic Jaw Motion Analyzer.

This system extends Zebris'US JMA systems with state-ofthe-art optical sensor technology. The analyzer is made of a handy table stand with an inductive charging station and face bow with a lower jaw sensor.

The face bow is easily mounted by adjusting the nasion support, sliding porion earpieces and spring-mounted side arms. The jaw sensor is magnetically fixed onto the paraocclusal or occlusal attachments to the lower teeth. The bite fork establishes the exact relationship between the movement data in the measuring system and the surfaces of the teeth scanned by the model and intraoral scanner.

The system has the possibility to cover a wide range of applications from the functional analysis, the analysis of the position of the condyles, the determination of the neuromuscular jaw relationship, to the creation of functional dental restorations, the planning, documentation and monitoring of the rehabilitation of the stomatognathic system.

The system has the ability to optionally operate with a USB interface or over Wi-Fi. The JMAOptic-system has a modular and intuitive analytical software WINJAW+ which includes a database, the basic module and an export function. Real patient data or settings of virtual articulators can be transferred to the external CAD systems by exporting into XML format.

In conclusion, the optical JMA system includes:

- an electronic face bow with camera and infrared modules;

- a T-pointer;

- a lower jaw sensor

- attachments;

- an analytical WINJAW + software with basic module articulator and data export:

- a user manual;

- a carry case.

With the experience gained by using the Zebris' US JMA System since 2008, I look forward to receiving this new evaluation device and to sharing my experience with this system once the JMA Optic series are produced.

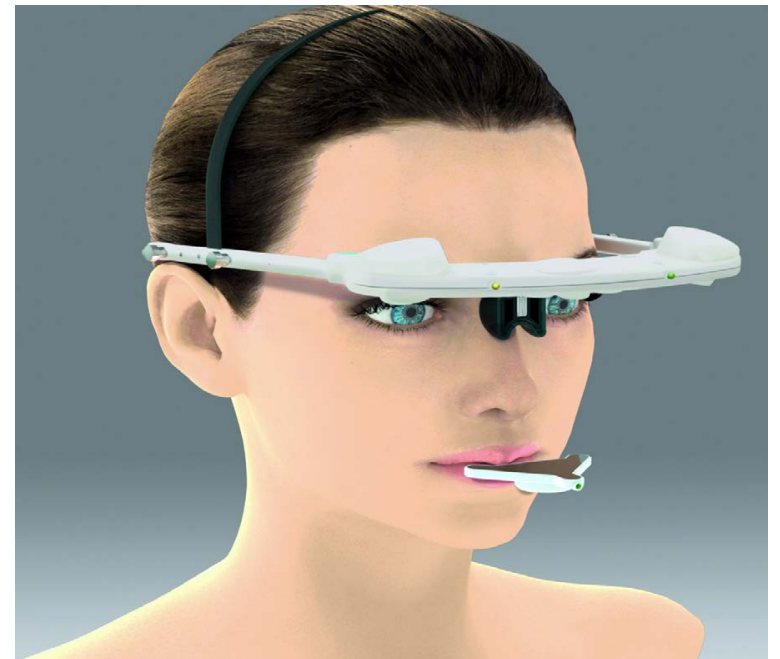

The Optic Jaw Motion Analyser (Zebris Medical GmbH, D-88316 Isny, Germany) https://www.zebris.de/en/dental/products-solutions/

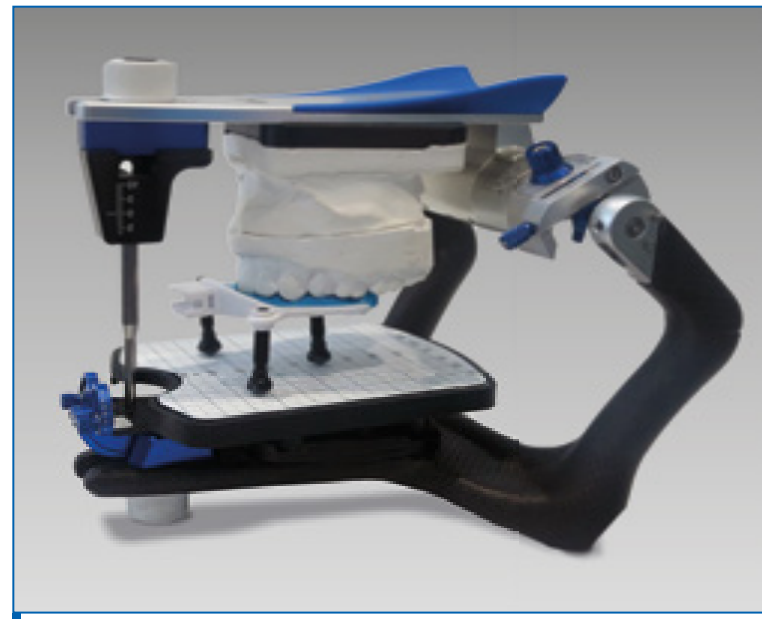

Transfer stand for transferring the maxillary position to mechanical articulators using the bite fork

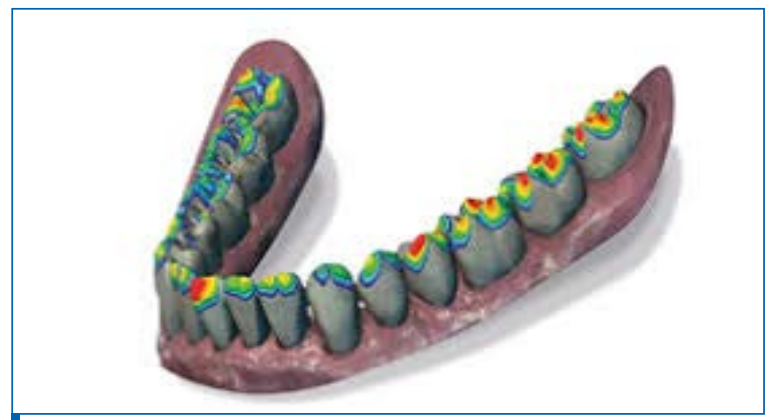

The system is ready to visualize the static and dynamic contact situation.

Florin - Eugen Constantinescu DMD, PhD Student Editorial Director, Product News 


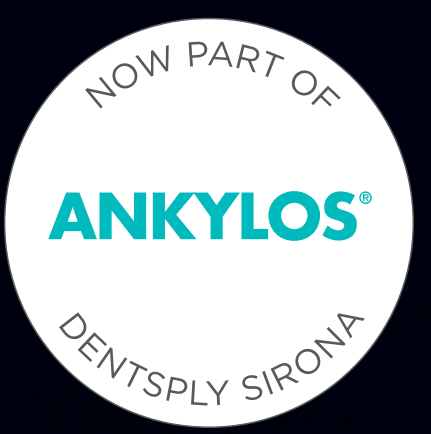

Ankylos ${ }^{\oplus}$

\section{The secret behind excellent anterior esthetics}

When you replace missing anterior teeth, the esthetics simply have to be excellent. That calls for your expertise and Ankylos, an implant system whose TissueCare concept allows for subcrestal placement. Together with the micro-rough surface, this helps bone to form up onto the implant shoulders, which maintains the soft tissue. Finally, the horizontal offset of the implant shoulders promotes both hard and soft tissue stability.

All this creates optimal conditions for long-term hard and soft tissue maintenance, with minimal need for additional augmentation. And the final esthetics is simply stunning.

Excellence without exception.

Ankylos by Dentsply Sirona Implants.

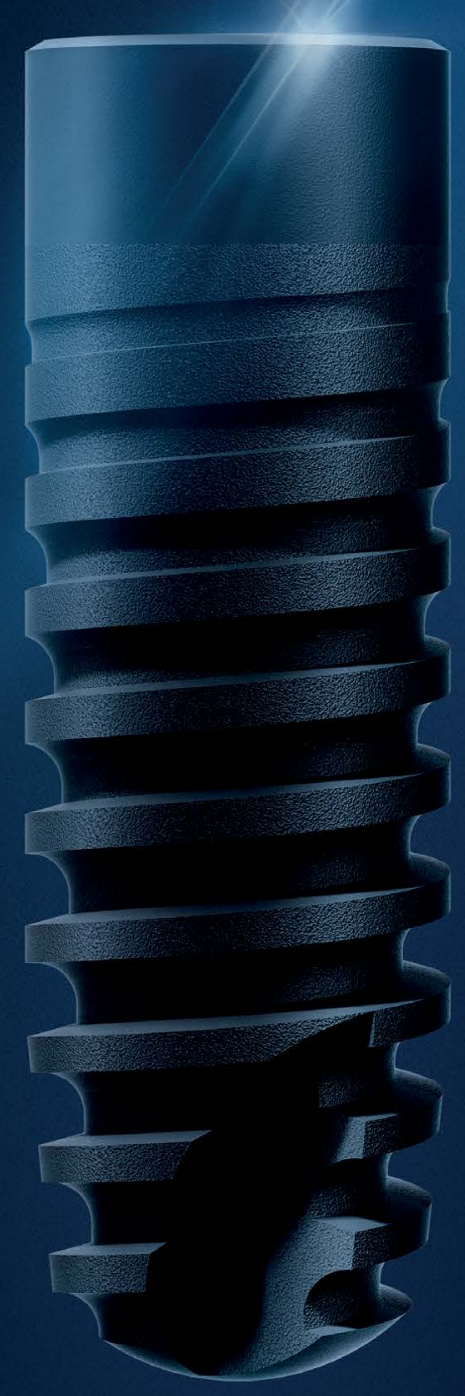




\section{The Complete Dentist Manual}

Authors: Peter E. Dawson / John C. Cranham

Publisher:Widiom Publishing,

LLC, St. Petersburg, FL 33701, USA

Language: English

ISBN: 978-0-9985336-0-5

Edition: $1 / \mathrm{e}$

Published: 2017

Pages: 370, illustrated

Price: $149.00 \$$

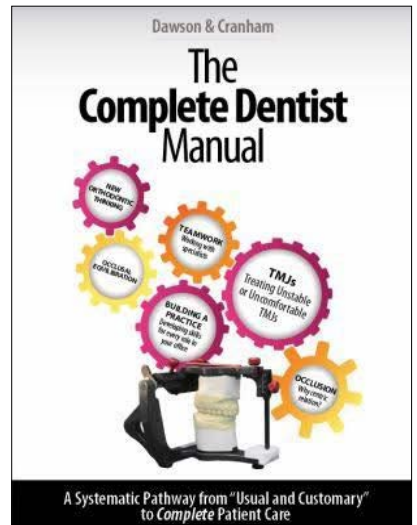

During my career, I first had the opportunity to get in touch and attentively study a book entitled "Evaluation, diagnosis, and treatment of occlusal problems" and then coordinate my work in accordance with "TMJ Functional Occlusion at Smile Design "by Peter E. Dawson. Recently, thanks to the well-known and tireless Dr. Peter E. Dawson, I received the most recent of his publications. The Complete Dental Manual presents the essential experience of Dr. Peter E. Dawson, DDS and John C. Cranham, DDS, as well as the work done for thousands of patients at the Dawson Academy for Advanced Dental Study.

The book contains 43 chapters, a guide from "Usual and Customary" to "Complete Patient Care," which uses objective criteria for comprehensive examinations, comprehensive patient care, and patient management. Each chapter is clearly presented and suggestively illustrated by numerous high-quality images.

The first chapters describe the concept of Complete Dentist as a system physician and how to measure success with objective criteria.

Following the presentation of the 10 common criteria that we have to respect in achieving a successful occlusion treatment that assures good oral health, the book presents the most important concept for understanding occlusion: the central relationship.

The concept of a centric relation is clearly defined, as well as how to make precise recording by manipulating the bimanual procedure correctly required to mount the model in the articulator. TMJ stability is determined by the adjusted centric posture. TMJ assessment is a condition that must be ensured for each patient in the occlusal examination. TMD treatment can not be provided without a complete understanding of all TMJ problems, unstable or uncomfortable to achieve occlusal harmony. The book also describes the criteria for the successful restoration of anterior guidance. To be able to develop of a good treatment plan, it is necessary to use the Dawson Diagnostic Wizard for orthodontics, surgery, or periodontics.

Quality control management for treatment planning for oral health assurance requires 3 stages: Determination, Communication, Verification. The practitioner may be called a Complete Dentist only if he assesses orofacial pain, vertebral dimension of occlusion (VDO), neutral zone, occlusal plane and uses diagnostic imaging methods (CT, CBCT, MR) at each examination. The complete dentistry involving combined restorative and orthodontic treatment, we must attach particular importance to occlusion (bite). The general practitioner is required to become a collaborator of the orthodontist. The concept of rehabilitation through removable partial dental protheses and dental implants is also tackled along with the interdisciplinary team coordination criteria (restorative dentist, periodontist, orthodontist, maxillofacial surgeon).

Finally, the way how Complete Dentists can attract and retain new patients by exemplifying different protocols is presented.

"The Complete Dentist Manual" is a plea from the usual to tooth repair to becoming a masticatory physician, according to the Dawson Philosophy of Clinical Research.

The book is a permanent guide to quality practice, which should not be missing from the library of any responsible dentist.

DOI: http://www.stomaeduj.com 10.25241/stomaeduj.2019.6(2).bookreview.1

The Books Review is drafted in the reviewer's sole wording and illustrates his opinions. 


\section{Florin-Eugen}

Constantinescu

DMD, PhD Student

Holistic Dental \& Medical Institute

of Bucharest-ROPOSTURO,

Bucharest, Romania

e-mail:

dr.florin.constantinescu@gmail.com

\section{Implant Dentistry at a Glance Second Edition}

Authors: Jacques Malet / Francis Mora /

Philippe Bouchard

Publisher:Wiley-Blackwell, UK

Language: English

ISBN: 978-1-119-29260-9

Edition: 2/e

Published: 2018

Pages: 248, illustrated

Price: $€ 45.20$

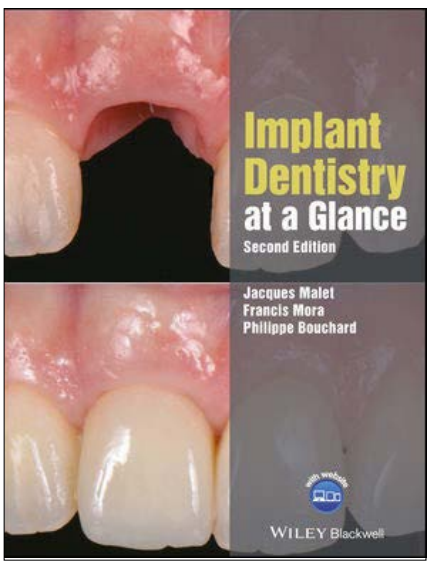

The field of oral implantology is becoming more and more attractive for the general practitioner as well as for the students. The authors of the second edition of Dental Implant at a Glance offer students and young practitioners a clear, simple and abundantly illustrated book. The book contains 63 chapters and several edifying appendices. Each chapter has only two pages containing a clear diagram, accompanied by an explanatory text. The authors improved the first edition by adding 13 new chapters, updating it with information on advances in clinical and fundamental research that have taken place since 2012, the year of the first edition. The book includes access to an online platform, some chapters being complemented by multiple-choice questions (MCQs) and videos. The second edition of Dental Implant at a Glance, allows the authors to create an essential source for students and young practitioners who want to improve their knowledge of the latest concepts in oral implantology.

DOI: http://www.stomaeduj.com 10.25241/stomaeduj.2019.6(2).bookreview.2

\section{Oral Cancer Detection Novel Strategies and Clinical Impact}

Marian-Vladimir
Constantinescu
DDS, PhD
Holistic Dental \&Medical Institute
of Bucharest - ROPOSTURO,
Bucharest, Romania
e-mail:
dr.vladimir.constantinescu@gmail.com

Editor: Prashanth Panta

Publisher: Springer International Publishing,

Switzerland

Language: English

ISBN: 978-3-319-61255-3

Edition: $1 / \mathrm{e}$

Published: 2019

Pages: 314, illustrated

Price: $€ 118.99$

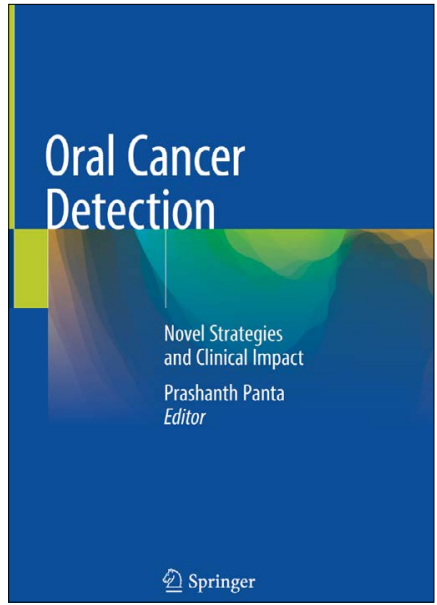

Despite the researchers' efforts, worldwide, more patients are diagnosed having cancer, and especially oral cancer. The book entitled "Oral Cancer Detection - Novel Strategies and Clinical Impact", coordinated by Dr. Prashanth Panta addresses all topics related to oral cancer, from precancerous lesions, epidemiology, imaging to histopathology. The book is divided into 15 chapters. The first chapters present general data on oral cancer, such as genetics and molecular mechanisms in oral cancer progression, respectively data on oral cancer epidemiology. After presenting standardized data for delayed diagnosis in oral cancer, the imaging methods used in oral cancer evaluation with the biopsy exam and histopathology in oral squamous cell carcinoma are also described. Assessment criteria for the clinical examination of the oral cavity are presented as the application of vital stains as adjuncts of clinical examination. Oral cancer investigations are consistently and convincingly described and illustrated by optical techniques, optical imaging, optical coherence tomography, bioimpedance, sensitive crystallization patterns, and salivary biomarkers. The book is clearly written, each chapter is abundantly illustrated, and is accompanied by up-to-date references on the subject.

Dr. Prashanth Panta, along with a team of clinicians, has been able to provide the reader with an excellent monograph on oral cancer detection. Oral cancer screening should be part of every initial and periodical examination of the oral cavity. Therefore, every clinician should consult this book. 


\section{Journal of Prosthodontics on Complete and Removable Dentures}

Authors: Jonathan P.Wiens /

Jennifer Wiens Priebe / Donald A. Curtis

Publisher: John Wiley \& Sons, Inc, USA

Language: English

ISBN: 978-1-119-44264-6

Edition: 1/e

Published: 2018

Pages: 228, illustrated

Price: $100.99 \$$

\section{Journal of \\ Prosthodontics}

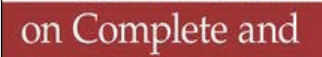

Removable Dentures

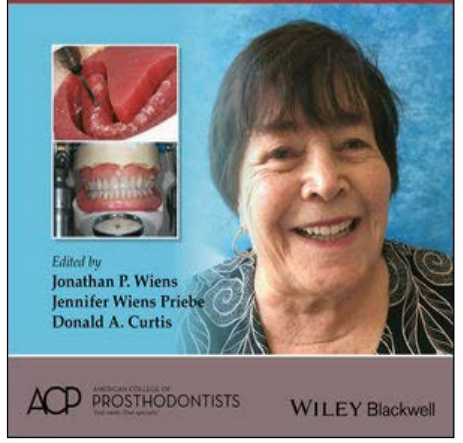

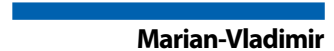

Constantinescu $\mathrm{DDS}, \mathrm{PhD}$

Holistic Dental \& Medical Institute of Bucharest - ROPOSTURO, Bucharest, Romania

e-mail:

dr.vladimir.constantinescu@gmail.com

The book entitled "Journal of Prosthodontics on Complete and Removable Dentures" includes a compilation of 30 most influential articles by experts in this field. The book is divided into five parts.

Part I, namely "Edentulism and Comorbidities", is based on evidence-based guidelines for the care and maintenance of complete dentures by the American College of Prosthodontists, and presents the systems of classification of comorbid diseases, prosthodontics, diagnoses in oral cancer, current and future treatment of the edentulism, the impact of various prosthodontic treatment modalities on nutritional parameters, conventional rehabilitation and dentures which are a reservoir for respiratory pathogens.

Biofilms, denture stomatitis, clinical and histological findings and evidence regarding the treatment of denture stomatitis are collected in Part II.

Part III, namely "Treatment Innovations" exemplifies the fabrication of complete dentures with CAD / CAM and RP technologies, the part-digitization of impression and interocclusal records, as well as the design by adopting CAD for fixed prostheses and optimizing outcomes with tissue management and impression technics.

The position of the occlusal plane in the natural and artificial dentitions, the prediction of satisfaction, the analysis of the masticatory cycle efficiency, the evaluation of the OHIP-14 scale and the factors associated with successful dental therapy are the subject of the "Functional Parameters and Assessment", Part IV.

The last part, "Esthetic Considerations", discusses the perception of the esthetic impact of the smile line by different age groups, the assessment of the ability to relate anterior tooth form and arrangement to gender, guidelines for maxillary, incisional edge position, nasal width as a guide for the selection of maxillary anterior teeth in four racial groups and the selection and arrangement of the maxillary anterior teeth.

Reading this book, the practitioner comes into contact with the latest and relevant information on the edentulous patient, which will serve him in making dentures as efficient as possible and in accordance with the needs of his patient.

DOI: http://www.stomaeduj.com 10.25241/stomaeduj.2019.6(2).bookreview.4

The Books Review is drafted in the reviewer's sole wording and illustrates his opinions. 


\section{Florin-Eugen}

\section{Constantinescu}

DMD, PhD Student

Holistic Dental \& Medical Institute

of Bucharest-ROPOSTURO,

Bucharest, Romania

e-mail:

dr.florin.constantinescu@gmail.com

\section{Contemporary Management of Temporomandibular Disorders Surgical Treatment}

Editors: S. Thaddeus Connelly /

Gianluca Martino Tartaglia / Rebeka G. Silva

Publisher: Springer International Publishing

AG, Switzerland

Language: English

ISBN: 978-3-319-99909-8

Edition: $1 / \mathrm{e}$

Published: 2019

Pages: 382, illustrated

Price: $118.99 €$
Contemporary Management

of Temporomandibular

Disorders

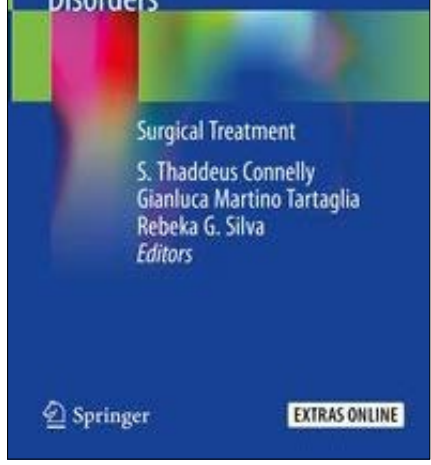

The frequency of temporomandibular signs and symptoms is continuously increasing both in the infant population and the current adult population.

In addition to known non-invasive treatments, invasive, surgical treatment techniques have been introduced lately. The book titled "Contemporary Management of Temporomandibular Disorders" focuses on the surgical treatment of temporomandibular disorders.

The book includes four parts and 16 chapters. Part I presents the evolution of modern surgical management, the diagnosis and surgical pathways of the temporomandibular joint.

Part II addresses surgical arthroscopy, the intraoral vertical ramus of osteotomy, and discectomy and arthroplasty which are described in surgical procedures other than the total joint replacement.

Part III covers total temporomandibular joint replacement and describes virtual planning, autogenous tissue vs alloplastic TMJ condylar replacement, complications and concomitant costume-fitted temporomandibular joint reconstruction, considering and treatment of advanced osteoradionecrosis (ORN), pediatric TMJ surgery, and treatment of mandibular deformities related to TMD.

Part IV discusses the bioengineer construction of the ramus / condyle unit and trains the next generations of oral and maxillofacial surgeons who will be the future specialists of temporomandibular surgery.

The book is clearly written, each chapter is abundantly illustrated and is accompanied by up-to-date references on the subject.

The book titled "Contemporary Management of Temporomandibular Disorders" shows a multidisciplinary approach to success on TMD management. It addresses dentists, surgeons, primary care doctors, pain doctors and all allied health professionals who address TM disorders in their activity.

DOI: http://www.stomaeduj.com 10.25241/stomaeduj.2019.6(2).bookreview.5

The Books Review is drafted in the reviewer's sole wording and illustrates his opinions. 
The ADA Practical Guide to

\section{Soft Tissue \\ Oral Disease}

Authors: Michael A. Kahn / J. Michael Hall

Publisher:Wiley-Blackwell, UK

Language: English

ISBN: 978-1-119-43730-7

Edition: 2/e

Published: 2018

Pages: 280, illustrated

Price: $€ 120.60$

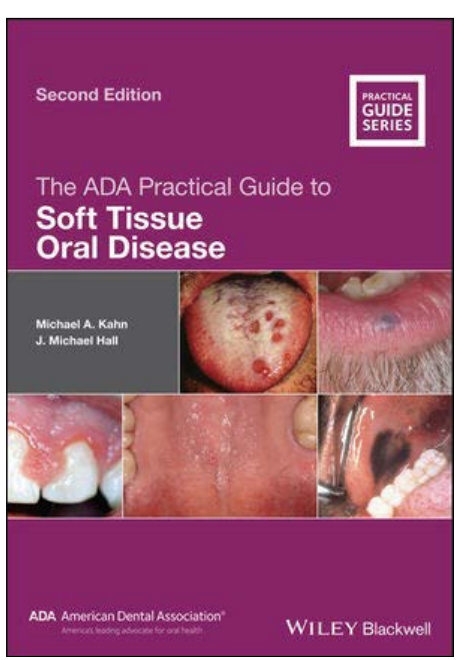

Iulia Ciolachi

DMD

Holistic Dental \& Medical Institute

of Bucharest-ROPOSTURO,

Bucharest, Romania

e-mail:

driuliaciolachi@yahoo.ro

The book titled The ADA Practical Guide to Soft Tissue Oral Disease, Second Edition presents the authors' experience in the field of oral pathology covering many years of activity in this area.

The authors have been able to identify specific essentials of oral pathology that need to be learned, understood and used by all dentists.

Starting from the positive reception of the first edition by dentists, dental students and dental hygienists as well as the general medical community, the authors provide us with this improved and updated 2nd edition. The book has three sections and 7 chapters accompanied by a glossary and a template for the over the counter and prescription medications.

Section one, Detection and Documentation, talks about methods of intraoral and extraoral examination of the neck, head and oral mucosa and explains the associated pathology.

Section two, Diagnosis and Management, presents and illustrates common oral soft tissue lesions, differential diagnosis, guidelines for observation and techniques of biopsy and cytology.

The last section, Clinicopathologic Exercises, offers the reader the opportunity to self- evaluate their knowledge by presenting a series of clinical cases with multiple variants of response.

Each chapter is accompanied by a series of questions whose answers are in a separate appendix.

This second edition of The ADA Practical Guide to Soft Tissue Oral Disease covers clinical information on the most important aspects of oral and maxillofacial diseases, being explicit and very well illustrated to provide better understanding and recognition for general dentists, dental specialists, hygienists, graduate and undergraduate dental students.

DOI: http://www.stomaeduj.com 10.25241/stomaeduj.2019.6(2).bookreview.6

The Books Review is drafted in the reviewer's sole wording and illustrates his opinions. 


\section{Florin-Eugen}

\section{Constantinescu}

DMD, PhD Student

Holistic Dental \& Medical Institute

of Bucharest-ROPOSTURO,

Bucharest, Romania

e-mail:

dr.florin.constantinescu@gmail.com

\section{Bone Management in Dental Implantology}

Editors: Andi Setiawan Budihardja /

Thomas Mücke

Publisher: Springer Nature Switzerland AG.

Language: English

ISBN: 978-3-319-78951-4

Edition: 1/e

Published: 2019

Pages: 192, illustrated

Price: $139,09 €$

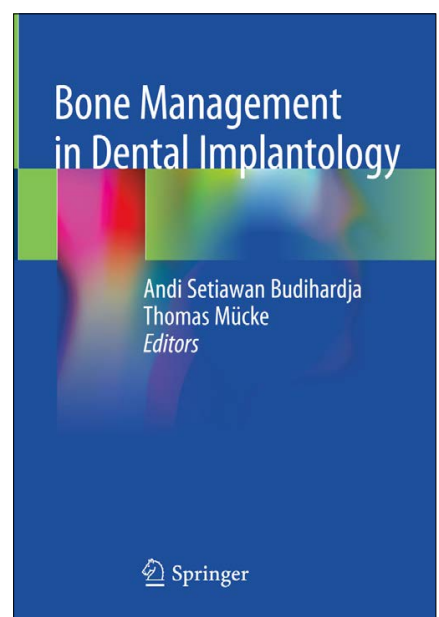

In current practice, in order to meet the needs or wishes of their patients, dentists, often use various oral implant techniques.

The book entitled "Bone Management in Dental Implantology," editors Andi S. Budihardja, and Thomas Mücke, presents to the reader all the necessary information on the bone augmentation in oral implantology. The book is divided into 8 chapters.

After presenting the basic principles and requirements for successful bone augmentation, there follow exemplifications on mandible bone grafting, guided bone regeneration, bone splitting, interpositional osteoplasty based on indications, patient preparation, surgical technique and illustration with some significant cases.

Maxillary sinus lift, anatomy, indications and counterindications as well as techniques are presented in a consistent chapter. Iliac and vascularized bone grafts are described in two separate chapters covering clinical assessment and planning, surgical approach and special consideration. Bone substituting materials pertaining to dental implantology, autograft and allograft, synthetically derived bone grafting and current perspectives and future directions are detailed and supported by clear iconography.

The book has a chapter on the treatment of peri implant infections discussing the diagnosis, the treatment of peri implant mucositis, periimplantitis and their clinical implications.

The last chapter is dedicated to laser in oral implantology and presents the advantages and disadvantages, dental laser systems, indications, future developments and laser safety.

The book is an updated work on the possibilities of bone regeneration, constituting a guide for oral implantologists, oral maxillofacial surgeons, periodontists and dentists involved in oral surgery.

DOI: http://www.stomaeduj.com 10.25241/stomaeduj.2019.6(2).bookreview.7

The Books Review is drafted in the reviewer's sole wording and illustrates his opinions. 


\section{Treatment Centers}

\section{Quality Beyond Reliability}

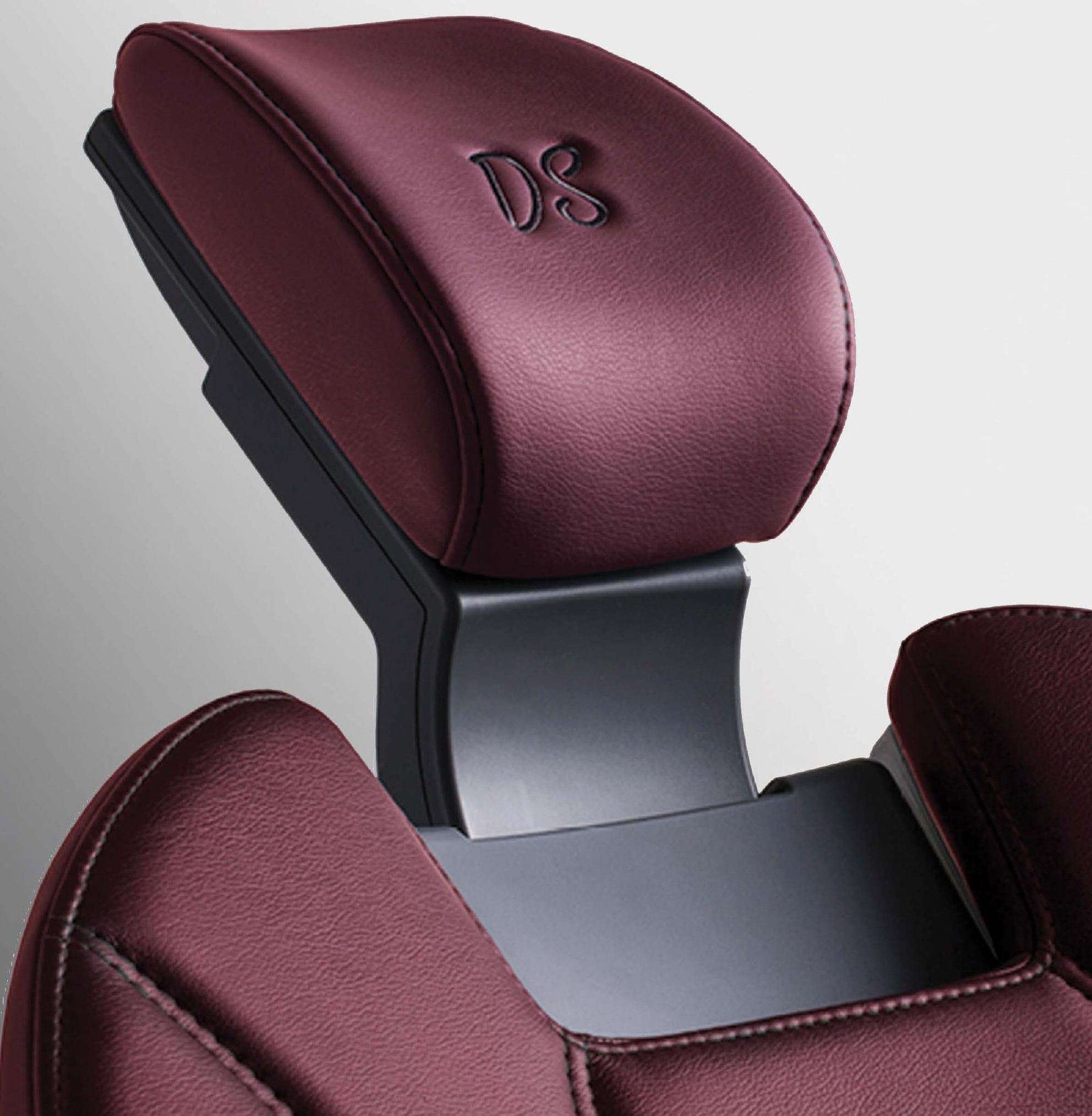


The Stomatology Edu Journal (Stoma Edu J) is a quarterly international journal, double blind peer-reviewed, open access journal to be database indexed, which accepts original articles for publication in all aspects of dental development and research. It addresses those interested in oral and maxillofacial sciences including students, graduates, postgraduates, educators, researchers, dental practitioners, those involved in dental industry and policy-makers relevant to the practice of dentistry.

\section{Submission Instructions}

The Stomatology Edu Journal (Stoma Edu J) publishes articles written only in English. All articles will be accompanied by the signed copyright form which can be returned by e-mail, fax (as scanned documents). All the responsibility for the originality of the material sent belongs to the author(s) alone. Each article will be evaluated by the peer-review committee composed of two independent peer-reviewers, in a blinded fashion, according to the peer-review protocol. All manuscripts must be original and exclusive. The Stomatology Edu Journal Editor will consider only articles that are original, have not been published elsewhere and have been submitted exclusively to the Stomatology Edu Journal. The manuscripts should be submitted online at www. ManuscriptManager.net/stom.

\section{Ethics in publishing}

The Stomatology Edu Journal (Stoma Edu J) and its editoria board fully adhere and comply to the policies and principles of Committee on Publication Ethics (COPE) (https:// publicationethics.org/files/2008 Code of Conduct.pdf). Your manuscript should not contain any information that has already been published. If you include already published figures or images, please obtain the necessary permission from the copyright holder to publish under the CC-BY license. Plagiarism, data fabrication and image manipulation are not tolerated. Plagiarism is not acceptable in the Stomatology Edu Journal (Stoma Edu J) submissions. Plagiarism includes copying text, ideas, images, or data from another source, even from your own publications, without giving any credit to the original source. Reuse of text that is copied from another source must be between quotes and the original source must be cited. If a study's design or the manuscript's structure or language has been inspired by previous works, these works must be explicitly cited.

If plagiarism is detected during the peer review process, the manuscript may be rejected. If plagiarism is detected after publication, we may publish a correction or retract the paper. Image files must not be manipulated or adjusted in any way that could lead to misinterpretation of the information provided by the original image. To verify the originality of content submitted to our journals, we use iThenticate (www.ithenticate. com) to check submissions against previous publications. All submitted manuscripts will be checked for any possible duplication or plagiarism with iThenticate (www.ithenticate. com). Nevertheless, corresponding authors are responsible for any fraud, intentional or unintentional malpractice.

\section{Articles sent for publishing}

The Stomatology Edu Journal (Stoma Edu J) publishes: original articles; reviews; case reports; technical procedures; consensus declaration coming from an association or from a group of specialists; letters to the editor. All articles must be up to 3,000 and 5,000 words for meta- analysis (the word count is for the manuscript text only). Letters to the editor must not exceed 400 words of text and have no more than 3 authors. Letters to the editor can be related to an article already published in the journal or it can represent original scientific contributions or events news/presentations etc. of interest for the reader.

\section{Permissions and Ethics}

For citations, tables, figures etc. which are not original, these must be accompanied by the written permission for their use and the full reference must be provided. Photographs of identifiable persons must be sent alongside the written permission of the person(s) and all regions that may allow the identification of the subject must be covered. The author must have obtained, for all studies including human subjects, the permission of the subjects to be part of the study whilst keeping their anonymity. By sending the article, the author declares that he obtained this permission from all his subjects. All studies must respect the Helsinki Declaration (1975). For human and animal studies, the authors must have obtained the approval of the ethics committee from the University/Institute/etc. where the study was done. Consent for publication is required for studies involving human subjects - ALL case reports, letters that describe cases and some original articles. Cohort studies are exempt; instead evidence of IRB approval (name of IRB, date of approval and approval code/reference number) must be provided.

\section{Manuscript preparation}

The article must be written in conformity with the general recommendations of the International Committee of Medical Journal Editors. http://www.icmje.org/icmjerecommendations.pdf

The Stomatology Edu Journal (Stoma Edu J) uses double-blind review, which means that both the reviewer and author name(s) are not allowed to be revealed to one another for a manuscript under review. The identities of the authors are concealed from the reviewers, and vice versa. To facilitate this, please include the following separately:

Title page (with author details): This should include the title, authors' names and affiliations, and a complete address for the corresponding author including an e-mail address, Author Contributions, Acknowledgements and Curriculum Vitae.

Blinded manuscript (no author details): The main body of the paper (including the references, figures, and tables) should not include any identifying information, such as the authors' names or affiliations.

The articles must be sent either as a Microsoft Word 2000 document $\left({ }^{*}\right.$.doc) or as a Microsoft Word 2003 document (*.docx). The article will be written using Times New Roman font, size 12 for the characters with one and half $(11 / 2)$ spaces between paragraphs. The manuscript must be sent in its final form. The pages will be numbered with the manuscript containing the following sections: title, authors, abstract, keywords, the text of article, contributions, acknowledgments, references, the figures and the tables legend.

A. The title of the manuscript will have a maximum of 100 characters without spaces, written in title case, centered capitals, and in 12 point bold Times New Roman font at the top of page. Abbreviations should be avoided within the title.

B. The author(s) will send their full name(s) and surname(s) the highest academic position, their full titles and their affiliations. All names are listed together and separated by commas. Provide exact and correct author names as these will be indexed in official archives. Affiliations should be keyed to the author's name with superscript numbers and be listed as follows: Laboratory, Department, Institute, Organization, City, State abbreviation (USA, Canada, Australia), and Country (without detailed address information such as city zip codes or street names).

The correspondent author will send his/her full name and surname, the highest academic position, his/her full title, his/ her affiliation, his/her institution address, his/ her telephone, fax and e-mail. The authors will send this information in the same format as that in the published articles.

\section{The Structured Abstract}

The abstract can have a maximum of 250 words. After the abstract, the author(s) must mention a maximum of 5 keywords. Keywords must be selected from Medline Mesh. Abbreviations are not accepted in the title or the abstract.

The abstract for Original Scientific Articles should be no more than 250 words using the following structure: Introduction; Methodology; Results; Conclusion.

The abstract for Review Articles should be no more than 250 words with the authors covering all the following information regarding the subject presented under the following subheadings: Background, Objective, Data Sources, Study Selection, Data Extraction, Data Synthesis.

The abstract for Case Reports should be no more than 250 words using the following structure: Aim, Summary and Key learning points: provide up to 5 short statements of the report The abstract for Clinical Articles should be no more than 250 words using the following structure: Aim, Methodology, Results and Conclusions. 


\section{The Article Text}

Headings and Sub-headings

Except for special names (e.g. GABAergic), capitalize only the first letter of headings and subheadings. Headings and subheadings need to be defined in Times New Roman, 12, bold. You may insert up to 5 heading levels into your manuscript (not more than for example: 3.2.2.1.2 Heading title).

For original articles:

1. Introduction - a presentation of the most important aspects in the studied domain without doing a review of the literature. The purpose of this part is to present and backup the hypothesis on which the study was based.

2. Material and Methods - this section will include all required information so that the reader can verify the validity of the study including, but not limited to, subjects, measurements, statistics and ethics. The methods used should be discussed (why the methods have been chosen, which the limitations/ advantages). A paragraph about the statistical analysis is required as well.

3. Results - the results of the study will be presented in a descending order of importance. An interpretation of the results will not be done in this section.

4. Discussion - the authors will present the way the results backup the original hypothesis, as well as the way in which the results are backed up or contradicted by the published literature. A paragraph must be dedicated to presenting the limitations of the study.

5. Conclusion - The conclusion presents the implications of this latest work. In addition, authors may consider discussing future plans or recommendations for future research etc. For all other types of articles, we recommend the use of a clear structure based on sections and sub-sections.

\section{E. Author Contributions}

The Author Contributions section is mandatory for all articles, including articles by sole authors. The Author Contributions statement must describe the contributions of individual authors and, in doing so, all authors agree to be accountable for the content of the work. Please list only 2 initials for each author, without periods, but separated by commas (e.g. AC, AS). In the case of two authors with the same initials, please use their middle initial to differentiate between them (e.g. AEC, ASC). Each author must be able to prove his active participation in the study by contributing to the concept, protocol, data gathering or analysis, their interpretation or by critically revising the manuscript.

\section{F. Acknowledgments}

Acknowledge persons who have made substantive contributions to the study. Specify grant or other financial support, citing the name of the supporting organization and grant number.

\section{G. References}

- The references will be written using the Vancouver style (https://www.imperial.ac.uk/media/imperial-college/ administration-and-support-services/library/public/vancouver. pdf). All references that are identified with DOI (Digital Object Identifier) must be mentioned.

- For each reference use active links to the full text (DOI link), free PMC article, PubMed, Google Scholar, and Scopus pages, were they exist:

- For all references identified with DOI the full-text link must be the CrossRef hyperlink

\section{Examples}

\section{Articles with DOI}

Singbartl G. Pre-operative autologous blood donation: clinical parameters and efficacy. Blood Transfus. 2011;9(1):10-18.

[CrossRef] [Free PMC Article] [PubMed] Google Scholar Scopus Articles without DOI

Mehta H, Shah S. Management of Buccal Gap and Resorption of Buccal Plate in Immediate Implant Placement: A Clinical Case Report. J Int Oral Health. 2015;7(Suppl 1):72-75.

\section{[Full text links] [PubMed] Google Scholar}

- The references will be numbered, in the order they appear in the text, in square brackets, as such: [3], [5,7-9].

- All sources found in the text must be present in the bibliography and all the papers mentioned in the bibliography must appear in the text.

- For references with more than 5 authors, list the first 3 authors followed by "et al."
- Full-page ranges should be given in expanded form (e.g., 426429, not 426-9).

- If non-English-language titles are translated into English, bracketed indication of the original language should follow the title.

- All journals will be abbreviated and italicized names of journals according to the style in PubMed; refer to the National Library of Medicine (NLM) Journals Database (http://www.ncbi.nlm. nih.gov/nlmcatalog/journals) if needed. Journal names will be abbreviated according to the List of Title Word Abbreviations - Information obtained from sources which are not published yet, but accepted for publishing will include at the end of the reference the mention "in print" between round parentheses.

- If the cited results have not been published yet the mention will be "personal communication" written in the text of article between round parentheses.

- Only references read by the authors of the article will be cited.

- An original article will have at most 50 references, a review will have at most 100 references, a letter to the editor 5 references, whilst all other types of articles will have the minimum number of references required.

\section{Curriculum Vitae - Ultra Short version}

Please provide a brief presentation of the first author and his contribution in the field, of maximum 130 words (with a $3.5 \times 4.5$ $\mathrm{cm}$ color photo).

\section{Figures, Images, Tables}

All illustrations must be numbered and cited in the text in order of appearance.

Figures and Images will be drawn professionally and sent in separate file(s) as jpeg, tiff or png files. Illustrations should preferably fill single column width $(54 \mathrm{~mm})$ after reduction, although in some cases $113 \mathrm{~mm}$ (double column) and $171 \mathrm{~mm}$ (full page) widths will be accepted. See the Image quality specifications chart for details. Image files also must be cropped as close to the actual image as possible.

In the text, each figure must be represented by a number, a title and a description. The authors will indicate where should the figure be placed in the text. All images or figures must come from the author's personal collection or the author must have rights to publish the image or figure. All images must be at or above intended display size with the following image resolutions: Line Art $800 \mathrm{dpi}$, Combination (Line Art + Halftone) 600 dpi, Halftone 300 dpi. We do not accept images or figures taken from the Internet.

The Tooth Identification System used in manuscripts must conform to the FDI International System. Units used in manuscripts must conform to the Système Internationale d'Unités (SI).

Tables will be included in the text and each table will have a number and a short description if required.

\section{Ownership Rights}

By sending the article for publication the author(s):

- take full responsibility for the scientific content of the text and for the accuracy of the send data;

- become (co)author(s) of the manuscript (all further plagiarism accusation are addressed solely to the author(s) who signed the manuscript);

- declare they are the rightful owners of the images, figures and/or information sent for publishing and that they have the permission to publish all the materials for which they do not own the intellectual property rights;

- declare that the message/content of the manuscript is not influenced in anyway by commercial interests/previous engagements/ any sort of relations with other people or companies;

- transfer all rights for the manuscript to the Editorial Council for the Stomatology Edu Journal.

\section{Other}

Previously mentioned limitations can be ignored in special cases with the agreement of the chief-editor and/or the publisher. All published materials cannot be returned.

Not taking into consideration the recommen-dations mentioned before can lead to delay in publishing the materials or may lead to not publishing the article.

The Stomatology Edu Journal (Stoma Edu J) also helps authors measure the impact of their research through specialist partnerships with Kudos and Altmetric. 


\section{SUBSGRIPTION}

\section{I want to subscribe to stonacoj}

- 1 year Subscription (4 issues of the journal) - 280 RON (72 Euro for foreign subscribers)

- 2 years Subscription ( 8 issues of the journal) - 540 RON (136 Euro for foreign subscribers)

- Single Issue - 80 RON (20 Euro for foreign subscribers)

Please send the filled subscription at the following e-mail: roposturo@gmail.com.

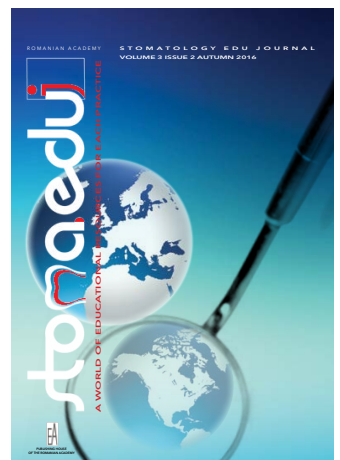

\section{PLEASE COMPLETE ALL THE SUBSCRIPTION FIELDS IN CAPITAL LETTERS!}

Name.......................................... Surname

Mrs. $\square$ Mr. $\square$ Ms. $\square$

Home Address

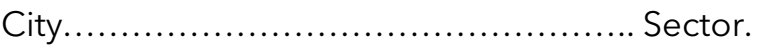

Mobile phone...

Post office code

E-mail:.

................ Web.

Student $\square$ Resident $\square$ Specialist doctor $\square$ Primary doctor

Competence.

Institution...

Activity domain: $\square$ Private $\square$ Public

Department....

Position.

Specialty

Institution address

City.

Sector

District.

Post office code

Phone.

E-mail:

Web.

CUI (Institution Unique Registration Code)

VAT Payer: $\square$ Yes $\square$ No

Invoice - please fill all the necessary details for invoice:

Name.

CNP (Personal Identification Number).

Or

Institution

CUI (Institution Unique Registration Code).

Date.

After filling the subscription, please send it together with the proof of payment to:

\section{ROMANIAN ACADEMY PUBLISHING HOUSE}

13, Calea 13 Septembrie, $5^{\text {th }}$ District

RO-050711 Bucharest, Romania

Tel: +4021318 81 46, 40213188106

Fax: +402131824 44

e-mail: edacad@ear.ro

www.ear.ro

\section{S.C. MANPRES DISTRIBUTION S.R.L.}

1, Piaţa Presei Libere, Corp B

3rd floor, room 301-302, $1^{\text {st }}$ District

RO-013701 Bucharest, Romania

Tel/Fax: +40213146339

e-mail: abonamente@manpres.ro

www.manpres.ro 


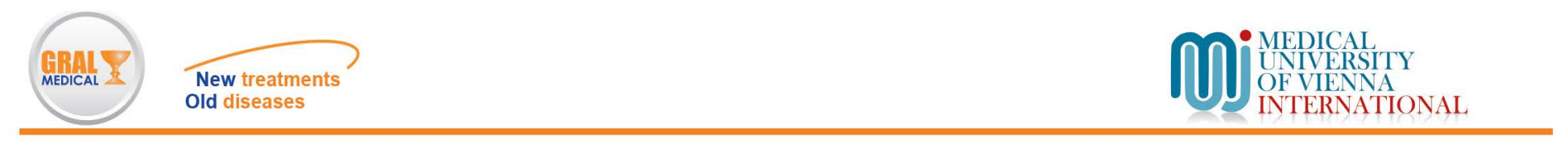

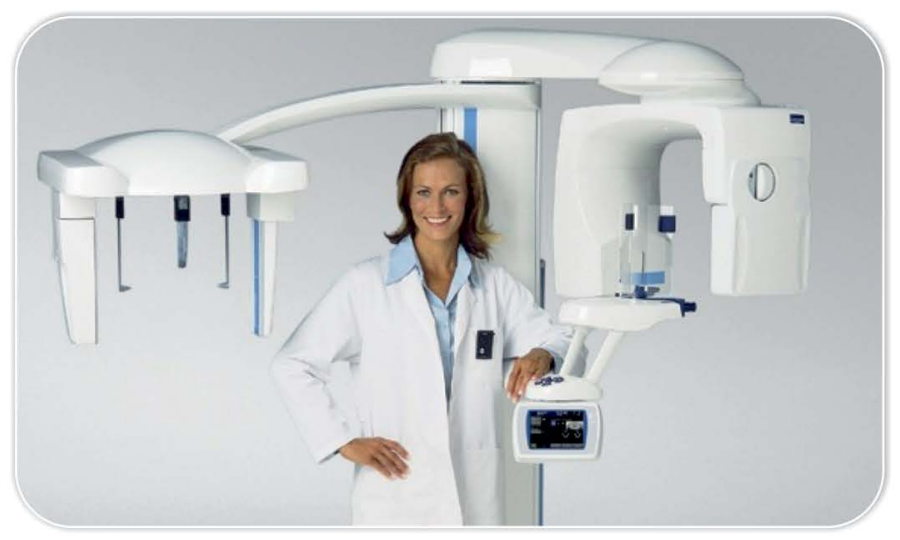

\section{ORTHODONTIC X-RAYS (RADIOGRAPHS)}

Profile (lateral) cephalometric views

Standard OPG (Orthopantomogram) for adults and children (magnification 1.3-1.6)

Orthodontic diagnostic photos

\section{X-RAYS (RADIOGRAPHS) FOR SPECIAL TREATMENTS} Standard OPG (Orthopantomogram) for adults and children (magnification 1.3-1.6)

Ortoradial orthopantogram for adults and

children (magnification 1.3-1.6)

Orthopantogram with reduced for adults and children

Combination for the same patient

(standard OPG +orthoradial+ reduced shadow)

Four-view TMJ- right to left joint

Anterior maxillary sinus panoramic radiographs

Posterior maxillary sinus panoramic radiographs

Salivary gland panoramic radiographs

Prophile (lateral) cephalometric radiographs

Orthodontic diagnostic photos

\section{D CT SCANS}

Full maxilla and mandible CT scan

Maxilla and maxillary sinus CT scan

Mandible and mandible

Mandible and mandibular canal CT scan

Partial maxillary and mandibular CT scan

TMJ CT scan

CT scan of included teeth

\section{MRI -CT}

Ortho-maxillofacial MRI

Ortho-maxillofacial CT

Examination of the throat using a special protocol for: cavum; oropharynx, oral cavity, tongue, soft palate, salivary glands, larynx and hypopharynx is conducted only at 79-91, Traian Popovici Street, $3^{\text {rd }}$ District,

RO-031422 Bucharest, ROMANIA

Tel: $021-323.00 .00$ | 0731-494.688
The Plevnei Gral Medical Dental Imaging Center provides dental imaging services dedicated to obtaining a quick and correct dental diagnostic in order to plan an adequate and efficient treatement.

Our state-of-the-art equipment provides dentists, implantologists or maxillofacial surgeons with accurate 2D and 3D images of the structures they will work upon, being of real service to the patients, by practically eliminating all major intervention-associated risks, both due to the use of very low radiation doses and the easy and comfortable positioning of the patient.
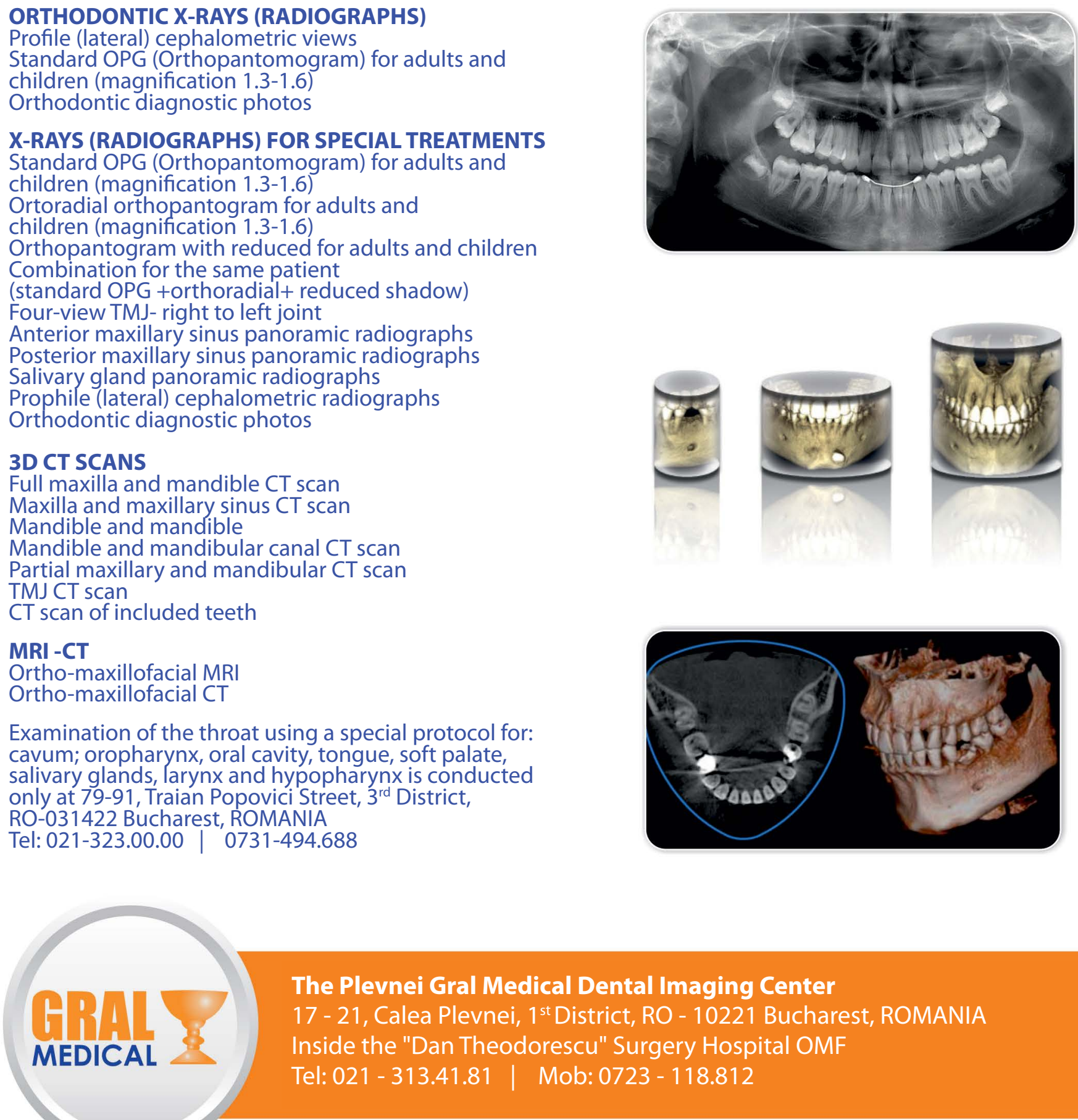


\section{Be a part of something extraordinary.}
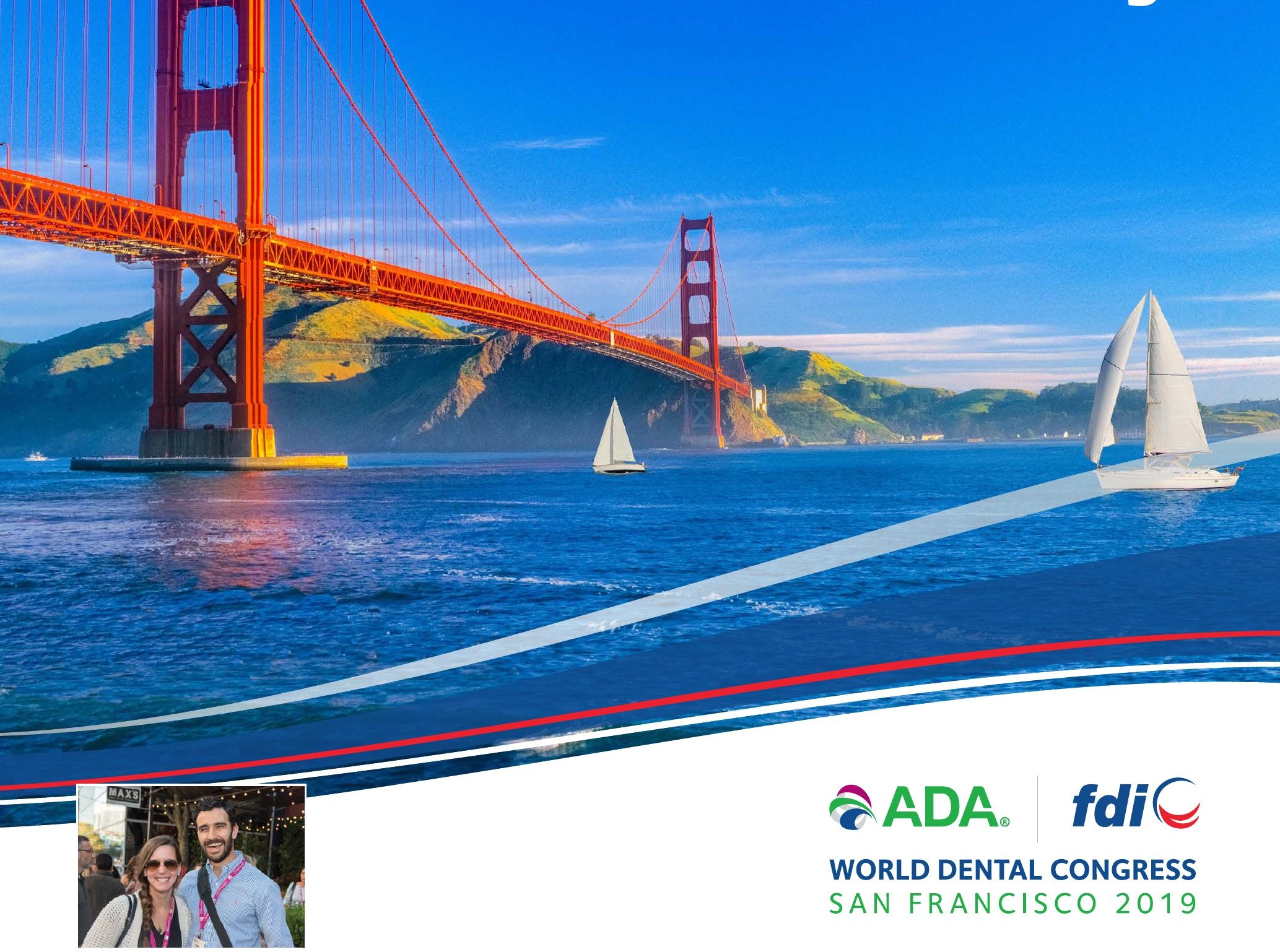

2ADA. fdiC

WORLD DENTAL CONGRESS

SAN FRANCISCO 2019

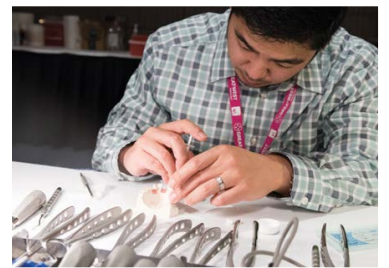

4-8 September 2019 Moscone Convention Center

\section{DAYS OF EXHIBITION}

5-7 SEPTEMBER

- MORE THAN 1,300 STANDS

- 40,000 M² OF EXHIBITION SPACE

\section{SCIENTIFIC PROGRAMME}

2 HALF DAYS (4, 8 SEPT) \& 3 FULL DAYS (5-7 SEPT)

- 200 WORLDWIDE SPEAKERS

- MORE THAN 30,000 PARTICIPANTS 